\title{
MARIANA FERNANDES
}

PROPOSTA E COMPARAÇÃO DE UM MODELO FENOMENOLÓGICO COM BASE EM ALTO TRANSPORTE DE MASSA E SUPERSATURAÇÃO PARA TORRE DE RESFRIAMENTO DE ÁGUA

São Paulo - SP

2012 


\section{MARIANA FERNANDES}

PROPOSTA E COMPARAÇÃO DE UM MODELO FENOMENOLÓGICO COM BASE EM ALTO TRANSPORTE DE MASSA E SUPERSATURAÇÃO PARA TORRE DE RESFRIAMENTO DE ÁGUA

Dissertação apresentada à Escola

Politécnica da Universidade de São Paulo para a obtenção do Título de Mestre em Engenharia Química

Área de Concentração:

Engenharia Química

Orientador:

Prof. Dr. José Luís de Paiva

São Paulo

2012 
Autorizo a reprodução e divulgação total ou parcial deste trabalho, por qualquer meio convencional ou eletrônico, para fins de estudo e pesquisa, desde que citada a fonte.

Este exemplar foi revisado e alterado em relação à versão original, sob responsabilidade única do autor e com a anuência de seu orientador.

São Paulo, 13 de fevereiro de 2012.

Assinatura do autor

Assinatura do orientador

Serviço de Biblioteca e Documentação da

Escola Politécnica da Universidade de São Paulo

\section{FICHA CATALOGRÁFICA}

Fernandes, Mariana

Proposta e comparação de um modelo fenomenológico com base em alto transporte de massa e supersaturação para torre de resfriamento de água / M. Fernandes. -- ed.rev. -- São Paulo, 2012.

114 p.

Dissertação (Mestrado) - Escola Politécnica da Universidade de São Paulo. Departamento de Engenharia Química.

1. Transporte de massa 2. Torres de resfriamento 3. Trans porte de calor 4. Supersaturação I. Universidade de São Paulo. Escola Politécnica. Departamento de Engenharia Química II. t. 


\section{AGRADECIMENTOS}

Agradeço ao Prof. Dr. José Luís de Paiva pela orientação, dedicação e incentivo.

Agradeço ao meu noivo por estar sempre do meu lado e pelo apoio nos momentos mais difíceis.

Agradeço aos meus pais e à minha irmã pelo carinho e apoio. 


\section{RESUMO}

\section{FERNANDES, M. Proposta e Comparação de um Modelo Fenomenológico}

com Base em Alto Transporte de Massa e Supersaturação para Torre de Resfriamento de Água. 2012. 109f. Dissertação (Mestrado) - Escola Politécnica, Universidade de São Paulo, São Paulo-SP, 2012.

Torres de resfriamento são equipamentos muito utilizados na indústria e que muitas vezes operam sob condições adversas, particularmente, temperatura de água acima dos $50^{\circ} \mathrm{C}$ na entrada da torre. Nesta condição, tem-se alta taxa de evaporação e eventualmente condição de alto transporte de massa, normalmente não considerado no equacionamento de torres de resfriamento. Apresenta-se assim uma análise comparativa de diferentes métodos de cálculo de torres de resfriamento: Merkel, Poppe e o modelo proposto. No modelo proposto neste estudo, consideram-se os balanços diferenciais de massa e energia e os mecanismos de transporte simultâneo de calor e massa, na condição de alto transporte de massa e de supersaturação do ar, caso o vapor de água condense na forma de névoa. Para os casos em que há saturação do ar, os balanços diferenciais de massa e energia passam a contemplar este fenômeno a partir do momento em que ocorre a saturação. O modelo matemático desenvolvido consiste de equações diferenciais ordinárias e equações auxiliares, e foi implementado em uma interface Matlab. Os principais parâmetros investigados foram: as vazões de água e ar, a temperatura de bulbo úmido do ar, a temperatura da água na entrada da coluna e a altura da torre. A partir das simulações matemáticas, foram obtidos resultados de temperaturas do ar, da água e da umidade do ar ao longo da coluna, para os diferentes métodos.

Palavras-chave: Transporte de Massa, Torres de resfriamento, Transporte de calor, Supersaturação 


\section{ABSTRACT}

FERNANDES, M. Presentation and Comparison of a Model Based in High Mass Transfer and Supersaturation in a Cooling Water Tower. 2012. 109f. Dissertação (Mestrado) - Escola Politécnica, Universidade de São Paulo, São Paulo-SP, 2012.

Cooling towers are equipment widely used in industrial plants, where these operate under severe conditions such as cooling water inlet temperatures above $50^{\circ} \mathrm{C}$. Under this condition, there are high evaporation of water and high mass transfer, generally not considered in performance analysis of a cooling tower. This work presents and analyzes the differences between the proposed model and the Merkel and Poppe approaches. The proposed model in this work is based on differential equations for energy and mass balances and on the mechanisms of combined heat and mass transfers, at high mass transfer condition and considering the supersaturated air from the height of the tower that the excess of water vapor condenses as a mist. At the point that the air became supersaturated, the differential equations for energy and mass balances start to consider the supersaturation phenomena. The mathematical model developed in this work is composed by ordinary differential equations and auxiliary equations which were solved at Matlab. The parameters investigated were water and air mass flow rates, air wet bulb temperature, water inlet temperature and tower height. The results of air and water temperatures, humidity air across the tower height are presented for each method analyzed.

Keywords: Mass transport, Cooling tower, Heat transfer, Supersaturation 


\section{LISTA DE FIGURAS}

Figura 2.1 - Contato ar água em uma torre de resfriamento contracorrente .18

Figura 2.2 - Diagrama de entalpia específica versus temperatura em torre de

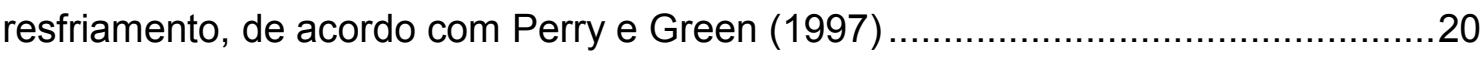

Figura 2.3 - Volume de controle para escoamento contracorrente..........................21

Figura 2.4 - Temperatura do ar de saída medido experimentalmente versus calculada por Merkel e Poppe de acordo com Kloppers e Kröger (2005b) .26

Figura 2.5 - Carta psicrométrica, $T_{w}>T_{a}$ de acordo com Kloppers e Kröger (2005b).

Figura 2.6 - Carta psicrométrica, $T_{a}>T_{w}$ de acordo com Kloppers e Kröger (2005b).

Figura 2.7 - Efeito da evaporação e da condensação no escoamento de um gás em torno de uma partícula esférica, para $\mathrm{Re}=50$ de acordo com Chuchottaworn et al. (1983)

Figura 2.8 - Efeito da injeção/sucção de massa no coeficiente de arraste de uma partícula esférica de acordo com Chuchottaworn et al. (1983)

Figura 2.9 - Efeito da injeção/sucção de massa na transferência de calor e massa em uma partícula esférica de acordo com Koichi (2006)

Figura 2.10 - Percurso do ar que entra saturado na torre, representado na carta psicrométrica de acordo com Kloppers e Kröger (2005a)

Figura 2.11 - Percurso do ar que entra quente e seco na torre, representado na carta psicrométrica de acordo com Kloppers e Kröger (2005a) .....................................38

Figura 2.12 - Esquema representativo ar-água ................................................. 42

Figura 3.1- Volume de controle considerado no equacionamento ..........................47

Figura 3.2 - Efeito do alto transporte de massa no perfil de velocidade ....................54

Figura 3.3 - Fluxo de transporte de massa para escoamento paralelo ….................54

Figura 3.4 - Forças motrizes e fatores de correção de alto transporte de massa para $x=0,02$

Figura 3.5 - Perfis de temperatura da água e do ar e umidade ao longo da altura da torre de acordo com Muangnoi et al. (2006).

Figura 3.6 - Resultados obtidos pela modelagem proposta para os perfis de $T_{w}, T_{a}$, $T_{b u}$ e $w$. 
Figura 4.1- Algoritmo para o modelo sem supersaturação, com e sem alto transporte

Figura 4.2 - Algoritmo para modelo sem supersaturação, com alto ou baixo transporte de massa .71

Figura 4.3 - Algoritmo para o modelo com supersaturação, com e sem alto transporte

Figura 4.4 - Algoritmo para modelo com supersaturação, alto ou baixo transporte de massa..... .80

Figura 5.1 - Representação das condições do ar de entrada e saída conforme o modelo utilizado nos cálculos .85

Figura 5.2 - Perfis de $T_{w}$ e $T_{a}$ para todos os modelos. .86

Figura 5.3 - Perfil de umidade e de névoa ao longo da torre. .87

Figura 5.4 - Perfil de $w, w_{s a}$ e $w_{s w}$ ao longo da torre. .88

Figura 5.5 - Perfis de $T_{w}$ e $T_{a}$ para todos os modelos $\left(m_{w} / m_{a}=1\right)$ .90

Figura 5.6 - Perfis de $T_{w}$ e $T_{a}$ para todos os modelos $\left(m_{w} / m_{a}=2\right)$ 90

Figura 5.7 - Perfis de $T_{w}$ e $T_{a}$ para todos os modelos $\left(m_{w} / m_{a}=3\right)$. 91

Figura 5.8 - Perfil de névoa, $w, w_{s a}, w_{s w}$ e névoa ao longo da torre para $m_{w} / m_{a}=1.92$

Figura 5.9 - Perfil de névoa, $w, w_{s a}, w_{s w}$ e névoa ao longo da torre para $m_{w} / m_{a}=2.92$ Figura 5.10 - Perfil de névoa, $w, w_{s a}, w_{s w}$ e névoa ao longo da torre para $m_{w} / m_{a}=3$.

Figura 5.11 - Perfil de névoa, $w$ e névoa ao longo da torre para $m_{w} / m_{a}=1,2$ e $3 \ldots .93$

Figura 5.12 - Temperatura de saída da água versus temperatura de temperatura de bulbo úmido na entrada.... .95

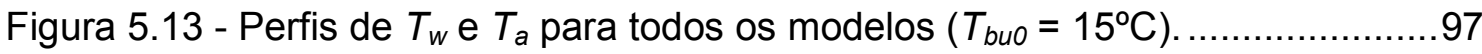

Figura 5.14 - Perfis de $T_{w}$ e $T_{a}$ para todos os modelos $\left(T_{b u 0}=24^{\circ} \mathrm{C}\right) \ldots \ldots \ldots \ldots \ldots \ldots . . . . . . \ldots 7$

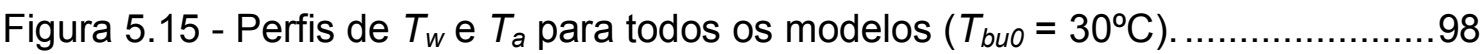

Figura 5.16 - Perfil de névoa formada e umidade ao longo da torre, para $T_{b u}=15^{\circ} \mathrm{C}$.

Figura 5.17 - Perfil de névoa formada e umidade ao longo da torre, para $T_{b u}=24^{\circ} \mathrm{C}$.

Figura 5.18 - Perfil de névoa formada e umidade ao longo da torre, para $T_{b u}=30^{\circ} \mathrm{C}$. 
Figura 5.19 - Temperatura de saída da água versus temperatura de entrada da água.

Figura 5.20 - Umidade do ar de saída versus temperatura de entrada da água. ...103

Figura 5.21 - Perfis de $T_{w}$ e $T_{a}$ para Poppe e AT com Supersaturação $\left(T_{w 0}=40^{\circ} \mathrm{C}\right)$. 104

Figura 5.22 - Perfis de $T_{w}$ e $T_{a}$ para Poppe e AT com Supersaturação $\left(T_{w 0}=60^{\circ} \mathrm{C}\right)$. 104

Figura 5.23 - Perfis de $T_{w}$ e $T_{a}$ para Poppe e AT com Supersaturação $\left(T_{w 0}=80^{\circ} \mathrm{C}\right)$. 105

Figura 5.24 - Perfil de névoa formada e umidade ao longo da torre, para $T_{w 0}=60^{\circ} \mathrm{C}$. 106

Figura 5.25 - Perfil de névoa formada e umidade ao longo da torre, para Tw0 $=80^{\circ} \mathrm{C}$. 


\section{LISTA DE TABELAS}

Tabela 5.1 - Comparação entre os resultados obtidos para um torre de resfriamento

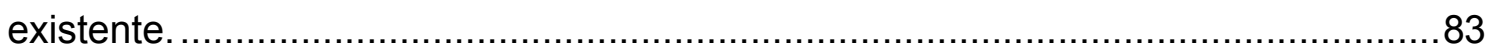

Tabela 5.2 - Comparação entre os resultados obtidos variando-se $m_{w} / m_{a}$. ...........88

Tabela 5.3 - Altura em que o ar saturou de acordo com a razão $m_{w} / m_{a}$................89

Tabela 5.4 - Comparação entre os resultados obtidos variando-se $T_{b u}$.................94

Tabela 5.5 - Diferença entre as umidades do ar que deixa a torre calculadas para os

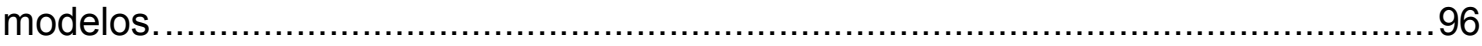

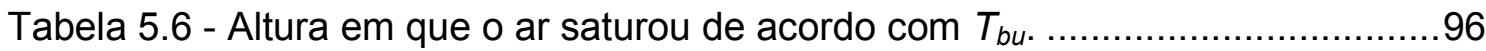

Tabela 5.7 - Comparação entre os resultados obtidos variando-se $T_{\text {wo }} \ldots \ldots \ldots \ldots \ldots . . . . . .101$

Tabela 5.8 - Altura em que o ar saturou de acordo com a $T_{w 0} \ldots \ldots \ldots \ldots \ldots \ldots \ldots \ldots . . . \ldots 103$ 


\section{NOMENCLATURA}

$a_{i} \quad$ área de recheio específica $\left(\mathrm{m}^{2} \cdot \mathrm{m}^{-3}\right)$

$A_{r} \quad$ área da seção transversal $\left(\mathrm{m}^{2}\right)$

$B_{h} \quad$ "blowing factor para transporte de calor" (--)

$B_{m} \quad$ "blowing factor para transporte de massa" (--)

$B_{H} \quad$ número de transferência para transporte de calor (--)

$B_{M} \quad$ número de transferência para transporte de massa (--)

$C_{D} \quad$ coeficiente de arraste para alto transporte de massa (--)

$C_{D 0} \quad$ coeficiente de arraste para baixo transporte de massa (--)

$C p_{a} \quad$ calor específico do ar seco (J. K-1. $\mathrm{kg}^{-1}$ ar seco)

$C p_{m a} \quad$ calor específico do ar úmido $\left(\mathrm{J} . \mathrm{K}^{-1} \cdot \mathrm{kg}^{-1}\right.$ ar seco)

$C p_{v} \quad$ calor específico do vapor de água saturado $\left(\mathrm{J} . \mathrm{K}^{-1} \cdot \mathrm{kg}^{-1}\right.$ água)

$C p_{w} \quad$ calor específico do vapor de água (J.K ${ }^{-1} \cdot \mathrm{kg}^{-1}$ água)

$C p_{s p} \quad$ calor específico do ar supersaturado $\left(\mathrm{J} . \mathrm{K}^{-1} \cdot \mathrm{kg}^{-1}\right.$ ar seco)

$D \quad$ coeficiente de difusividade de massa $\left(\mathrm{m}^{2} \cdot \mathrm{s}^{-1}\right)$

$g(B)$ efeito do alto fluxo de massa causado por evaporação ou condensação $(--)$

$f^{\prime} \quad$ fator de correção da força motriz definido pela equação 3.38

$f_{1}$ fator de correção de transporte de massa definido pela equação 3.60

$f_{2}$ fator de correção de transferência de calor definido pela equação 3.66

$h$ coeficiente de transferência de calor para alto transporte de massa (W. K $\mathrm{K}^{-1} \cdot \mathrm{m}^{-2}$ )

$h^{*} \quad$ coeficiente de transferência de calor para baixo transporte de massa (W. $\mathrm{K}^{-1} \cdot \mathrm{m}^{-2}$ )

$i_{m a} \quad$ entalpia específica do ar úmido (J. $\mathrm{kg}^{-1}$ ar seco)

$i_{\text {maw }}$ entalpia específica do ar saturado na temperatura da água $\left({\mathrm{J} . \mathrm{kg}^{-1} \mathrm{ar}}\right.$ seco)

$i_{\text {masp }} \quad$ entalpia específica do ar saturado na temperatura do ar (J.kg ${ }^{-1}$ ar seco)

$i_{V} \quad$ entalpia específica do vapor de água na temperatura da água ( ${\mathrm{J} . \mathrm{kg}^{-1}}^{-1}$ água)

$i_{\text {var }} \quad$ entalpia específica do vapor de água na temperatura do ar (J.kg ${ }^{-1}$ água)

$i_{s p} \quad$ entalpia específica do ar supersaturado $\left({\mathrm{J} . \mathrm{kg}^{-1}}\right.$ ar seco) 


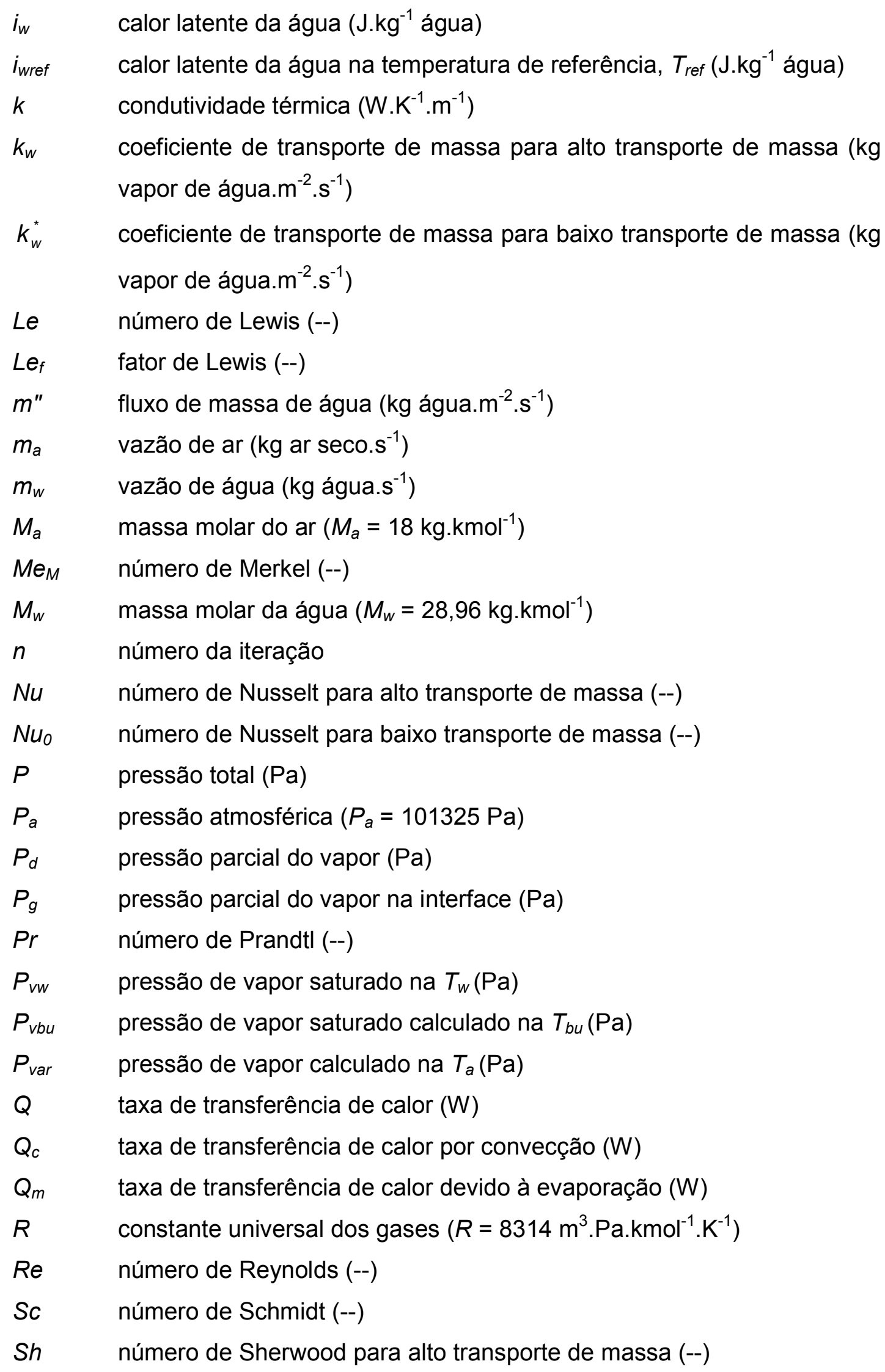




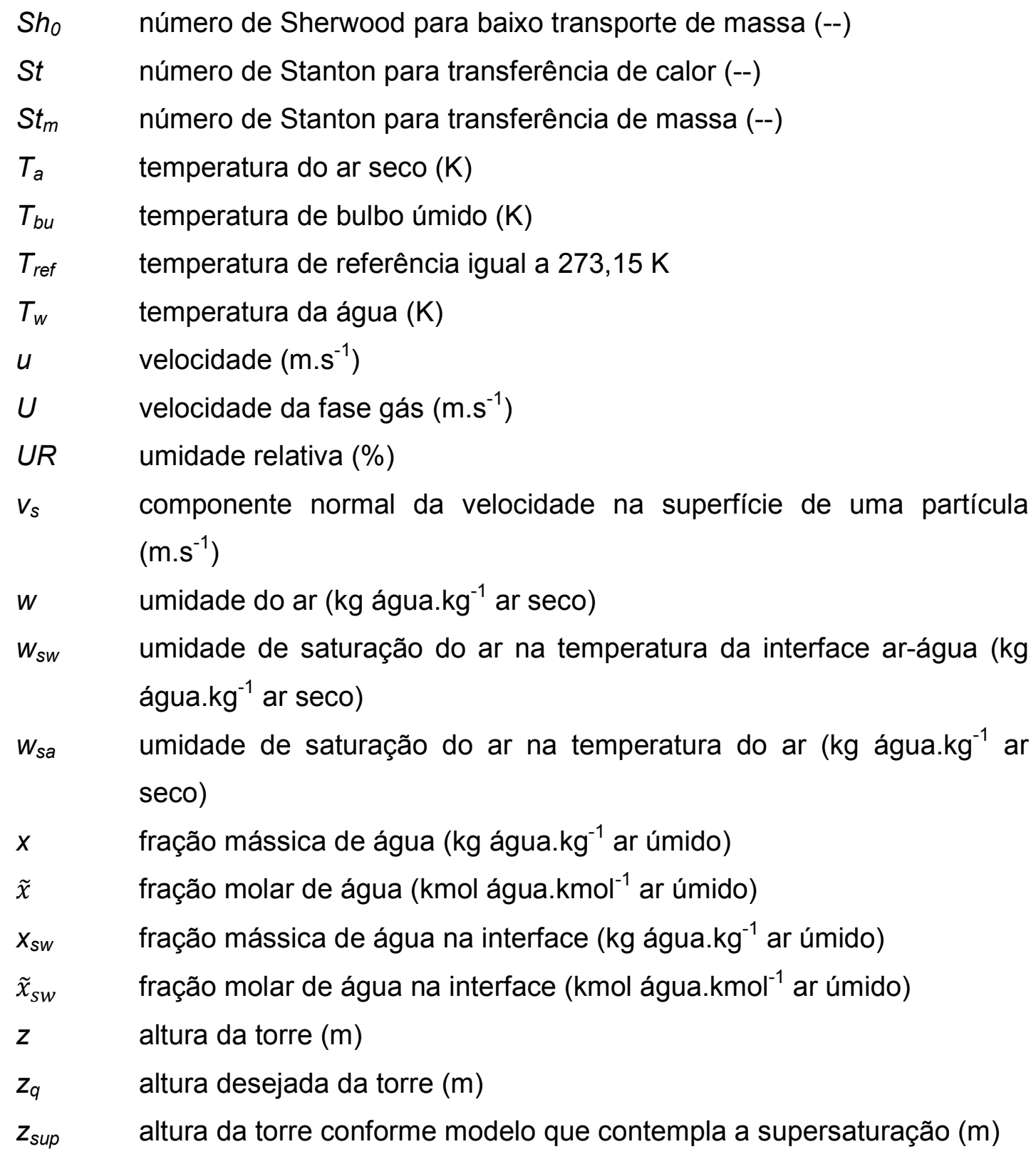




\section{SÍMBOLOS GREGOS}

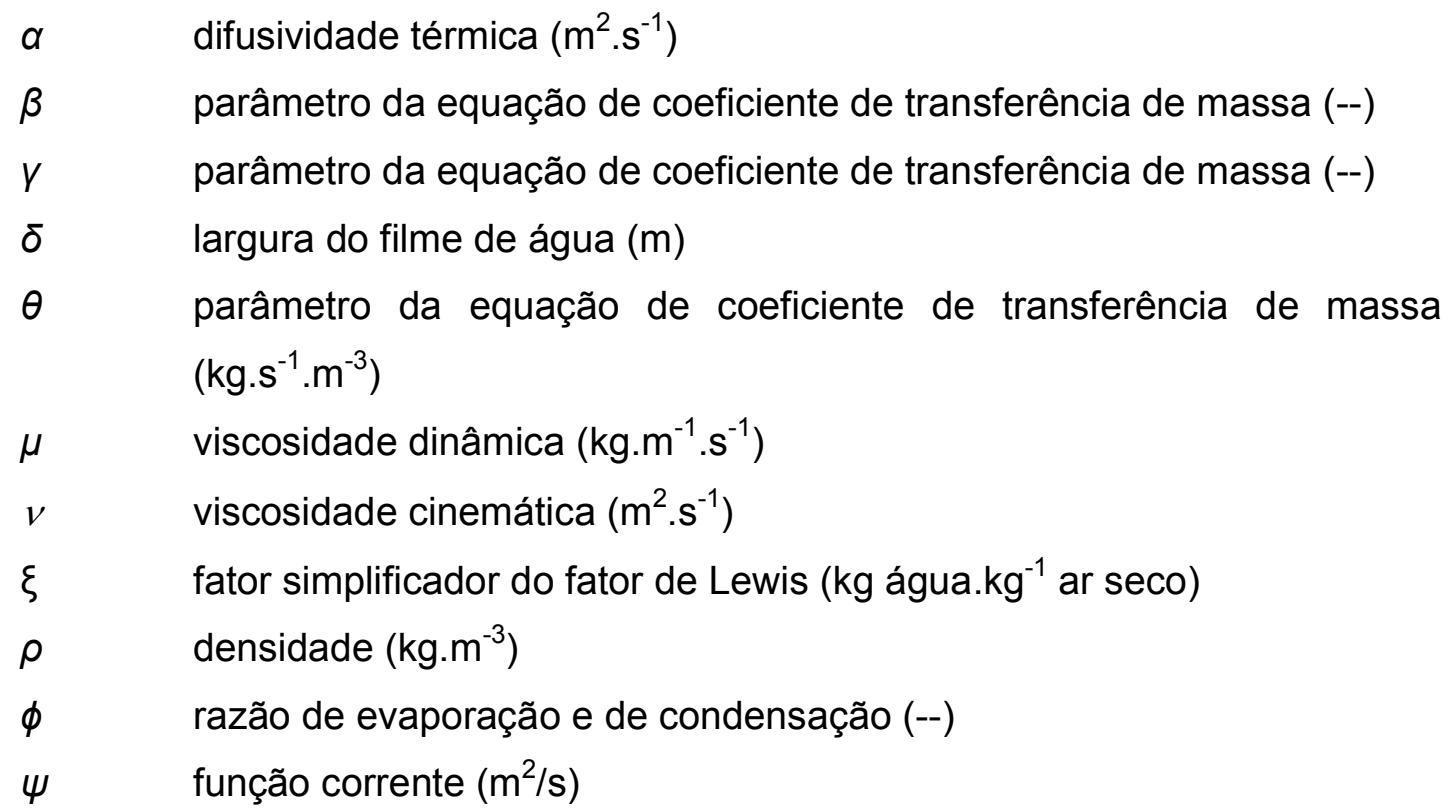

\section{SUBSCRITOS}

$\begin{array}{ll}0 & \text { entrada } \\ f & \text { saída } \\ a & \text { ar } \\ w & \text { água } \\ \text { sw } & \text { interface } \\ \text { ref } & \text { referência }\end{array}$




\section{SUMÁRIO}

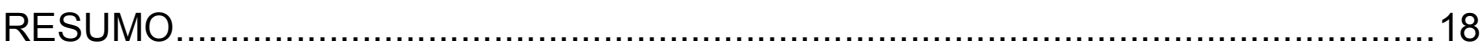

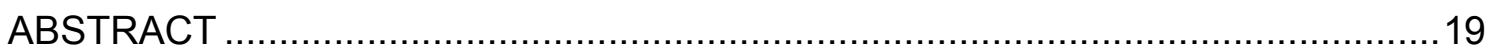

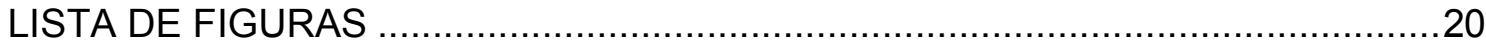

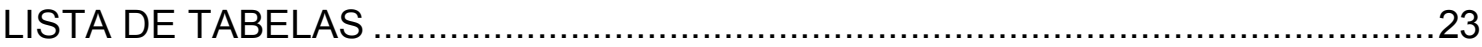

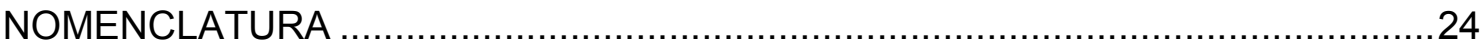

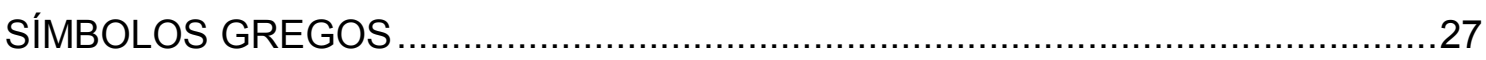

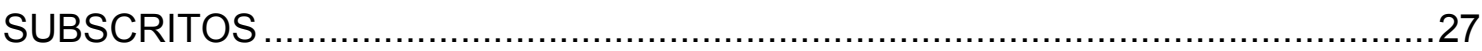

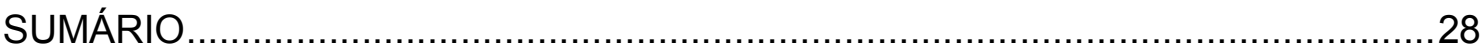

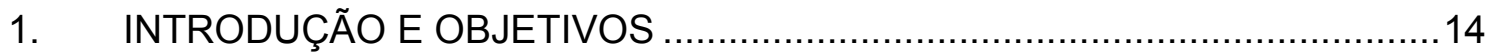

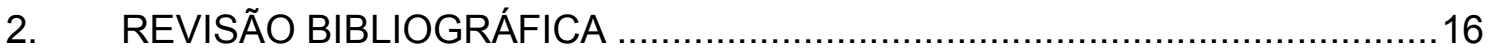

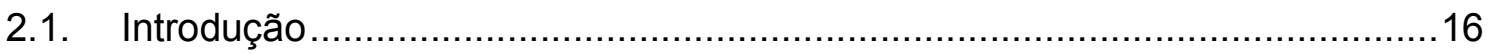

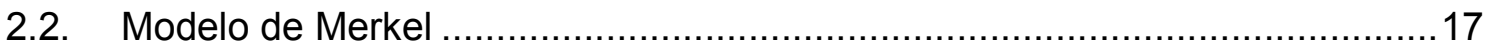

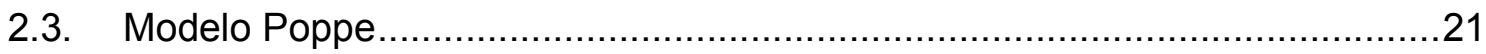

2.4. Comparação entre os métodos de Merkel e Poppe...................................25

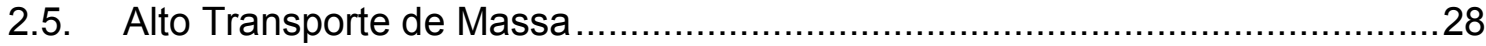

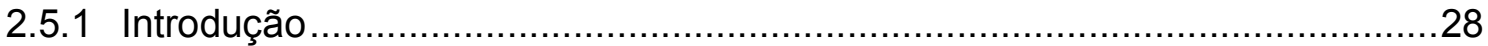

2.5.2 O efeito da injeção ou sucção de massa no escoamento em volta de uma

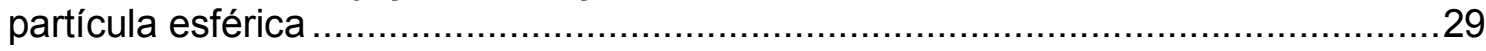

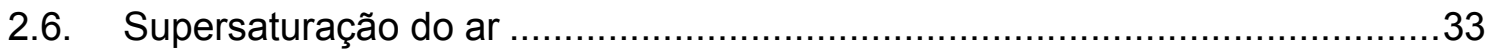

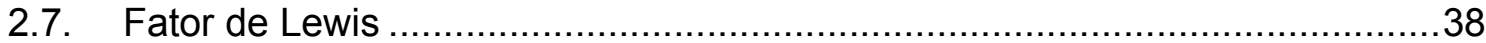

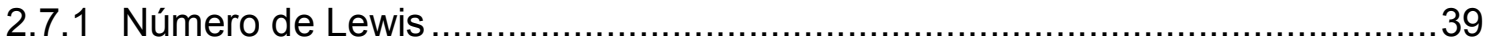

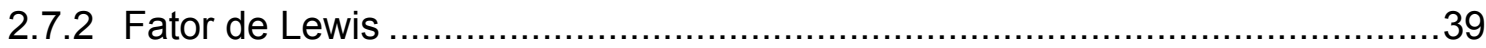

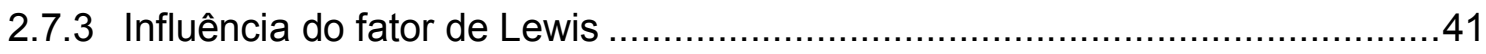

2.8. Dedução da equação de Bosnjakovic.............................................. 41

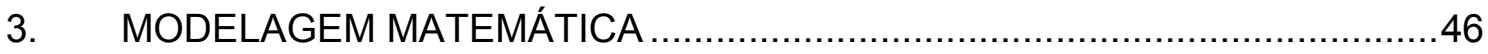

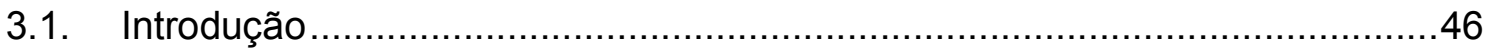


3.2. Equacionamento para baixo transporte de massa.................................46

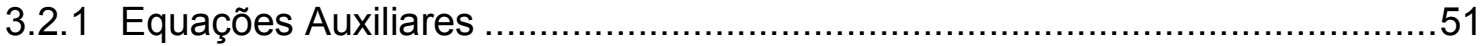

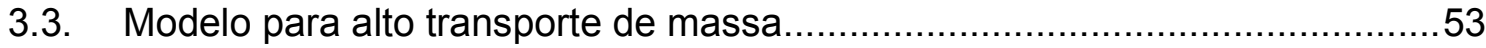

3.4. Modelo para o transporte de calor e fator de Lewis ................................59

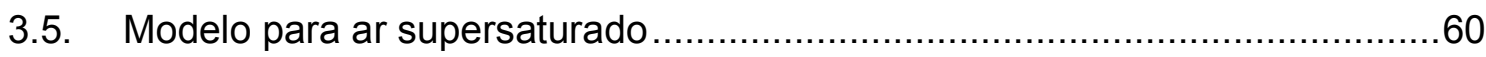

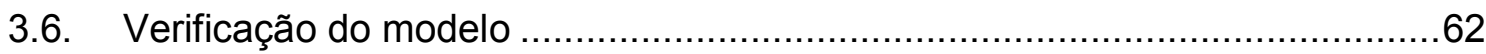

4. ALGORITMO DO PROGRAMA DE SIMULAÇÃO .................................65

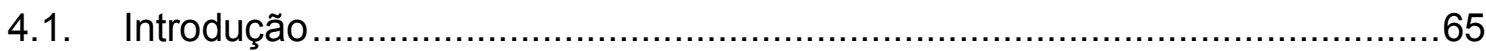

4.2. Sem supersaturação e com baixo transporte de massa / sem supersaturação e com alto transporte de massa ......................................................................... 65

4.3. Com supersaturação e com baixo transporte de massa / com supersaturação e com alto transporte de massa ......................................................................... 72

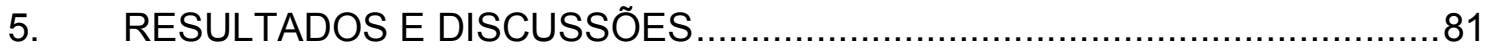

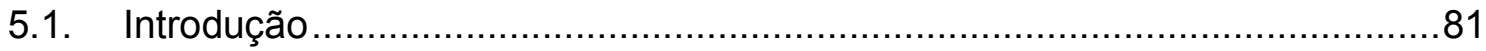

5.2. Simulação de uma torre de resfriamento existente ............................... 82

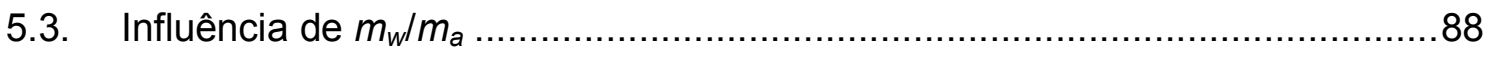

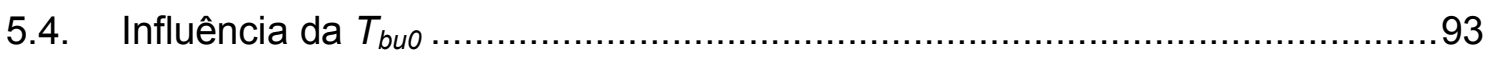

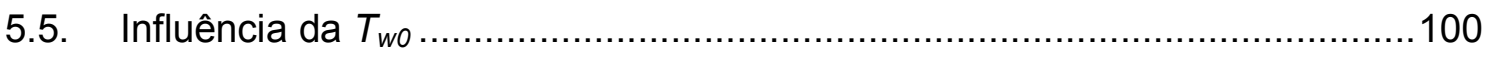

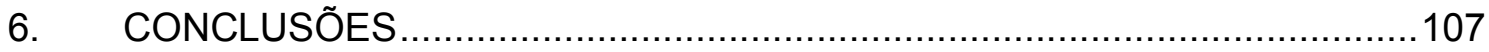

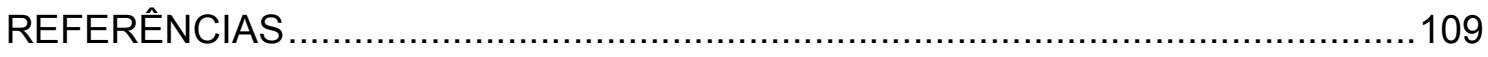




\section{INTRODUÇÃO E OBJETIVOS}

Torres de resfriamento são empregadas em diferentes etapas de processos industriais. Nestes equipamentos, a água que deve ser resfriada é alimentada no topo da torre de resfriamento, constituída de um dispositivo de contato para melhor distribuição de água. Ar ambiente é insuflado através do recheio interno, em contracorrente ou em corrente cruzada com a água que desce. Por meio desse contato líquido / gás, parte da água evapora e ocorre o seu resfriamento.

Variações na temperatura da água de resfriamento influenciam diretamente na operação de equipamentos da indústria. O conhecimento da temperatura da água de resfriamento é decisivo não só na operação de uma planta, mas também na fase de projeto. Decorre desta amplitude de utilização a operação da torre em condições adversas em relação às concebidas na etapa de projeto.

No presente trabalho, será apresentado um estudo com o objetivo de avaliar o desempenho de torres de resfriamento sob condições adversas de operação, particularmente, para temperatura de água acima de $50^{\circ} \mathrm{C}$ na entrada da torre. Nesta condição, tem-se alta taxa de evaporação e eventualmente condição de alto transporte de massa, normalmente não considerado no equacionamento de torres de resfriamento. Também é frequente haver a saturação do ar ao longo da torre e, para estes casos os balanços diferenciais de massa e energia devem contemplar este fenômeno a partir ponto em que ocorre a saturação.

Apresentar-se-á, uma análise comparativa dos diferentes métodos de cálculo de torres de resfriamento, a saber, Merkel, Poppe e Poppe modificado. Este último refere-se ao modelo desenvolvido neste trabalho, que contempla os modelos de alto transporte de massa e de supersaturação do ar.

O modelo matemático desenvolvido consiste de equações diferenciais ordinárias que expressam os modelos de transporte de calor e massa, os balanços de massa e energia e equações auxiliares, e foi implementado em uma interface Matlab.

Este trabalho dá continuidade ao estudo desenvolvido por Mello et al. (2009) referente ao desempenho de torres de resfriamento operando em 
condições severas, com temperaturas da água quente superiores a 50 ${ }^{\circ} \mathrm{C}$. 


\section{REVISÃO BIBLIOGRÁFICA}

$\mathrm{Na}$ presente revisão, inicialmente, faz-se uma breve análise dos enfoques considerados na literatura para estudo de torres de resfriamento.

Nos itens 2.2 a 2.4, são apresentados de maneira sumarizada, os dois principais modelos para cálculo de torre de resfriamento (Merkel e Poppe).

No item 2.5, apresenta-se a teoria do alto transporte de massa, base do presente trabalho.

No item 2.6, apresenta-se a modelagem para o estudo do transporte de calor e de massa no caso da condição de ar supersaturado.

Finalmente, nos itens 2.7 e 2.8, apresenta-se uma análise do fator de Lewis e sua importância no caso do transporte simultâneo de calor e massa.

\subsection{Introdução}

Nos últimos anos têm sido desenvolvidos estudos relacionados à torres de resfriamento com dois enfoques distintos: a análise sistêmica da integração de torres de resfriamento com o processo e a modelagem mais rigorosa dos mecanismos de transferência de calor e massa no interior da torre.

O enfoque sistêmico geralmente consiste no estudo da integração do sistema de água de resfriamento com o processo, considerando-se as diferentes operações e a interação entre as variáveis de processo envolvidas, tanto em termos hidráulicos como térmicos. Nesta linha, pode-se citar o trabalho de Castro et al. (2000), que faz uma análise técnico econômica da influência das condições climáticas e da temperatura de saída da água da torre. De acordo com Castro et al. (2000), as variáveis que mais influenciam o custo operacional de uma torre são temperatura de saída da água da torre e a umidade do ar ambiente. Ainda neste enfoque, pode-se citar o trabalho de Cortinovis et al. (2009), que apresenta uma análise sistêmica da performance experimental consistente com uma modelagem matemática de uma torre de resfriamento integrada a trocadores de calor em escala piloto. 
Ainda com enfoque sistêmico, Kim e Smith (2001) apresentam alternativas para aumentar a capacidade de torres de resfriamento alterando-se apenas a disposição de trocadores de calor de forma a obter um melhor desempenho na torre.

A modelagem e o equacionamento mais rigoroso do processo de transferência de calor e massa entre o ar e água, no interior da coluna, tem sido objeto de estudo de vários autores, nos últimos anos, destacando-se os trabalhos de Kloppers e Kröger (2005a) e Kloppers e Kröger (2005b), que comparam os métodos de Poppe e Merkel para modelagem de torres. Mello et al. (2009) apresenta um estudo sobre a influência das variáveis de processo (vazões de ar e água e condição ambiente) no desempenho de torres. Klimanek e Bialecki (2009) apresentam uma modelagem com acuracidade equivalente ao modelo de Poppe, e Muangnoi et al. (2006) inclui a análise exergética para investigar o desempenho de torres de resfriamento.

Apresentam-se a seguir os principais modelos existentes para cálculo de torres de resfriamento, disponíveis na literatura aberta: Merkel e Poppe.

\subsection{Modelo de Merkel}

O modelo de Merkel é, com certeza, o mais conhecido e empregado na avaliação e projetos de torres de resfriamento. Segundo Kloppers e Kröger (2005b), este modelo baseia-se em hipóteses que reduzem os cálculos a um procedimento relativamente simples. Sendo assim, não representa rigorosamente os processos de transferências de calor e massa em uma torre de resfriamento. As principais simplificações do método de Merkel são as seguintes:

- o fator de Lewis, $L e_{f}$, que relaciona os coeficientes convectivos de transferência de calor e massa, é igual a 1;

- a redução na vazão de água devido à perda por evaporação não é considerada nos balanços de massa e de energia.

Para determinar a umidade do ar que sai da torre de resfriamento, considera-se que está saturado com vapor de água e desta forma determina-se sua entalpia específica e umidade. 
Importante frisar, que o método da efetividade, conhecido como e-NTU, baseia-se nas mesmas simplificações do método de Merkel.

Os balanços de massa e energia, conforme a teoria de Merkel, para escoamento contracorrente de água e ar são dados pelas equações (2.1) e (2.2), baseados no esquema ilustrado na Figura 2.1. A equação (2.1) expressa a variação da entalpia específica do ar ao longo da altura, z. Relacionando o balanço de energia na fase gás e o fluxo de transporte de calor e de massa e sendo considerada a analogia da transferência de calor e de massa para fator de Lewis igual a 1.

$\frac{d i_{m a}}{d z}=\frac{k_{w} a_{i} A_{r}}{m_{a}}\left(i_{m a w}-i_{m a}\right)$

A equação (2.2) expressa o balanço de energia ao longo da altura $z$, considerandose as fases ar e água, para vazão de água constante ao longo da torre.

$\frac{d T_{w}}{d z}=\frac{m_{a}}{m_{w}} \frac{1}{C p_{w}} \frac{d i_{m a}}{d z}$

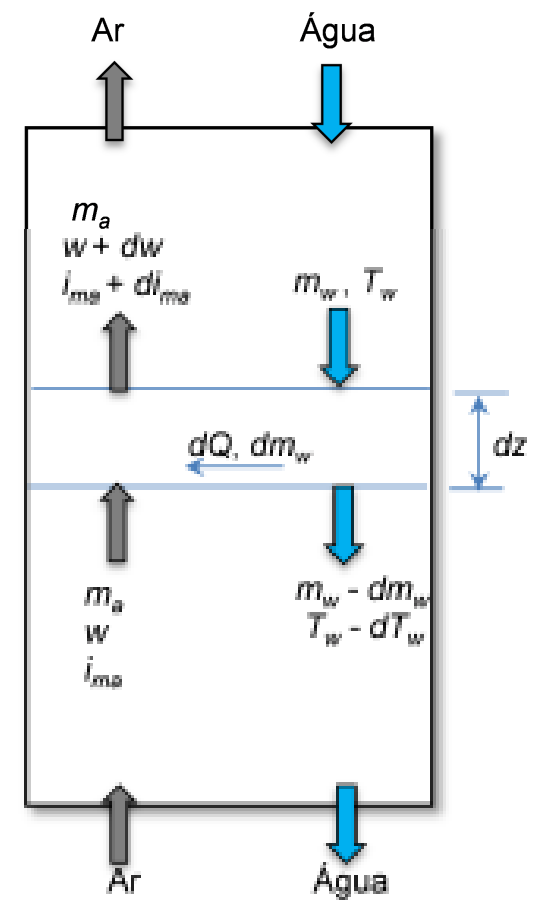

Figura 2.1 - Contato ar água em uma torre de resfriamento contracorrente 
Como pode ser observado na equação (2.1), o potencial de transferência de calor e massa, a uma dada temperatura da água, é dado pela diferença entre a entalpia específica do ar saturado na interface ar água, $i_{\text {maw }}$, e a entalpia específica do ar no seio do ar, $i_{m a}$.

Substituindo-se a equação (2.1) em (2.2) e integrando-se a equação resultante, tem-se a equação (2.3).

$M e_{M}=\frac{k_{w} a_{i} A_{r} Z}{m_{w}}=\int_{T_{w 0}}^{T_{w f}} \frac{C p_{w} d T_{w}}{\left(i_{m a w}-i_{m a}\right)}$

sendo $M e_{M}$ o número de Merkel.

A equação (2.3) é utilizada para obtenção da altura da torre através da integração entre a temperatura de entrada, $T_{w 0}$, e a temperatura de saída, $T_{w f}$, da água.

Normalmente é difícil determinar a área superficial pelo volume de recheio pelo fato de se tratar de um escoamento bifásico em leito recheado.

Através do método de Merkel, não há a possibilidade de se determinar a verdadeira condição do ar que deixa a torre. Admite-se que o ar que deixa a torre está saturado com vapor de água.

Para resolver a integral da equação (2.3), o Cooling Tower Institute recomenda a técnica de integração por quatro pontos de Chebyshev, que usa 4 intervalos para o cálculo da integral.

Conforme ilustrado na Figura 2.2, de Perry e Green (1997), a linha de equilíbrio da torre é dada pela curva "AB", que representa a entalpia do ar saturado na interface em função da temperatura da água. A linha de operação relaciona a entalpia do ar em função da temperatura da água. O segmento "BC" representa o potencial de transferência de calor e massa entre a água que está saindo da torre e o ar que está entrando $\left(h^{\prime}-h\right)$.

O "approach" é definido como a diferença entre a temperatura da água fria que deixa a torre e a temperatura de bulbo úmido do ar ambiente. 


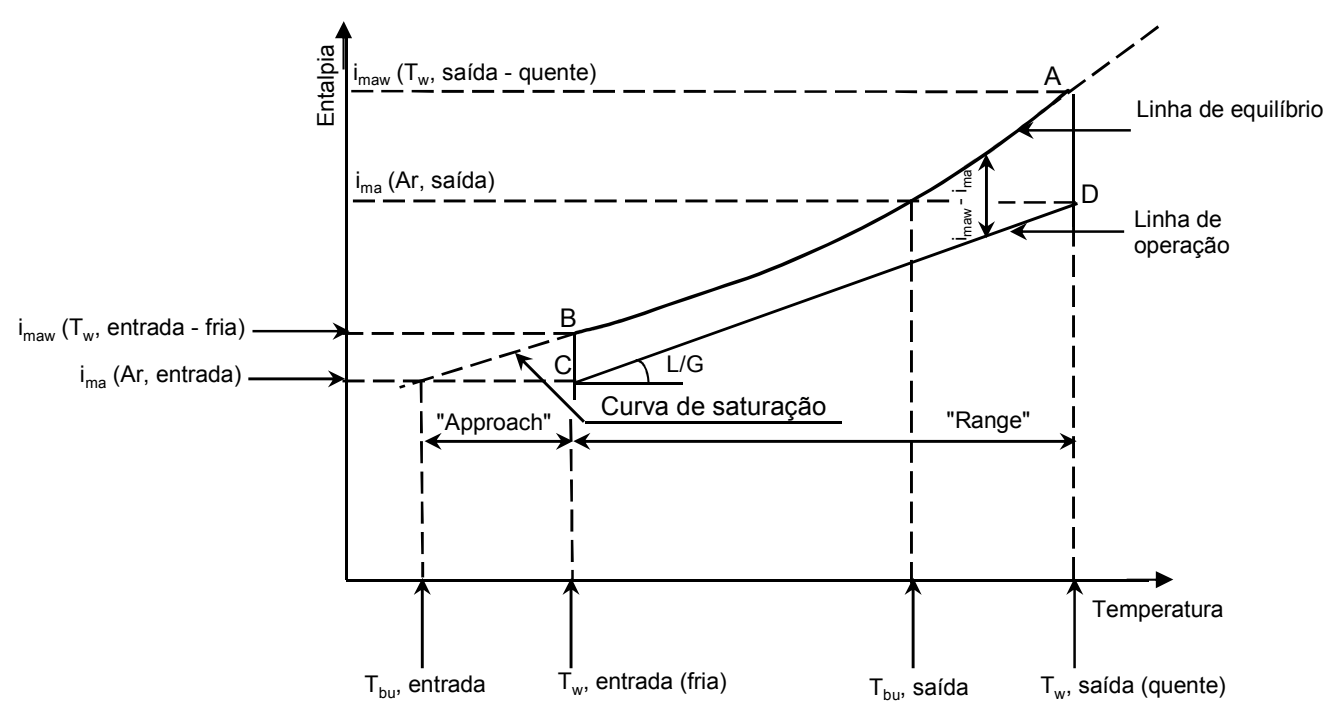

Figura 2.2 - Diagrama de entalpia específica versus temperatura em torre de resfriamento, de acordo com Perry e Green (1997)

Perry e Green (1997) apresentam a seguinte equação para o método de Merkel, referente à equação (2.3), que implicitamente adota $\mathrm{Cp}_{\mathrm{w}}=1 \mathrm{Btu} / \mathrm{lb} \mathrm{b}^{\circ} \mathrm{F}$ :

$\frac{\mathrm{KaV}}{\mathrm{L}}=\int_{\mathrm{T}_{1}}^{\mathrm{T}_{2}} \frac{\mathrm{dT}}{\mathrm{h}_{\mathrm{w}}-\mathrm{h}_{\mathrm{a}}} \cong \frac{\mathrm{T}_{1}-\mathrm{T}_{2}}{4}\left(\frac{1}{\Delta \mathrm{h}_{1}}+\frac{1}{\Delta \mathrm{h}_{2}}+\frac{1}{\Delta \mathrm{h}_{3}}+\frac{1}{\Delta \mathrm{h}_{4}}\right)$

onde:

$\Delta h_{1}=\left(h_{w}-h_{a}\right)_{T 2}+0,1(T 1-T 2)$, sendo $\left(h_{w}-h_{a}\right)_{T 2+0,1(T 1-T 2)}$, a diferença $\left(h_{w}-h_{a}\right)$ obtida a $T_{2}+0,1\left(T_{1}-T_{2}\right)$,

$\Delta h_{2}=\left(h_{w}-h_{a}\right)_{T 2}+0,4(T 1-T 2)$, sendo $\left(h_{w}-h_{a}\right)_{T 2}+0,4(T 1-T 2)$, a diferença $\left(h_{w}-h_{a}\right)$ obtida a $T_{2}+0,4\left(T_{1}-T_{2}\right)$,

$\Delta h_{3}=\left(h_{w}-h_{a}\right)_{T 1-0,4(T 1-T 2)}$, sendo $\left(h_{w}-h_{a}\right)_{T 1-0,4(T 1-T 2)}$, a diferença $\left(h_{w}-h_{a}\right)$ obtida a $T_{1}-0,4\left(T_{1}-T_{2}\right)$, $\Delta h_{4}=\left(h_{w}-h_{a}\right)_{T 1-0,1(T 1-T 2)}$, sendo $\left(h_{w}-h_{a}\right)_{T 1-0,1(T 1-T 2)}$, a diferença $\left(h_{w}-h_{a}\right)$ obtida a $T_{1}-0,1\left(T_{1}-T_{2}\right)$.

$K$ - coeficiente de transferência de massa (lb águal/(h. $\left.\mathrm{ft}^{2}\right)$ ) $a$ - área superficial de contato $\left(\mathrm{ft}^{2} / \mathrm{ft}^{3}\right)$ 
$V$ - volume ativo da torre $\left(\mathrm{ft}^{3} / \mathrm{ft}^{2}\right)$

$L$ - fluxo de água (lb água/(h. $\left.\left.\mathrm{ft}^{2}\right)\right)$

$h_{w}$ - entalpia específica do ar úmido na temperatura da água (Btu/lb ar seco)

$h_{a}$ - entalpia específica do ar úmido na temperatura de bulbo úmido (Btu/lb ar seco)

$T_{1}$ - temperatura de entrada da água $\left({ }^{\circ} \mathrm{F}\right)$

$T_{2}$ - temperatura de saída da água $\left({ }^{\circ} \mathrm{F}\right)$

Contudo, o lado esquerdo da equação (2.4) é adimensional, enquanto o lado direito não é, a não ser que multiplicamos este lado pelo calor específico da água. Sendo assim, a equação deveria ser escrita conforme a seguir.

$\frac{K a V}{L}=\int_{T_{1}}^{T_{2}} C p_{w} \frac{d T}{h_{w}-h_{a}} \cong \frac{C p_{w}\left(T_{1}-T_{2}\right)}{4}\left(\frac{1}{\Delta h_{1}}+\frac{1}{\Delta h_{2}}+\frac{1}{\Delta h_{3}}+\frac{1}{\Delta h_{4}}\right)$

\subsection{Modelo Poppe}

O método de Poppe, conforme publicado por Kloppers e Kröger (2005a), foi desenvolvido em 1970, e não faz as mesmas simplificações que o método de Merkel. Através do método de Poppe é possível calcular a quantidade de vapor de água na corrente de ar que deixa a torre, assim como a quantidade de água evaporada, que são fatores importantes no projeto de torres de resfriamento.

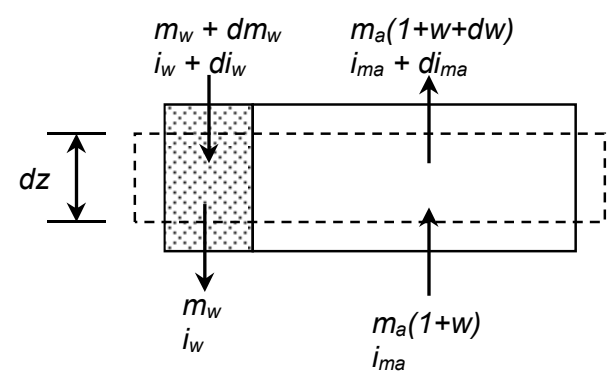

Figura 2.3 - Volume de controle para escoamento contracorrente 
Do balanço de massa no elemento de volume da torre, representado na Figura 2.3, tem-se:

$d m_{w}=m_{a} d w$

O balanço de energia para o volume de controle representado pela Figura 2.3 é dado por:

$m_{a} d i_{m a}-m_{w} d i_{w}-i_{w} d m_{w}=0$

Substituindo-se a equação (2.6) na equação (2.7) e expressando-se a entalpia específica da água $i_{w}$ em função da sua temperatura $T_{w}$, tem-se:

$d\left(T_{w}-T_{r e f}\right)=\frac{m_{a}}{m_{w}}\left(\frac{1}{c p_{w}} d i_{m a}-\left(T_{w}-T_{r e f}\right) d w\right)$

Considerando a interface ar-água conforme a Figura 2.3, o balanço de energia na interface pode ser expresso por:

$d Q=d Q_{m}+d Q_{c}$

sendo, $Q_{m}$ a energia transferida devido à transferência de massa, associada à diferença na concentração de vapor entre o ar saturado na interface e a corrente de ar, e $Q_{c}$ a transferência de calor sensível devido à diferença entre as temperaturas.

A transferência de massa (evaporação da água) através da interface é expressa por:

$d m_{w}=k_{w}^{*}\left(w_{s w}-w\right) d A$

sendo $d A$ a área efetiva de transferência de calor e massa no volume elementar de recheio de altura $d z$, e está relacionada à área específica $a_{i}$, conforme a equação (2.11).

$d A=a_{i} A_{r} d z$

Assim, o transporte de entalpia específica associado à transferência de massa ar / interface é expresso pela equação (2.12).

$d Q_{m}=i_{v} d m_{w}=i_{v} k_{w}^{*}\left(w_{s w}-w\right) d A$

A transferência de calor ar / interface é dada por:

$d Q_{c}=h\left(T_{w}-T_{a}\right) d A$ 
A entalpia específica do vapor de água, $i_{v}$, na interface que está à temperatura da água $T_{w}$, é dada por:

$i_{v}=i_{w r e f}+C p_{v}\left(T_{w}-T_{r e f}\right)$

A entalpia específica do ar saturado, $i_{\text {maw }}$, na interface, calculada na temperatura da água é representada pela equação (2.15).

$i_{\text {maw }}=C p_{a} T_{w}+w_{s w}\left(i_{w r e f}+C p_{v}\left(T_{w}-T_{\text {ref }}\right)\right)$

A equação (2.16) determina a entalpia específica do ar úmido por unidade de ar seco.

$i_{m a}=C p_{a}\left(T_{a}-T_{r e f}\right)+w\left(i_{w r e f}+C p_{v}\left(T_{a}-T_{r e f}\right)\right)$

Subtraindo-se a equação (2.16) da (2.15), tem-se:

$T_{w}-T_{a}=\frac{\left(i_{m a w}-i_{m a}\right)-i_{v}\left(w_{s w}-w\right)}{C p_{a}+w C p_{v}}$

Substituindo-se a equação (2.17) na equação (2.13), e, a equação resultante e a equação (2.12) na equação (2.9), tem-se:

$d Q=k_{w}^{*}\left[L e_{f}\left(i_{m a w}-i_{m a}\right)+\left(1-L e_{f}\right) i_{v}\left(w_{s w}-w\right)\right]$

sendo $L e_{f}$ o fator de Lewis, que relaciona os coeficientes de transferência de calor e massa, e é dado pela seguinte equação:

$L e_{f}=\frac{h}{C p_{a} k_{w}^{*}}$

Kloppers e Kröger (2005a) utilizam a expressão (2.20) para o fator de Lewis, de acordo com Bosnjakovic (1965). A dedução desta equação se encontra no item 2.7.

$L e_{f}=0,865^{0,667} \frac{\left(\frac{w_{S w}+0,622}{w+0,622}-1\right)}{\ln \left(\frac{w_{S w}+0,622}{w+0,622}\right)}$

A partir da equação (2.18), a variação de entalpia específica do ar pode ser expressa pela seguinte equação:

$d i_{m a}=\frac{1}{m_{a}} d Q=\frac{k_{w}^{*} d A}{m_{a}}\left[L e_{f}\left(i_{m a w}-i_{m a}\right)+\left(1-L e_{f}\right) i_{v}\left(w_{s w}-w\right)\right]$

Substituindo a equação (2.11) na equação (2.21), tem-se uma equação para a variação da entalpia específica do ar com a altura: 
$\frac{d i_{m a}}{d z}=\frac{k_{w}^{*} a_{i} A_{r}}{m_{a}}\left[L e_{f}\left(i_{m a w}-i_{m a}\right)+\left(1-L e_{f}\right) i_{v}\left(w_{s w}-w\right)\right]$

Substituindo as equações (2.10) e (2.21) na equação (2.7), obtém-se a equação (2.23).

$m_{w} d i_{w}=k_{w}^{*} d A\left[i_{m a w}-i_{m a}+\left(L e_{f}-1\right)\left[i_{m a w}-i_{m a}-\left(w_{s w}-w\right) i_{v}\right]-\left(w_{s w}-\right.\right.$

w) $\left.C p_{w}\left(T_{w}-T_{r e f}\right)\right]$

Rearranjando-se a equação (2.8), encontra-se a seguinte equação:

$\frac{d w}{d T_{w}}=\frac{d i_{m a}}{\left(T_{w}-T_{r e f}\right) d i_{w}}-\frac{1}{\left(T_{w}-T_{r e f}\right)} \frac{m_{w}}{m_{a}}$

Substituindo-se as equações (2.21) e (2.23) em (2.24), tem-se a equação (2.25) que relaciona a variação da umidade do ar com a variação da temperatura da água.

$\frac{d w}{d T_{w}}=\frac{C p_{w} \frac{m_{w}}{m_{a}}\left(w_{s w}-w\right)}{i_{m a w}-i_{m a}+\left(L e_{f}-1\right)\left[i_{m a w}-i_{m a}-\left(w_{s w}-w\right) i_{v}\right]-\left(w_{s w}-w\right) C p_{w}\left(T_{w}-T_{r e f}\right)}$

E substituindo-se a equação (2.25) na (2.24), tem-se:

$\frac{d i_{m a}}{d T_{w}}=\frac{m_{w} C p_{w}}{m_{a}}\left(1+\frac{\left(w_{s w}-w\right) C p_{w}\left(T_{w}-T_{r e f}\right)}{i_{m a w}-i_{m a}+\left(L e_{f}-1\right)\left[i_{m a w}-i_{m a}-\left(w_{s w}-w\right) i_{v}\right]-\left(w_{s w}-w\right) C p_{w}\left(T_{w}-T_{r e f}\right)}\right)$

(2.26)

A umidade do ar na entrada da torre pode ser calculada a partir da sua $T_{b u}$ conforme equação (2.27).

$W=\left(\frac{2501,6-2,3263\left(T_{b u}-T_{r e f}\right)}{2501,6+1,877\left(T_{a}-T_{r e f}\right)-4,184\left(T_{b u}-T_{r e f}\right)}\right)\left(\frac{0,62509 P_{v b u}}{P_{a}-1,005 P_{v b u}}\right)-$

$\left(\frac{1,00416\left(T_{a}-T_{b u}\right)}{2501,6+1,877\left(T_{a}-T_{r e f}\right)-4,184\left(T_{b u}-T_{r e f}\right)}\right)$

Na equação (2.27), $P_{v b u}$ é a pressão de vapor calculada na temperatura de bulbo úmido $\left(T_{b u}\right)$.

Kloppers e Kröger (2005a) apresentam o equacionamento para o caso de o ar estar supersaturado. No entanto, não se discute a diferença entre considerar ou não as 
equações de supersaturação no cálculo da torre, nem evidencia resultados considerando estas equações de supersaturação.

\subsection{Comparação entre os métodos de Merkel e Poppe}

No trabalho de Kloppers e Kröger (2005b), foram feitas comparações entre resultados experimentais e os obtidos pelos métodos de Merkel e Poppe, fixando-se as vazões de água e de ar e variando-se as temperaturas de entrada da água. As temperaturas de saída da água calculadas pelos métodos de Merkel, e-NTU e Poppe foram praticamente idênticas: 291,59 K, 291,46 K, 291,55 K, respectivamente.

Os valores do número de Merkel, obtidos por Poppe e e-NTU são, respectivamente, $9 \%$ superior e $1 \%$ inferior ao número de Merkel obtido pelo método de Merkel. Por outro lado, apesar desta diferença entre os números de Merkel obtidos, as temperaturas de saída da água são praticamente iguais conforme mencionado anteriormente.

Um valor aproximado da temperatura de saída do ar pode ser previsto pelo método de Merkel ou e-NTU, assumindo-se que o ar que sai da torre está saturado. Já o método de Poppe permite o cálculo da temperatura de saída do ar. Estas temperaturas, obtidas a partir de diferentes modelos ou aproximações, podem ser usadas para testar a exatidão dos modelos, comparando-as com as temperaturas medidas experimentalmente. Conforme mostra o gráfico da Figura 2.4, retirado do trabalho de Kloppers e Kröger (2005b), as temperaturas de saída do ar calculadas pelo método de Poppe são bem mais próximas das obtidas experimentalmente que o de Merkel. Estes resultados foram obtidos em ensaios, nos quais fixaram-se as vazões de ar e água e variou-se a temperatura de entrada da água. 


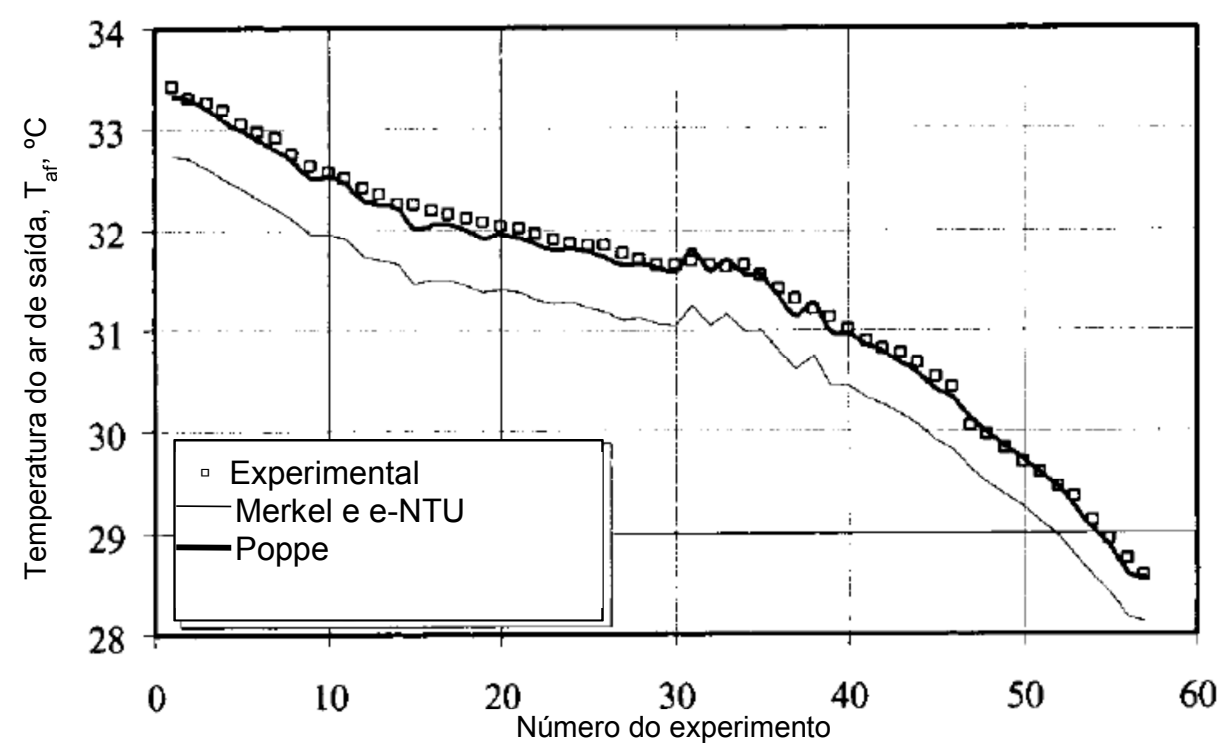

Figura 2.4 - Temperatura do ar de saída medido experimentalmente versus calculada por Merkel e Poppe de acordo com Kloppers e Kröger (2005b)

Em torres de resfriamento, geralmente a temperatura de saída do ar aumenta com o aumento da temperatura de entrada do ar e da umidade. Em condições de alta temperatura do ar de entrada e baixa umidade do ar, a temperatura do ar de saída pode ser inferior à do ar de entrada. Isto indica que tanto a água quanto o ar estão sendo resfriados, o que a princípio parece improvável, mas há uma explicação para isso. $O$ potencial para transferência de entalpia especifica entre a interface e $O \mathrm{ar}$ resulta em uma indicação qualitativa do sentido do fluxo de calor na torre. A Figura 2.5 ilustra uma região da carta psicrométrica, onde, $w_{s w}>w$, e assim o sentido da transferência de entalpia específica se dá da água para o ar. Além disso, $T_{w}>T_{a}$, o que significa que a transferência de calor sensível ocorre no sentido da água para o ar. Resumindo, neste caso, a entalpia específica total transferida se dá da água para $\circ$ ar desde que $i_{\text {masw }}>i_{\text {ma }}$ e a transferência de entalpia específica e calor sensível ocorrem no mesmo sentido. Nessas condições, a água é resfriada e o ar é aquecido.

Por outro lado, a situação ilustrada na Figura 2.6 indica $w_{s w}>w$, assim a direção da transferência de calor latente é no sentido da água para o ar. No entanto, tem-se $T_{a}$ $>T_{w}$, o que significa que o calor sensível é transferido do ar para a água. A transferência de entalpia específica continua sendo da água para o $\mathrm{ar}$, desde que $i_{\text {masw }}>i_{\text {ma. }}$. Neste caso, tem-se que a temperatura do ar que sai da torre é menor que 
a temperatura do ar ambiente, e a água ainda assim é resfriada pois a temperatura de saída da água é menor do que a temperatura de entrada.

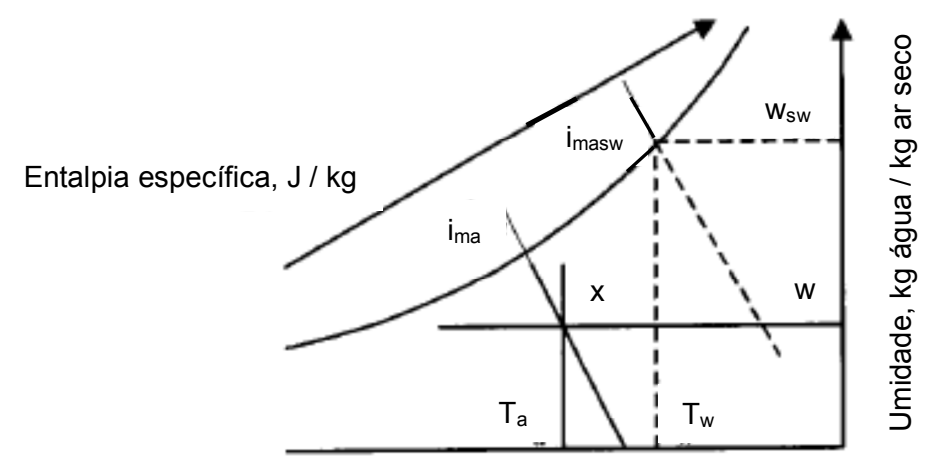

Temperatura bulbo seco, $\mathrm{K}$

Figura 2.5 - Carta psicrométrica, $T_{w}>T_{a}$ de acordo com Kloppers e Kröger (2005b).

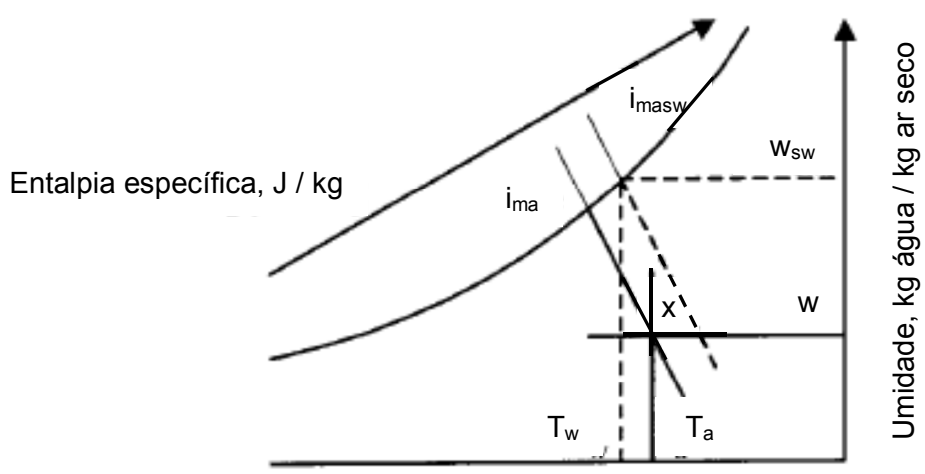

Temperatura bulbo seco, $\mathrm{K}$

Figura 2.6 - Carta psicrométrica, $T_{a}>T_{w}$ de acordo com Kloppers e Kröger (2005b). 


\subsection{Alto Transporte de Massa}

\subsubsection{Introdução}

O comportamento de uma gota evaporando, sujeita a uma temperatura ambiente alta tem sido estudado nas últimas décadas por estudos teóricos e experimentais. No entanto, estes estudos não levam em conta coeficientes de arraste e de transferência de calor e de massa de uma gota evaporando em condições de alto transporte de massa e movimento instável (Chuchottaworn et al., 1984b).

Conforme apresentado por Koichi (2006), o movimento e a transferência de massa em bolhas e gotas estão relacionados às formas de suas superfícies, além de serem sensíveis às condições de escoamento, assim como às propriedades físicas dos sistemas.

Em pequenas bolhas ou gotas a tensão superficial é dominante na interface e, consequentemente, estas tendem a ter uma forma esférica. Para tamanhos intermediários de bolhas, entretanto, estas formas sofrem deformações e podem se tornar instáveis.

Gotas de diâmetros menores que $1 \mathrm{~mm}$ em fases líquidas são esféricas, enquanto gotas de tamanhos médios, alguns milímetros de diâmetro, tendem a ter um formato deformado, parecido a uma esfera achatada.

Gotas em fases gasosas são mais estáveis em comparação a gotas em fases líquidas e possuem formato quase esférico se os seus diâmetros forem menores que alguns milímetros.

Bolhas e gotas são denominadas fase dispersa, enquanto o fluido que contém esta fase dispersa é denominado fase contínua. Sabendo que a transferência de calor e massa na fase dispersa e na fase contínua são fenômenos afetados por diferentes fatores, e a resistência à transferência de massa em bolhas e gotas existir em ambos os lados da interface, deve-se ter um cuidado ao decidir qual dos lados representa uma resistência tal que controlará o processo. Por exemplo, a evaporação de gotas em uma fase gás é um processo controlado pela resistência à transferência de massa da fase contínua, assim como absorção por gotas de chuva é um processo controlado pela resistência da fase dispersa. Absorção por bolhas 
em uma fase líquida é comumente um processo controlado pela resistência à transferência de massa da fase contínua.

\subsubsection{O efeito da injeção ou sucção de massa no escoamento em volta de uma partícula esférica}

Os fenômenos de transporte (Chuchottaworn et al., 1983), sob condições de temperaturas altas, em que há simultaneamente transporte de quantidade de movimento, calor e massa e ainda há a interação destes fenômenos entre si são situações em que as taxas de evaporação se tornam tão altas que o transporte de massa através da superfície do líquido afeta a velocidade, a temperatura e o perfil de concentração da fase gás ao redor da gota.

A combustão de líquidos em máquinas de combustão interna, ou em queimadores a óleo e recuperação de vapores de hidrocarbonetos a partir de ar poluído utilizando "sprays" de óleo frio são exemplos de casos em que ocorre um fenômeno conhecido como alto transporte de massa (Koichi, 2006). Nestes casos, tem-se altas taxas de transferência de massa e o fluxo de massa ao redor das gotas é completamente diferente do fluxo que ocorre em situações de baixo transporte de massa. Devido à este fenômeno, os coeficientes de arraste, de transferência de calor e de massa para uma gota sujeita a evaporação ou a condensação são completamente diferentes dos coeficientes para uma partícula esférica sujeita às mesmas condições.

Por outro lado o movimento de uma gota pequena, conforme mencionado anteriormente, em uma fase gás pode ser aproximado ao movimento de uma partícula esférica. Assim, o fluxo de massa ao redor de uma gota evaporando ou condensando em uma fase gás pode ser aproximado ao fluxo de massa ao redor de uma partícula esférica sujeita a injeção ou sucção de massa. 


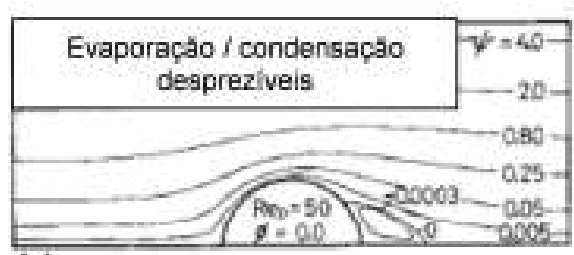

(a)
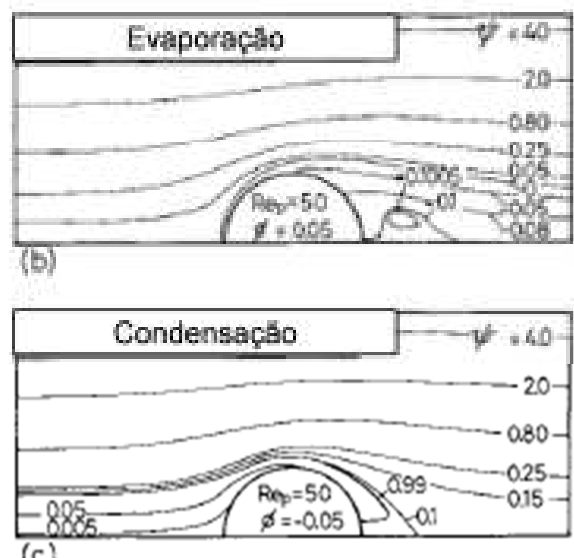

(c)

Figura 2.7 - Efeito da evaporação e da condensação no escoamento de um gás em torno de uma partícula esférica, para $\mathrm{Re}=50$ de acordo com Chuchottaworn et al. (1983)

A Figura 2.7 ilustra o comportamento das linhas de corrente da fase gás em volta de uma esfera sob o efeito da injeção de massa (evaporação) e da sucção de massa (condensação), denominadas por $\psi$, ao redor de uma partícula esférica para um número de Reynolds igual a 50. Sendo:

$\phi$ - a taxa de injeção ou sucção de massa, que é definida pela equação (2.28):

$\phi=\frac{v_{s}}{U}$

$v_{s}$ - a componente normal da velocidade na superfície da partícula esférica;

$U$ - a velocidade da corrente gás.

As linhas de corrente são succionadas para a superfície pela sucção de massa $(\phi<$ 0 ), Figura 2.7c, e o gradiente de velocidade aumenta conforme o fator de fricção.

Para o caso em que não há injeção nem sucção de massa na partícula esférica $(\phi=$ $0)$, Figura 2.7(a), as linhas de corrente de gás são distantes entre si na parte de trás da partícula esférica, enquanto se observa uma região circular ou ponto de estagnação, em que a função corrente é nula. Além disso, o gradiente de velocidade próximo à superfície diminui. Nota-se que na Figura 2.7(b), em que $\phi>0$ 
(injeção de massa), as linhas de corrente são afastadas da superfície da bolha pela injeção de massa e que o gradiente de velocidade próximo à superfície diminui no decorrer dela conforme o fator de friç̧ão. Por outro lado, quando $\phi<0$ (sucção de massa), Figura 2.7(c), as linhas de corrente estão mais próximas à superfície da partícula esférica e o gradiente de velocidade aumenta no decorrer desta superfície.

De acordo com a Figura 2.8, para um dado número de Reynolds, $R e$, o coeficiente de arraste diminui com a taxa de injeção, e aumenta com a taxa de sucção. Além disso, segundo Chuchottaworn et al. (1983) os efeitos da injeção ou sucção de massa se tornam mais significativos para Reynolds maiores.

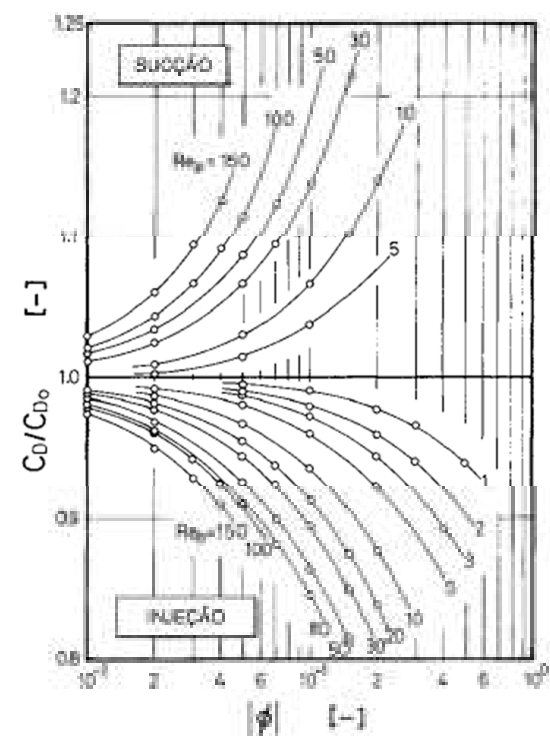

Figura 2.8 - Efeito da injeção/sucção de massa no coeficiente de arraste de uma partícula esférica de acordo com Chuchottaworn et al. (1983)

Chuchottaworn et al. (1983) apresentam uma correlação que relaciona o efeito da injeção ou sucção de massa no coeficiente de arraste, $C_{D}$, de uma partícula esférica. Esta correlação segue representada abaixo.

$\frac{C_{D}}{C_{D 0}}=1-\frac{R e^{-0,043}}{1+0,328\left(\phi / C_{D 0}\right)^{-1}}$

$\mathrm{Na}$ equação acima, $C_{D o}$ é o coeficiente de arraste de uma partícula esférica sem injeção e sem sucção de massa. 
Chuchottaworn et al. (1984b) apresentam uma correlação para a transferência de calor e massa para o caso de uma gota em contato com uma fase gás.

A Figura 2.9 apresenta o efeito da injeção difusiva de massa (evaporação) ou sucção difusiva de massa (condensação) na transferência de calor e massa na evaporação ou condensação de uma gota em uma fase gás. A ordenada, $g(B)$, representa o efeito do alto fluxo de massa causado por evaporação ou condensação, enquanto a abscissa representa o número de transferência para transferência de calor e de massa, $B_{H}$ e $B_{M}$, definidos respectivamente pelas equações (2.31) e (2.33). A linha contínua do gráfico representado na Figura 2.9 refere-se à correlação, proposta pelo autor para injeção ou sucção difusiva de massa.

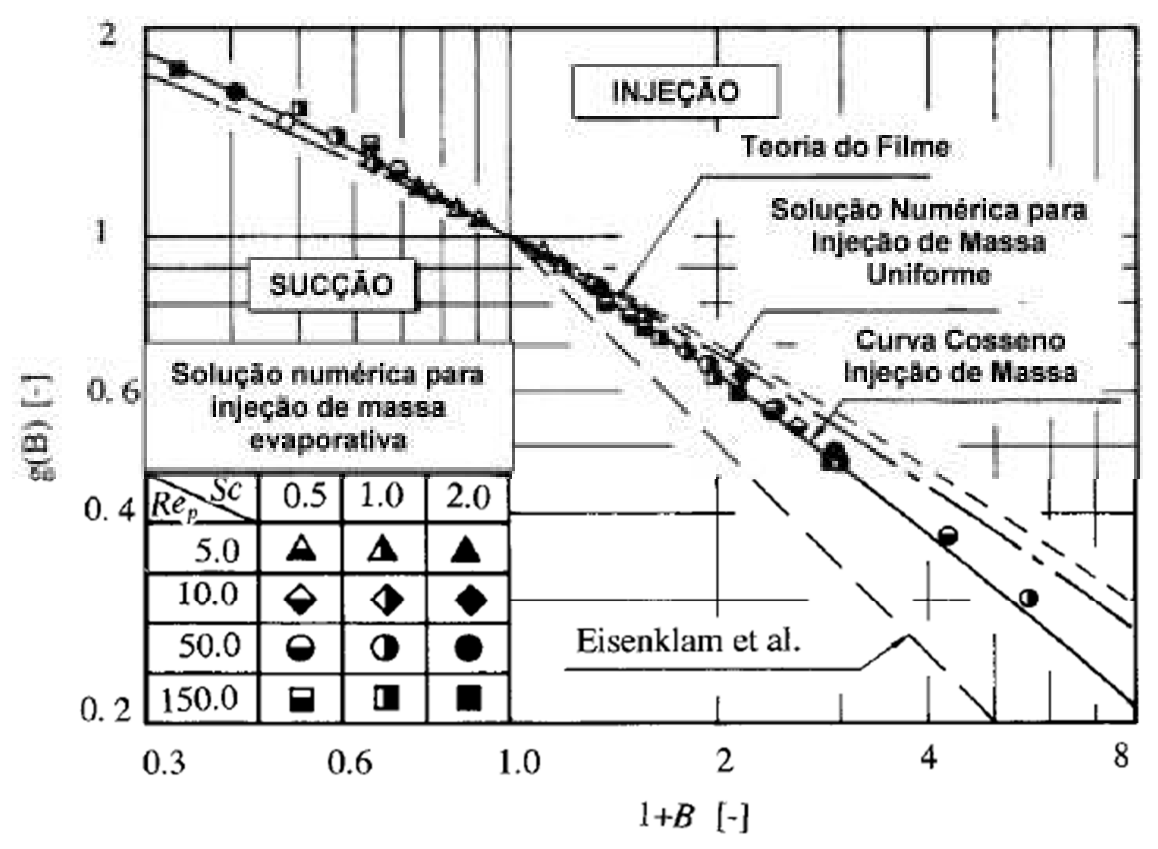

Figura 2.9 - Efeito da injeção/sucção de massa na transferência de calor e massa em uma partícula esférica de acordo com Koichi (2006)

Na Figura 2.9, estão representadas uma curva construída conforme a "Teoria do Filme", que considera que o filme de líquido possui espessura constante, e outras curvas conforme Eisenklam et al. e "Solução numérica para injeção de massa uniforme". A curva Cosseno de Injeção de Massa foi construída conforme dados experimentais e do ajustes destes dados para uma curva cosseno. A equação referente a essa curva, que representa a transferência de calor, é expressa por: 
$g(B)=g\left(B_{H}\right)=\frac{N u}{N u_{0}}=\frac{1}{0,3+0,7(1+B)^{0,88}}$

As variáveis $B$ ou $B_{H}$, são dados por:

$B=B_{H}=\left(\frac{\bar{v}_{s}}{U}\right)\left(\frac{R e \cdot P r}{N u_{0}}\right)$

onde $B_{H}$ é o número de transferência para transporte de calor.

De acordo com Chuchottaworn et al. (1984a), análises numéricas de transferência de calor e massa em um partícula esférica realizadas a partir da curva cosseno de injeção ou sucção de massa indica que o efeito da injeção de massa é representado pela seguinte equação:

$g(B)=g\left(B_{M}\right)=\frac{S h\left(1-x_{S w}\right)}{S h_{0}\left(1-x_{s w}\right)}=\frac{1}{0,3+0,7(1+B)^{0,88}}$

$E$ e $B_{M}$, são dados por:

$B=B_{M}=\left(\frac{\bar{v}_{s}}{U}\right)\left(\frac{R e . S c}{S h_{0}\left(1-x_{s w}\right)}\right)=\frac{\left(x_{s w}-x\right)}{\left(1-x_{s w}\right)}$

onde $B_{M}$ é o número de transferência para transporte de massa. A equação (2.33) indica que $B_{M}$ está relacionado com a força motriz de transferência de massa, $B$.

Nas equações acima, $N u_{0}$ é o número de Nusselt para baixo transporte de massa e $S h_{0}\left(1-x_{s w}\right)$ é o número de Sherwood para baixo transporte de massa em uma partícula esférica.

\subsection{Supersaturação do ar}

No trabalho de Qi e Liu (2007), é apresentada a modelagem para torres de resfriamento, levando em conta as equações de saturação do ar. Aplicando-se nesta modelagem o volume de controle da Figura 2.3 e considerando-se que o excesso de vapor de água na corrente de ar condensará na forma de névoa, a entalpia específica do ar supersaturado pode ser expressa por:

$i_{s p}=C p_{a}\left(T_{a}-T_{r e f}\right)+w_{s a}\left(i_{w r e f}+C p_{v}\left(T_{a}-T_{r e f}\right)\right)+\left(w-w_{s a}\right) C p_{w}\left(T_{a}-T_{r e f}\right)$ 
Os coeficientes de transferência de calor e massa utilizados para 0 ar supersaturado são os mesmos que são utilizados para o caso de o ar não estar supersaturado, conforme proposto por Kloppers e Kröger (2005a). O potencial que rege a transferência de massa neste caso é a diferença entre a umidade de saturação do ar saturado que está em equilíbrio e na temperatura de interface arágua $\left(w_{s w}\right)$ e a umidade de saturação do $\operatorname{ar}\left(w_{s a}\right)$, na temperatura do ar. Então, temse:

$d m_{w}=k_{w}^{*}\left(w_{s w}-w_{s a}\right) d A$

A entalpia específica de saturação do ar, na temperatura da água, que pode ser usada tanto para o caso de supersaturação do ar, quanto para o caso em que não ocorre a supersaturação, pode ser expressa pela equação (2.36).

$i_{\text {maw }}=C p_{a} T_{w}+w i_{v}+\left(w_{s w}-w\right) i_{v}$

Subtraindo-se a equação (2.34) da equação (2.36) e após algumas manipulações, tem-se a seguinte equação:

$T_{w}-T_{a}=\frac{i_{m a w}-i_{s p}-\left(w_{s w}-w_{s a}\right) i_{v}+\left(w-w_{s a}\right) C p_{w}\left(T_{w}-T_{a}\right)}{C p_{s p}}$

onde $C p_{s p}$ é o calor específico do ar supersaturado. A equação para o cálculo deste calor específico segue abaixo.

$C p_{s p}=C p_{a}+w_{s a} C p_{v}+\left(w-w_{s a}\right) C p_{w}$

Manipulando-se as equações (2.35) e (2.37), tem-se a seguinte equação para a variação da entalpia específica ar supersaturado:

$$
\begin{aligned}
& d i_{m a}=\frac{k_{w} d A}{m_{a}}\left(L e _ { f } \left(i_{m a w}-i_{s p}-\left(w_{s w}-w_{s a}\right) i_{v}+\left(w-w_{s a}\right) C p_{w}\left(T_{w}-\right.\right.\right. \\
& \left.\left.\left.T_{r e f}\right)\right)+i_{v}\left(w_{s w}-w_{s a}\right)\right)
\end{aligned}
$$

Para o cálculo do fator de Lewis, Kloppers e Kröger (2005a) utilizam a equação (2.20) citada no item 2.3 e repetida abaixo. 
$\mathrm{Le}_{\mathrm{f}}=0,865^{0,667} \frac{\left(\frac{\mathrm{w}_{\mathrm{sw}}+0,622}{\mathrm{w}+0,622}-1\right)}{\ln \left(\frac{\mathrm{w}_{\mathrm{sw}}+0,622}{w+0,622}\right)}$

Substituindo-se as equações (2.35) e (2.39) na equação (2.7), obtém-se a seguinte equação:

$m_{w} d i_{w}=m_{w} C p_{w} d T_{w}=k_{w}^{*} d A\left(L e_{f}\left(i_{m a w}-i_{s p}-\left(w_{s w}-w_{s a}\right) i_{v}+\left(w-w_{s a}\right) C p_{w}\left(T_{w}-\right.\right.\right.$

$\left.\left.\left.T_{r e f}\right)\right)+\left(w_{s w}-w_{s a}\right) i_{v}-\left(w_{s w}-w_{s a}\right) C p_{w}\left(T_{w}-T_{r e f}\right)\right)$

Rearranjando-se, obtém-se a equação (2.41).

$$
\begin{aligned}
& m_{w} d i_{w}=m_{w} C p_{w} d T_{w}=k_{w}^{*} d A\left(i_{\text {maw }}-i_{s p}+\left(L e_{f}-1\right)\left(i_{\text {maw }}-i_{s p}+\left(w_{s w}-w_{s a}\right) i_{v}+\right.\right. \\
& \left.\left.\left(w-w_{s a}\right) C p_{w}\left(T_{w}-T_{r e f}\right)\right)+\left(w-w_{s w}\right) C p_{w}\left(T_{w}-T_{r e f}\right)\right)
\end{aligned}
$$

Substituindo a equação (2.35) na equação (2.6), obtém-se:

$k_{w}^{*} d A=\frac{m_{a} d w}{\left(w_{s w}-w_{s a}\right)}$

Substituindo-se a equação (2.42) na equação (2.40), encontra-se:

$\frac{d w}{d T_{w}}=\frac{C p_{w} \frac{m_{w}}{m_{a}}\left(w_{s w}-w_{s a}\right)}{i_{m a w}-i_{s p}+\left(L e_{f}-1\right)\left(i_{m a w}-i_{s p}-\left(L e_{f}-1\right) i_{v}\right)-\left(w-w_{s a}\right) C p_{w}\left(T_{w}-T_{r e f}\right)}$

Substituindo a equação (2.43) na equação (2.24) e rearranjando-se:

$$
\begin{aligned}
& \frac{d i_{m a}}{d T_{w}}= \\
& C p_{w} \frac{m_{w}}{m_{a}}(1+
\end{aligned}
$$

$\left.\frac{C p_{w} T_{w}\left(w_{s w}-w_{s a}\right)}{i_{m a w}-i_{s p}+\left(L e_{f}-1\right)\left(i_{m a w}-i_{s p}-\left(w_{s w}-w_{s a}\right) i_{v}+\left(w-w_{s a}\right) C p_{w}\left(T_{w}-T_{r e f}\right)\right)+\left(w-w_{s w}\right) C p_{w}\left(T_{w}-T_{r e f}\right)}\right)$

A partir das equações (2.6) e (2.35), tem-se: 
$k_{w}^{*} d A=\frac{m_{a} d w}{w_{s w}-w_{s a}}$

Rearranjando-se a equação (2.45), tem-se:

$M e_{p}=\frac{k_{w}^{*} A}{m_{w}}=\int \frac{m_{a}}{m_{w}} \frac{d w / d T_{w}}{w_{s w}-w_{s a}} d T_{w}$

sendo $\mathrm{Me}_{p}$ o número de Merkel, de acordo com o método de Poppe.

Para o balanço de massa de água, tem-se:

$d m_{w}=m_{a} d w$

A partir das equações (2.47), (2.20), (2.43) e (2.44), calculam-se as condições do ar de saída em termos de entalpia específica e umidade.

Kloppers e Kröger (2005a) resolveram estas equações acima através do método de Runge-Kutta. Os autores discutem as diferenças entre os resultados obtidos pelos métodos de Merkel e e-NTU e os obtidos pelo método de Poppe, e apresentam-se a modelagem para supersaturação do ar, apesar de não explicitar resultados sobre supersaturação.

Considerando-se que o ar entre saturado, conforme o ponto 1 da Figura 2.10, imediatamente tem-se a supersaturação de acordo com o método de Poppe, assim que entra no recheio da torre. Enquanto escoa pela torre, o ar é aquecido e a sua umidade aumenta devido à evaporação. A curva $T_{a}$ versus $w$ segue próxima à curva de saturação. Isso ocorre pois conforme o ar é aquecido, pode acumular mais vapor de água antes que ele alcance o ponto de saturação.

O ponto $2 \mathrm{~b}$ da Figura 2.10 ilustra as condições do ar na saída do recheio da torre de acordo com o método de Poppe, enquanto o ponto 2a, da Figura 2.10, ilustra as condições do ar de saída de acordo com o método de Merkel, ou seja, o ar é assumido como saturado. As temperaturas de saída do ar obtidas pelo método de Poppe e pelo método de Merkel são bem próximas de acordo com o gráfico da Figura 2.10. Sendo assim, a hipótese feita pelo método de Merkel de que o ar que sai da torre está saturado pode ser uma consideração aceitável para os casos em que o ar que sai da torre está supersaturado. 


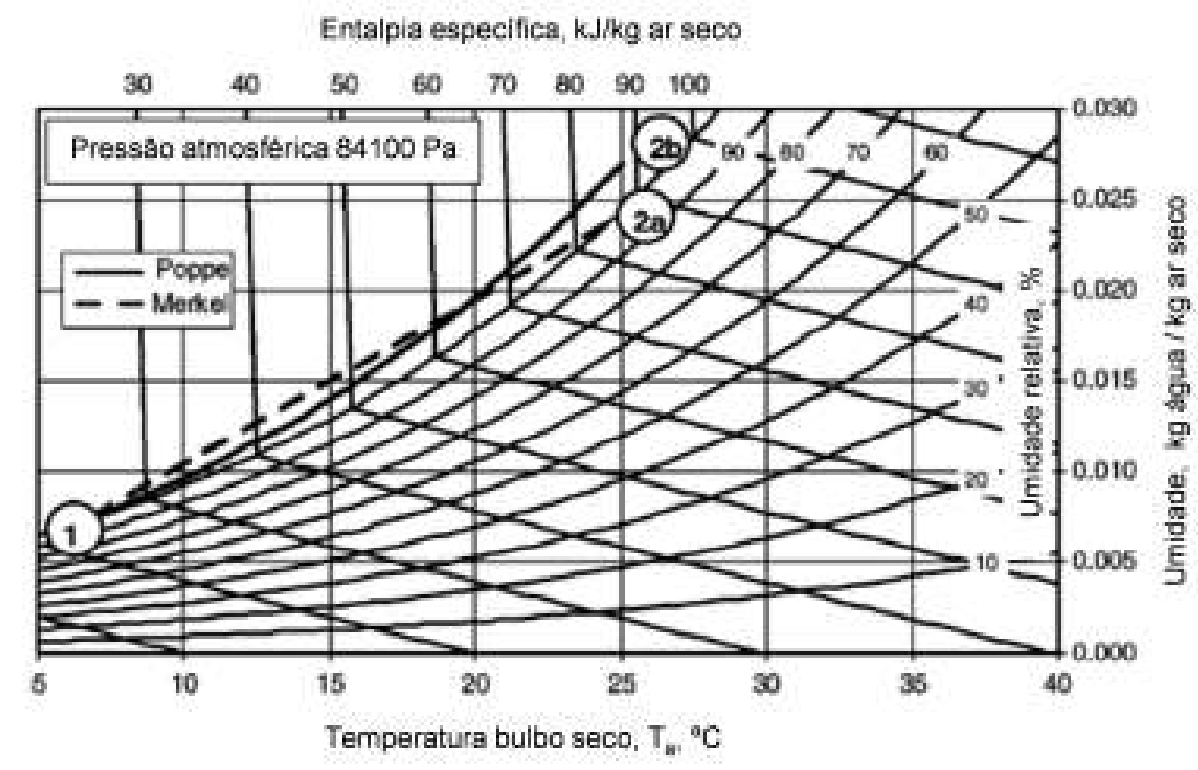

Figura 2.10 - Percurso do ar que entra saturado na torre, representado na carta psicrométrica de acordo com Kloppers e Kröger (2005a)

O grau de supersaturação do ar não tem uma influência considerável nas temperaturas obtidas por Merkel e Poppe. Isso acontece porque, conforme a Figura 2.10 mostra, as curvas de entalpia específica do ar constante (isoentálpicas), na região de supersaturação, são próximas de linhas verticais. Sendo assim, não importa a quantidade de água e névoa presentes no ar supersaturado, pois para uma entalpia específica do ar, a temperatura do ar é aproximadamente constante. A diferença entre as temperaturas de saída do ar ilustradas nos pontos $2 \mathrm{a}$ e $2 \mathrm{~b}$ da Figura 2.10, obtidas por Merkel e Poppe respectivamente, pode ser reduzida acrescentando-se no balanço de energia do método de Merkel a parcela de energia referente à perda de água por evaporação.

A Figura 2.11 ilustra um outro caso no qual o ar quente e seco é alimentado à torre, representado pelo ponto 1. O ponto 2a representa as condições do ar de saída da torre obtida a partir do método de Merkel. E o ponto $2 \mathrm{~b}$ representa as condições do ar de saída calculadas a partir do método de Poppe. De acordo com os pontos 2a e $2 \mathrm{~b}, \mathrm{o}$ ar de saída está mais frio que o ar de entrada. Nota-se que as condições de entalpia específica do ar de saída obtidas pelos dois métodos são próximas. Porém, o ponto 2a está na região de saturação, em que as linhas isoentálpicas são quase 
verticais e o ponto $2 \mathrm{~b}$ está localizado na região em que não há saturação do ar e as curvas de entalpia específica são inclinadas, assim tem-se uma discrepância entre as temperaturas de saída do ar obtidas pelo método de Merkel e pelo método de Poppe.

\section{Entalpia especifica, $\mathrm{kJ} / \mathrm{kg}$ ar seco}

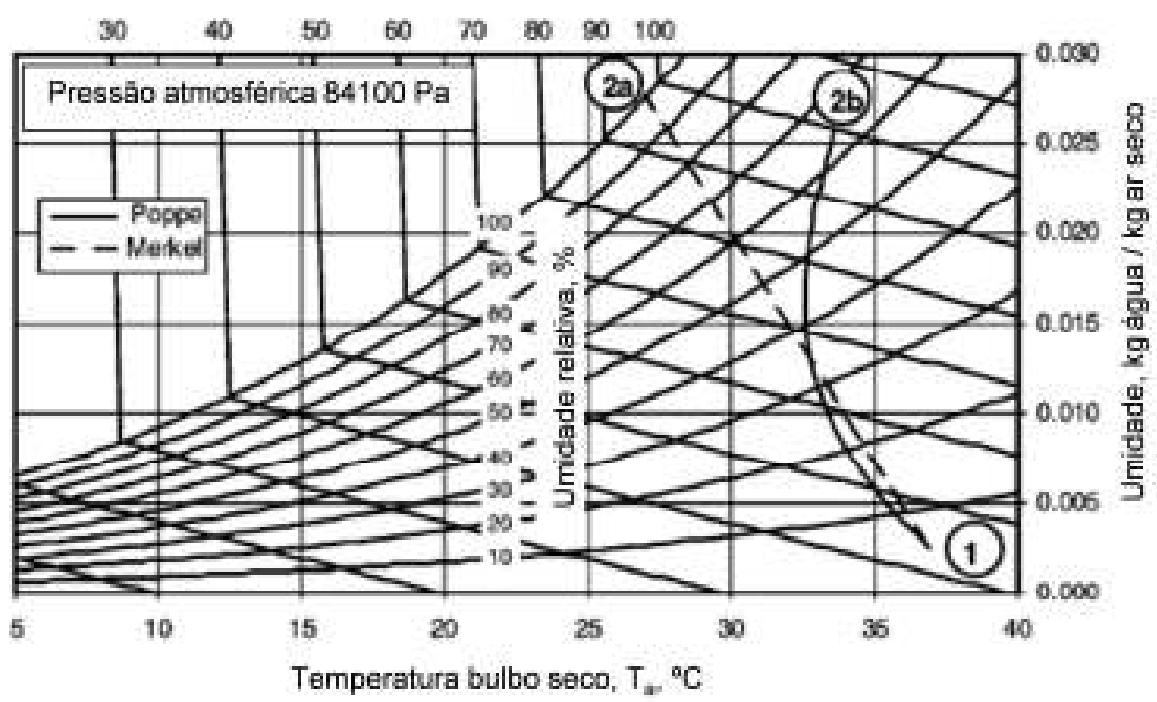

Figura 2.11 - Percurso do ar que entra quente e seco na torre, representado na carta psicrométrica de acordo com Kloppers e Kröger (2005a)

\subsection{Fator de Lewis}

A influência do fator de Lewis $\left(L e_{f}\right)$ no cálculo de torres de resfriamento foi estudado por Kloppers e Kröger (2005c). De acordo com o método de Merkel, o fator de Lewis é considerado igual a 1, enquanto o método de Poppe utiliza a equação (2.20) de Bosnjakovic (1965).

Alguns autores se referem ao número de Lewis $(L e)$, como se fosse o fator de Lewis $\left(L e_{f}\right)$. No entanto, de fato são definições diferentes, conforme apresentado na sequência. 


\subsubsection{Número de Lewis}

Em sistemas em que há transferência de calor por convecção e transferência de quantidade de movimento, a razão entre a viscosidade cinemática, $v$, e difusividade térmica, $\alpha$, é definida como número de Prandtl dado por:

$\operatorname{Pr}=\frac{v}{\alpha}=\frac{C_{p} \mu}{k}$

Da mesma forma, em processos envolvendo a transferência de massa e quantidade de movimento, o número de Schmidt é definido como a razão entre $v$ e $D$, coeficiente de difusividade.

$S c=\frac{v}{D}$

Em processos envolvendo simultaneamente transporte de calor convectivo e transporte de massa, a razão entre $\alpha$ e $D$ é definida como o número de Lewis.

$L e=\frac{\alpha}{D}=\frac{k}{\rho C p D}=\frac{S c}{P r}$

Esta razão número de Schmidt e Prandtl é relevante para transferência simultânea de calor por convecção e de massa, e expressa a relação entre difusividades de calor e massa.

\subsubsection{Fator de Lewis}

O fator de Lewis é definido como a razão entre o número de Stanton para transferência de calor, $S t$, e número de Stanton para transferência de massa, $S t_{m}$, expressos pelas equações (2.51) e (2.52), em função do número de Nusselt, Reynolds, Prandtl e Schmidt.

A seguir, tem-se as equações para $S t$ e $S t_{m}$. 
$S t=\frac{N u_{0}}{R e P r}=\frac{h}{\rho u C p}$

$S t_{m}=\frac{S h_{0}}{\operatorname{ReSc}}=\frac{k_{w}}{\rho u}$

sendo $\mathrm{Nu}_{0}$ o número de Nusselt, e $\mathrm{Sh}$ o o número de Sherwood.

Assim, o fator de Lewis é encontrado dividindo-se a equação (2.51) pela equação (2.52).

$L e_{f}=\frac{S t}{S t_{m}}=\frac{h}{\rho u C p} \frac{\rho u}{k_{w}}=\frac{h}{C p k_{w}}$

Lewis tentou provar que em sistemas ar - água tem-se $L e_{f}=1$. No entanto, concluiu que $L e_{f} \approx 1$ para misturas ar - água, mas esta aproximação não é válida para outras misturas. Da analogia entre os processos convectivos de transferência de calor e de massa, Chilton-Colburn (Kloppers e Kröger, 2005c) propuseram as seguintes relações para os números de Stanton:

$S t=C R e^{-1 / 2} \operatorname{Pr}^{-2 / 3}=\frac{h}{\rho u C p}$

$S t_{m}=C R e^{-1 / 2} S c^{-2 / 3}=\frac{k_{w}}{\rho u}$

Com base nessa analogia, o fator de Lewis, $L e_{f}$, pode ser relacionado ao número de Lewis (Kloppers e Kröger, 2005c), Le:

$L e_{f}=\frac{S t}{S t_{m}}=\left(\frac{P r}{S c}\right)^{-2 / 3}=L e^{2 / 3}$

Particularmente para o sistema ar / vapor de água, $L e \approx 1 \mathrm{e}$, portanto $L e_{f} \approx 1$. 


\subsubsection{Influência do fator de Lewis}

Kloppers e Kröger (2005c) investigaram a influência do fator de Lewis na carga térmica, em torres de resfriamento. Variam-se os valores de fator de Lewis entre 0,5 e 1,3, e as condições do ar de entrada de seco a saturado com temperaturas na entrada de 280 e $310 \mathrm{~K}$. Concluíram que, quanto maior o fator de Lewis, maior é a carga térmica da torre e consequentemente menor é a temperatura da água que sai da torre, assim como menor é a quantidade de água evaporada. E além disso, para casos em que o ar ambiente está quente, a $310 \mathrm{~K}$, e úmido, com umidade entre 0,03 e 0,05 kg de água/kg de ar seco, as cargas térmicas praticamente não variam em função do fator de Lewis utilizado e consequentemente a temperatura de saída da água e a quantidade evaporada também não variam.

\subsection{Dedução da equação de Bosnjakovic}

De acordo com Bosnjakovic (1965), em uma interface ar-água, existe uma camada laminar (ou subcamada laminar) de ar úmido através da qual pode existir um processo de difusão devido à evaporação ou condensação da água. Sendo $P_{d}$, a pressão parcial do vapor e $P_{g}$ a pressão parcial do vapor na interface, então para valores pequenos de $P_{d}$ e $P_{g}$ em relação a $P_{a}$ (pressão total ou pressão atmosférica) o fluxo de vapor através de uma camada limite de espessura $\delta$, é dada pela equação (2.57).

$$
m^{\prime \prime}=\frac{M_{w} D}{\delta R T_{w}}\left(P_{d}-P_{g}\right)
$$

para $P_{d} \approx P_{g} \approx 0$. 


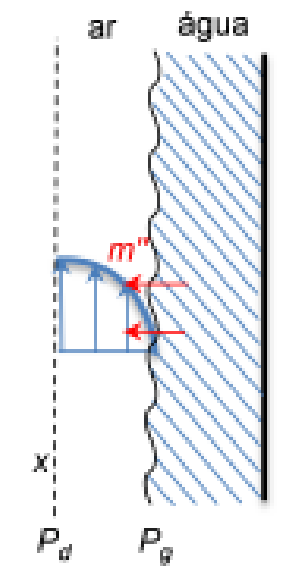

Figura 2.12 - Esquema representativo ar-água

Quando a diferença entre as pressões parciais, $P_{d}$ e $P_{g}$, é grande, tem-se um maior gradiente de pressão parcial do ar, que é a razão pela qual acontece difusão do ar no sentido oposto. Sendo a superfície da água impermeável ao ar, o fluxo de ar através da camada limite não ocorre, a difusão do ar é compensada pelo fluxo de ar convectivo. Assim, para diferenças altas entre as pressões parciais, deduz-se a seguinte equação:

$$
m^{\prime \prime}=\frac{M_{w} D}{\delta R T_{w}} \ln \left(\frac{P_{a}-P_{g}}{P_{a}-P_{d}}\right)
$$

A pressão parcial do vapor, $P_{d}$, e a pressão parcial do vapor na interface, $P_{g}$, são dadas pelas seguintes equações, respectivamente:

$P_{d}=P_{a} \tilde{x}$

$P_{g}=P_{a} \tilde{x}_{s w}$

onde $\tilde{x}$ é a fração molar do vapor e $\tilde{x}_{s w}$ é a fração molar do vapor na interface.

Escrevendo a equação (2.57) em termos das frações molares $\tilde{x}_{s w}$ e $\tilde{x}$, tem-se:

$m^{\prime \prime}=\frac{M_{w} D}{\delta R T_{w}} P_{a}\left(\tilde{x}-\tilde{x}_{s w}\right)$

O fluxo mássico de vapor através da superfície da água pode ser expresso em termos de $k_{w}$, dado pela equação (2.62).

$m^{\prime \prime}=k_{w}\left(w-w_{s w}\right)$ 
onde $w$ e $w_{s w}$ são as relações mássicas no seio do fluxo e na interface, respectivamente.

E o coeficiente de transporte de massa para sistemas em que a presença vapor de água na fase gás não é desprezível, $k_{w}$, é obtido a partir da equação (2.58) e expresso abaixo.

$k_{w}=\frac{M_{w} D P_{a}}{\delta R T_{w}} \frac{\ln \left(\frac{M_{w} / M_{a}+w}{M_{w} / M_{a}+w_{s w}}\right)}{w-w_{s w}}$

Sendo as frações molares $\tilde{x}_{s w}$ e $\tilde{x}$ dadas pelas seguintes equações:

$$
\begin{aligned}
& \tilde{x}=\frac{w}{\frac{M_{w}}{M_{a}}+w} \\
& \tilde{x}_{s w}=\frac{w_{s w}}{\frac{M_{w}}{M_{a}}+w_{s w}}
\end{aligned}
$$

Na equação (2.61), o termo " $\left(\tilde{x}_{s w}-\tilde{x}\right)$ " pode ser escrito da seguinte forma:

$$
\left(\tilde{x}-\tilde{x}_{s w}\right)=\frac{w}{\frac{M_{w}}{M_{a}}+w}-\frac{w_{s w}}{\frac{M_{w}}{M_{a}}+w_{s w}}
$$

Rearranjando o lado direito da equação (2.66), tem-se:

$$
\begin{aligned}
& \left(\tilde{x}-\tilde{x}_{s w}\right)=\frac{w\left(\frac{M_{w}}{M_{a}}+w_{s w}\right)-w_{s w}\left(\frac{M_{w}}{M_{a}}+w\right)}{\left(\frac{M_{w}}{M_{a}}+w\right)\left(\frac{M_{w}}{M_{a}}+w_{s w}\right)}=\frac{w \frac{M_{w}}{M_{a}}+w w_{s w}-w_{s w} \frac{M_{w}}{M_{a}}-w w_{s w}}{\left(\frac{M_{w}}{M_{a}}\right)^{2}+w_{s w}\left(\frac{M_{w}}{M_{a}}\right)+w\left(\frac{M_{w}}{M_{a}}\right)+w w_{s w}} \\
& \left(\tilde{x}-\tilde{x}_{s w}\right)=\frac{\left(\frac{M_{w}}{M_{a}}\right)\left(w-w_{s w}\right)}{\left(\frac{M_{w}}{M_{a}}\right)^{2}+\left(\frac{M_{w}}{M_{a}}\right)\left(w+w_{s w}\right)+w w_{s w}}
\end{aligned}
$$

Para o caso de um sistema diluído, tem-se:

$$
\begin{gathered}
w \ll \frac{M_{w}}{M_{a}} \\
w_{s w} \ll \frac{M_{w}}{M_{a r}}
\end{gathered}
$$

Substituindo as equações (2.70) e (2.69) na equação (2.68), obtém-se a equação abaixo.

$$
\left(\tilde{x}-\tilde{x}_{s w}\right) \cong\left(\frac{M_{a}}{M_{w}}\right)\left(w-w_{s w}\right)
$$


Substituindo a equação (2.70) na equação (2.61), tem-se a equação (2.71) que representa o fluxo de água para um sistema diluído.

$m^{\prime \prime} \cong \frac{M_{a} D P_{a}}{\delta R T_{w}}\left(w-w_{s w}\right)$

Substituindo a equação (2.62) na equação (2.71), obtém-se o coeficiente de transporte de massa para sistemas diluídos ou sujeitos a baixo transporte de massa, $k_{w}^{*}$.

$k_{w}^{*}=\frac{M_{a} D P_{a}}{\delta R T_{w}}$

onde $w \rightarrow 0$ e $w_{s w} \rightarrow 0$.

Dividindo-se a equação (2.63) pela equação (2.72) tem-se a relação entre $k_{w}$ e $k_{w}^{*}$.

$\frac{k_{w}}{k_{w}^{*}}=\frac{M_{w}}{M_{a}} \frac{\ln \left(\frac{M_{w} / M_{a}+w_{s w}}{M_{w} / M_{a}+w}\right)}{w_{s w}-w}$

Dessa forma, a equação (2.62) é válida tanto para sistemas em que a fase gás é diluída, quanto para sistemas em que a quantidade de vapor é significativa. A diferença entre uma situação e outra é representada pelo coeficiente de transporte de massa, que deve ser calculado pela equação (2.72), no caso de sistema diluído, e pela equação (2.63) quando esta hipótese não puder ser feita.

Conforme Bosnjakovic (1965), as deduções para o fluxo de massa, $m$ ", e os coeficientes de transporte de massa, $k_{w}$ e $k_{w}^{*}$ são feitas baseado nas relações mássicas $w$ e $w_{s w}$.

Fazendo:

$\xi=\frac{M_{w} / M_{a}+w_{s w}}{M_{w} / M_{a}+w}$

Para o caso específico de misturas vapor de água - ar tem-se que:

$\xi=\frac{0,622+w_{s w}}{0,622+w}$

A partir da equação (2.63), o fator de Lewis, Le $e_{f}$, conforme Bosnjakovic (1965) é então dado por: 
$L e_{f}=\frac{\alpha}{C p_{m a} k_{w}}=0,865^{0,667} \frac{\xi-1}{L n \xi}$

A equação acima também pode ser escrita conforme abaixo, que corresponde à equação (2.20):

$L e_{f}=0,865^{0,667} \frac{\left(\frac{w_{S w}+0,622}{w+0,622}-1\right)}{\ln \left(\frac{w_{S w}+0,622}{w+0,622}\right)}$ 


\section{MODELAGEM MATEMÁTICA}

\subsection{Introdução}

Neste capítulo, são apresentados os modelos e os equacionamentos para o cálculo das temperaturas da água e do ar e da umidade do ar ao longo da torre de resfriamento em operação contracorrente.

No item 3.2 apresenta-se o modelo para baixo transporte de massa, indicado para sistemas com água em temperaturas inferiores a $40^{\circ} \mathrm{C}$.

Apresenta-se nos itens 3.3 e 3.4 o modelo de alto transporte de massa, considerando-se o efeito deste na transferência de calor e de massa.

No item 3.5, o modelo incorpora os casos em que ocorre a supersaturação do ar ao longo da torre.

Finalmente, apresenta-se, no item 3.6 os resultados da verificação do modelo para um caso de baixo transporte de massa.

\subsection{Equacionamento para baixo transporte de massa}

Segue abaixo o equacionamento para o modelo de transferência de calor e massa em uma torre de resfriamento com operação em escoamento contracorrente, baseado no método de Poppe de acordo com Kloppers e Kröger (2005a).

Apresentam-se na Figura 3.1 um esquema simplificado da torre de resfriamento e o volume de controle considerado no equacionamento. 


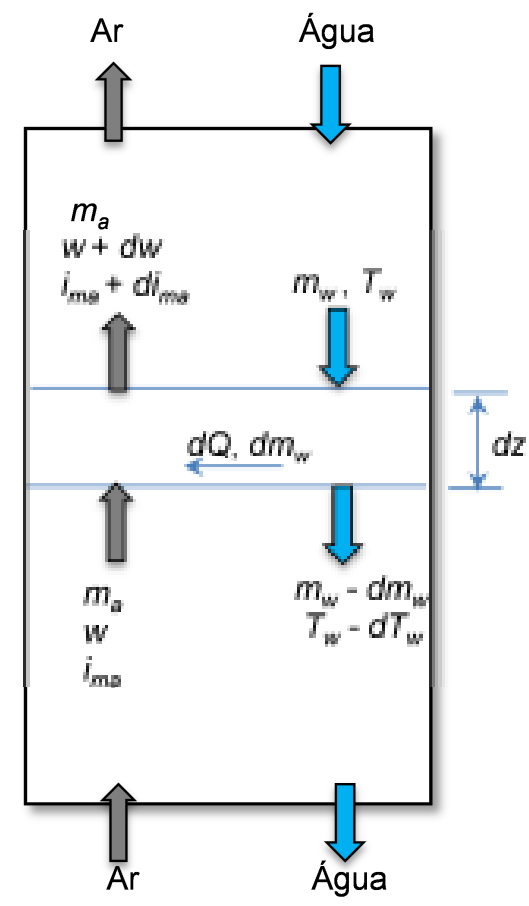

Figura 3.1- Volume de controle considerado no equacionamento

Admitem-se as seguintes hipóteses:

1. o processo está em regime permanente;

2. a resistência térmica no lado da água é desprezível em relação à do ar, assim como assumido por Kloppers e Kröger (2005a);

3. o escoamento do ar e da água ao longo da torre é pistonado ou seja, há pouca variação das propriedades da água e do ar ao longo de uma seção transversal;

4. a perda de calor do sistema é desprezível;

5. o arraste mecânico de água é desprezível;

6. a perda de carga no recheio é baixa em relação à pressão de entrada e, portanto, a pressão é admitida constante ao longo da coluna;

7. na interface ar - água, tem-se a condição de equilíbrio;

8. a transferência de massa ocorre apenas da fase líquida para a fase gás.

O equacionamento que segue é o apresentado por Kloppers e Kröger (2005a), com poucas alterações. 
Aplicando-se o balanço de massa de água, tem-se uma relação entre a taxa de evaporação e a variação de umidade na corrente de ar, que é expressa por:

$d m_{w}=m_{a} d w$

A partir do balanço de energia, tem-se a equação a seguir que expressa a variação da entalpia específica do ar com a variação da temperatura da água:

$m_{a} d i_{m a}=d\left[m_{w} C p_{w}\left(T_{w}-T_{r e f}\right)\right]$

Substituindo-se a equação (3.1) na equação (3.2), tem-se:

$m_{a} d i_{m a}=C p_{w} T_{w} m_{a} d w-m_{w} C p_{w} d T_{w}$

A transferência de massa através da interface é expressa por:

$d m_{w}=k_{w}^{*}\left(w_{s w}-w\right) d A$

sendo $d A$ a área efetiva de transferência de calor e massa no volume elementar de recheio de altura $d z$, e está relacionada à área específica $a_{i}$, conforme a equação (3.5).

$d A=a_{i} A_{r} d z$

O balanço de energia na interface ar-água baseia-se na transferência de calor por convecção e devido à transferência de massa, conforme expresso pela equação (3.6).

$d Q=d Q_{m}+d Q_{c}$

O transporte de entalpia específica associado à transferência de massa na interface é expresso pela equação (3.7).

$d Q_{m}=i_{v} d m_{w}=i_{v} k_{w}^{*}\left(w_{s w}-w\right) d A$

A transferência de calor ar/interface é expressa pela equação (3.8), admitindo-se a temperatura da interface como sendo igual à da fase líquida $\left(T_{w}\right)$ (hipótese 2).

$d Q_{c}=h\left(T_{w}-T_{a}\right) d A$

Assim, a equação (3.6) pode ser expressa a partir das equações (3.7) e (3.8), conforme equação (3.9):

$d Q=i_{v} d m_{w}+h\left(T_{w}-T_{a}\right) d A=i_{v} k_{w}^{*}\left(w_{s w}-w\right) d A+h\left(T_{w}-T_{a}\right) d A$ 
sendo $i_{v}$ a entalpia específica do vapor na temperatura da interface, $T_{w}$.

A entalpia específica do ar, $i_{m a}$ é expressa em função da temperatura, $T_{a}$, e da umidade, $w$, do ar, conforme a equação (3.10).

$i_{m a}=C p_{a}\left(T_{a}-T_{r e f}\right)+w\left(i_{w r e f}+C p_{v}\left(T_{a}-T_{r e f}\right)\right)$

A entalpia específica do ar na interface ar - água, $i_{\text {maw }}$, é expressa em função da temperatura da água, $T_{w}$, e das umidades, $w$ e $w_{s w}$, conforme a equação (3.11).

$i_{\text {maw }}=C p_{a}\left(T_{w}-T_{\text {ref }}\right)+w i_{v}+\left(w_{s w}-w\right) i_{v}$

Subtraindo a equação (3.10) da equação (3.11), tem-se:

$T_{w}-T_{a}=\frac{\left(i_{m a w}-i_{m a}\right)-i_{v}\left(w_{s w}-w\right)}{C p_{m a}}$

Na equação (3.12), o calor específico do ar úmido é dado pela equação (3.13).

$C p_{m a}=C p_{a}+w C p_{v}$

O fator de Lewis $\left(L e_{f}\right)$ que relaciona os coeficientes de transferência de calor e massa é dado pela equação (3.14).

$L e_{f}=\frac{h}{C p_{m a} k_{w}^{*}}$

Substituindo-se as equações (3.12) e (3.14) na equação (3.9) e rearranjando-se, tem-se a equação (3.15).

$d Q=k_{w}^{*}\left[L e_{f}\left(i_{m a w}-i_{m a}\right)+\left(1-L e_{f}\right)\left(w_{s w}-w\right) i_{v}\right] d A$

No equacionamento tradicional de torres de resfriamento, assume-se o fator de Lewis como sendo igual a 1 . No entanto, da analogia de Chilton-Colburn conforme Kloppers e Kröger (2005c), decorre a relação expressa pela equação (3.16), cujo valor para o ar é aproximadamente igual a 0,908 e pouco varia com a temperatura:

$L e_{f}($ à $300 \mathrm{~K})=0,908$

$L e_{f}($ à $350 \mathrm{~K})=0,870$

Kloppers e Kröger (2005a) propõem correções no cálculo do fator de Lewis em função da umidade do ar no seio e na interface. No entanto, no presente estudo, 
adotou-se a equação (3.16) pois correções serão consideradas na modelagem de alto transporte de massa.

$L e_{f}=\left(\frac{S c}{P r}\right)^{2 / 3} \cong 0,908$

A umidade de saturação corresponde ao ar na interface e é calculada na temperatura desta, que é admitida como sendo igual à da água. Ou seja, a pressão de vapor saturado $\left(P_{v w}\right)$ é calculada na temperatura da água.

Para o cálculo da pressão de vapor saturado $\left(P_{v w}\right)$, utilizou-se a equação de Antoine:

$\ln P_{v w}=A-\frac{B}{T_{w}+C}$

onde, $P_{v w}$ é calculada em $\mathrm{mmHg}, T_{w}$ é expresso em Kelvin e as constantes devem ser substituídas pelos seguintes valores: $A=18,3036, B=3816,44$ e $C=-46,13$ (REID et al., 1997), válida para temperaturas da água entre 284 e $441 \mathrm{~K}$.

A umidade de saturação é então calculada pela equação (3.18).

$w_{s w}=\frac{P_{v w}}{P_{a}-P_{v w}} \frac{M_{w}}{M_{a}}$

A umidade do ar na entrada da torre pode ser calculada a partir da sua $T_{b u}$ conforme equação (3.19).

$$
\begin{aligned}
& w=\left(\frac{2501,6-2,3263\left(T_{b u}-T_{r e f}\right)}{2501,6+1,877\left(T_{a}-T_{r e f}\right)-4,184\left(T_{b u}-T_{r e f}\right)}\right)\left(\frac{0,62509 P_{v b u}}{P_{a}-1,005 P_{v b u}}\right)- \\
& \left(\frac{1,00416\left(T_{a}-T_{b u}\right)}{2501,6+1,877\left(T_{a}-T_{r e f}\right)-4,184\left(T_{b u}-T_{r e f}\right)}\right)
\end{aligned}
$$

Na equação (3.19), $P_{v b u}$ é a pressão de vapor calculada através da equação de Antoine, (3.17), contudo na temperatura de bulbo úmido ( $\left.T_{b u}\right)$.

Rearranjando-se as equações (3.3), (3.5) e (3.15), tem-se, para a variação da entalpia específica do ar com a altura a equação diferencial (3.20).

$\frac{d i_{m a}}{d z}=\frac{k_{w}^{*} a_{i} A_{r}}{m_{a}}\left[L e_{f}\left(i_{m a w}-i_{m a}\right)+\left(1-L e_{f}\right) i_{v}\left(w_{s w}-w\right)\right]$ 
Rearranjando-se as equações (3.3), (3.5) e (3.20), tem-se a equação (3.21) que expressa a variação da umidade do ar com a variação da temperatura da água.

$\frac{d w}{d T_{w}}=\frac{c p_{w} \frac{m_{w}}{m_{a}}\left(w_{s w}-w\right)}{i_{m a w}-i_{m a}+\left(L e_{f}-1\right)\left[i_{m a w}-i_{m a}-\left(w_{s w}-w\right) i_{v}\right]-\left(w_{s w}-w\right) C p_{w}\left(T_{w}-T_{r e f}\right)}$

E, finalmente, rearranjando-se as equações (3.3) e (3.21), tem-se a equação (3.22) que expressa a variação da entalpia específica do ar com a variação da temperatura da água.

$$
\begin{aligned}
& \frac{d i_{m a}}{d T_{w}}= \\
& \frac{m_{w} C p_{w}}{m_{a}}\left(1+\frac{\left(w_{s w}-w\right) C p_{w}\left(T_{w}-T_{r e f}\right)}{i_{m a w^{-}}-i_{m a}+\left(L e_{f}-1\right)\left[i_{m a w^{-}}-i_{m a}-\left(w_{s w}-w\right) i_{v}\right]-\left(w_{s w}-w\right) C p_{w}\left(T_{w}-T_{r e f}\right)}\right)
\end{aligned}
$$

\subsubsection{Equações Auxiliares}

As correlações para os cálculos das propriedades termodinâmicas - calores específicos, pressão de vapor, umidade e entalpias específicas - são apresentados a seguir.

As equações para os calores específicos e entalpias específicas foram retirados de Kloppers e Kröger (2005a).

O calor específico do ar seco é dado pela equação (3.23).

$C p_{a}=1,045356.10^{3}-3,161783.10^{-1}\left(\frac{T_{a}+T_{r e f}}{2}\right)+7,083814.10^{-4}\left(\frac{T_{a}+T_{r e f}}{2}\right)^{2}-$

$2,705209.10^{-7}\left(\frac{T_{a}+T_{r e f}}{2}\right)^{3}$

O calor específico do vapor de água é dado pela equação (3.24).

$C p_{v}=$

$1,3605 \cdot 10^{3}+2,31334\left(\frac{T_{a}+T_{r e f}}{2}\right)-2,46784 \cdot 10^{-10}\left(\frac{T_{a}+T_{r e f}}{2}\right)^{5}+5,91332 \cdot 10^{-13}\left(\frac{T_{a}+T_{r e f}}{2}\right)^{6}$

O calor específico da água é dado pela equação (3.25). 
$C p_{w}=8,15599 \cdot 10^{3}-2,80627 \cdot 10 T_{w}+5,11283 \cdot 10^{-2} T_{w}^{2}-2,17582 \cdot 10^{-13} T_{w}^{6}$

O calor latente da água é dado pela equação (3.26).

$i_{w}=3,4831814 \cdot 10^{6}-5,8627703 \cdot 10^{3} T_{w}+12,139568 T_{w}^{2}-$

$1,40290431.10^{-2} T_{w}^{3}$

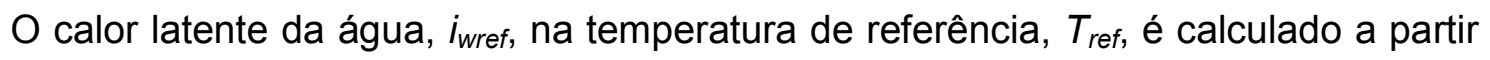
da equação (3.26), adotando-se $T_{w}=T_{\text {ref }}$.

A entalpia específica do vapor de água é calculada na temperatura "bulk" de água conforme a equação (3.27).

$i_{v}=i_{w r e f}+C p_{v}\left(T_{w}-T_{r e f}\right)$

O coeficiente de transferência de massa pode ser prescrito a partir de correlações semi-empíricas específicas para cada tipo de recheio e são, geralmente, expressas em função dos fluxos de água e ar, na seguinte forma:

$k_{w}^{*}=\frac{\theta}{a_{i}}\left(\frac{m_{w}}{A_{r}}\right)^{\beta}\left(\frac{m_{a}}{A_{r}}\right)^{\gamma}$

Particularmente, no presente trabalho, empregou-se a correlação proposta por Mello (2009), sendo: $\theta=0,76 \mathrm{~kg} / \mathrm{s} \cdot \mathrm{m}^{3}, \beta=0,49$ e $\gamma=0,66$.

A temperatura de bulbo úmido é uma variável de entrada para os cálculos, pois conhecendo esta variável e a temperatura do ar, $T_{a}$, é possível calcula a umidade do ar de entrada da torre a partir da equação (3.19). No entanto, no decorrer dos cálculos, não é necessário o cálculo da variável, $T_{b u}$. Entretanto, para validar os cálculos foram colocados na forma de gráficos os perfis de temperatura, inclusive da $T_{b u}$, conforme apresentado no item 3.5 e para isto utilizou-se a seguinte equação para cálculo da $T_{b u}$, em ${ }^{\circ} \mathrm{C}$, de acordo com Zemp et al. (2010):

$$
\begin{aligned}
& T_{b u}=T_{a}-T_{r e f}-\left(( 1 - U R ) \left(4,10793+0,52708\left(T_{a}-T_{r e f}\right)+3,28676 . U R-\right.\right. \\
& \left.\left.0,34353\left(T_{a}-T_{r e f}\right) U R\right)\right)
\end{aligned}
$$

Os intervalos de validade da equação (3.29) são:

- $\quad$ Temperatura de bulbo seco, $T_{a}$, entre 10 e $40^{\circ} \mathrm{C}$; 
- Temperatura de bulbo úmido, $T_{b u}$, entre $5{ }^{\circ} \mathrm{C}$ e a temperatura de bulbo úmido correspondente a temperatura máxima permitida para $T_{a}$;

- Pressão ambiente: de 80 a 101,325 kPa.

A umidade relativa é calculada a partir da seguinte equação:

$U R=\frac{w}{w_{s a}}$

onde $w_{s a}$ é calculada a partir da pressão de vapor calculada na temperatura do ar, $P_{\text {var. }}$

Para o cálculo da pressão de vapor saturado, $P_{\text {var, }}$ utilizou-se a equação de Antoine (3.17).

A umidade de saturação é então calculada pela equação (3.31).

$$
w_{s a}=\frac{P_{\text {var }}}{P_{a}-P_{\text {var }}} \frac{M_{w}}{M_{a}}
$$

\subsection{Modelo para alto transporte de massa}

O modelo proposto neste trabalho é uma adequação do modelo de Poppe, de forma a incorporar os fenômenos associados, ao que se denomina na literatura, como alto transporte de massa. Apesar da importância e aplicação deste fenômeno em diferentes processos de transferência de calor e massa e quantidade de movimento, não se observa a sua aplicação no estudo de torres de resfriamento evaporativas. Obviamente, justifica-se pela condição de efetivo baixo transporte decorrente de temperaturas de água inferiores a $50{ }^{\circ} \mathrm{C}$, a pressão atmosférica. No entanto, condições térmicas mais severas são frequentes em processos industriais, decorrentes de alterações drásticas operacionais e consequente sobrecarga do sistema de resfriamento de água.

O alto transporte se dá quando o fluxo devido ao transporte de massa é intenso o suficiente para afetar o escoamento do ar. A Figura 3.2 ilustra, de forma amplificada o efeito do alto transporte de massa. Para água a altas temperaturas, a fração 
mássica de vapor de água na interface, $x_{s w}$, é alta e, assim, a força motriz, $x_{s w}-x$, é maior, caracterizando um processo de transporte de massa mais intenso.

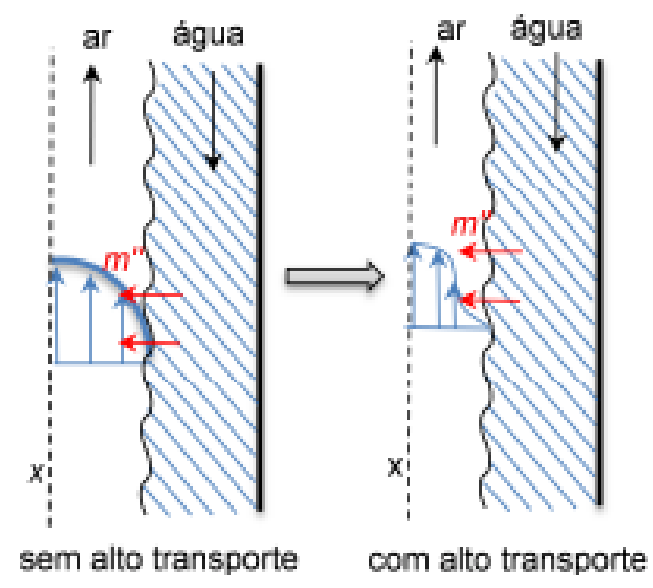

Figura 3.2 - Efeito do alto transporte de massa no perfil de velocidade

O equacionamento proposto a seguir está baseado, em parte, na modelagem proposta por Mills (2001).

A força motriz para baixo transporte de massa, expressa em termos de fração mássica, segue abaixo.

$m^{\prime \prime}=k_{w}^{*}\left(x_{s w}-x\right)$

$\mathrm{Na}$ equação (3.32), $k_{w}{ }^{*}$ refere-se ao coeficiente de transporte de massa para condição de baixo transporte de massa.

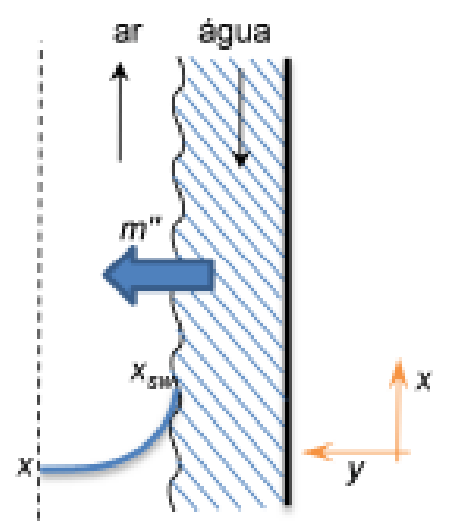

Figura 3.3 - Fluxo de transporte de massa para escoamento paralelo 
A Figura 3.3 ilustra o perfil de fração mássica do vapor de água entre a interface arágua, $x_{s w}$, e o seio do $\mathrm{ar}, x$. As equações, conforme a modelagem proposta por Mills, são expressas em termos de fração mássica ou base úmida. Por isso, nesta modelagem não há a hipótese de que o sistema está diluído. No entanto estas equações serão manipuladas para que fiquem em termos de umidade, em base seca, pela conveniência de manipulação.

A fração mássica na interface, $x_{s w}$, e a umidade de saturação, $w_{s w}$, são relacionadas pelas equações (3.33) e (3.34).

$x_{s w}=\frac{w_{s w}}{1+w_{s w}}$

$w_{s w}=\frac{x_{s w}}{1-x_{s w}}$

A fração mássica e a umidade no seio do $\operatorname{ar}, x$ e $w$ respectivamente, são relacionadas pelas seguintes equações:

$x=\frac{w}{1+w}$

$w=\frac{x}{1-x}$

Rearranjando-se as equações (3.33) e (3.35), tem-se a equação (3.37).

$x_{s w}-x=\frac{w_{s w}-w}{\left(1+w_{s w}\right)(1+w)}$

Assim, define-se o fator para conversão de força motriz em termos de fração mássica para força motriz em termos de umidade, $f$ '.

$f^{\prime}=\frac{1}{(1+w)\left(1+w_{s w}\right)}$

Substituindo-se as equações (3.37) e (3.38) na equação (3.32), tem-se a equação (3.39), que representa o fluxo para baixo transporte de massa em termos de umidade.

$m^{\prime \prime}=k_{w}^{*} f^{\prime}\left(w_{s w}-w\right)$ 
Conforme mostrado por Mills (2001) para a situação ilustrada na Figura 3.3, para o caso de escoamento paralelo com fluxo de transporte de massa normal ao escoamento, tem-se:

$m^{\prime \prime}=k_{w} \frac{x_{s w}-x}{1-x_{s w}}$

Sendo $k_{w}$ o coeficiente de transferência de massa para a condição de alto transporte.

Segundo Mills (2001), para o escoamento paralelo com fluxo de transporte de massa normal ao escoamento, o fluxo de massa é representado por:

$m^{\prime \prime}=J_{A}+x m^{\prime \prime}=-\rho D_{A B} \frac{d x}{d y}+x m^{\prime \prime}$

No lado direito da equação (3.41), o primeiro termo refere-se à parte difusiva do transporte de massa e o segundo termo refere-se à parte convectiva. Rearranjandose a equação (3.41), tem-se:

$m^{\prime \prime}(1-x)=-\rho D_{A B} \frac{d x}{d y}$

Integrando-se para um filme de espessura $\delta$, tem-se:

$-\int_{0}^{\delta} \frac{m^{\prime \prime}}{\rho D_{A B}} d y=\int_{x}^{x_{s w}} \frac{1}{(1-x)} d x$

Resolvendo-se a equação acima, tem-se:

$m^{\prime \prime}=\frac{\rho D_{A B}}{\delta} \ln \left(\frac{1-x}{1-x_{s w}}\right)$

Assim, identifica-se o coeficiente de transferência de massa para baixo transporte de massa:

$k_{w}^{*}=\frac{\rho D_{A B}}{\delta}$

A força motriz pode ser representada pelo fator, $b$ :

$b=\frac{x_{s w}-x}{1-x_{s w}}$

Em termos de umidade, o fator $b$ é dado por:

$b=\frac{w_{s w}-w}{1+w}$ 
Então, substituindo as equações (3.45) e (3.46) na equação (3.44), tem-se:

$m^{\prime \prime}=k_{w}^{*} \ln (1+b)$

Denomina-se "blowing factor", $B_{m}$, usualmente para alto transporte de massa, ao fator:

$B_{m}=\ln (1+b)$

Então substituindo a equação (3.49) na equação (3.48) tem-se:

$m^{\prime \prime}=k_{w}^{*} B_{m}$

A partir das equações (3.49) e (3.50), tem-se:

$m^{\prime \prime}=k_{w}^{*} \frac{\ln (1+b)}{b} b$

A partir da equação (3.51), determina-se o coeficiente de transporte de massa para alto transporte, $k_{w}$ :

$k_{w}=k_{w}^{*} \frac{\ln (1+b)}{b}$

Substituindo a equação (3.52) na equação (3.51), tem-se a seguinte equação para o fluxo de massa:

$m^{\prime \prime}=k_{w} b$

Analogamente à equação (3.52) tem-se as seguintes equações que relacionam o coeficiente de transporte de massa para baixo transporte, $k_{w}{ }^{*}$, e o coeficiente de transporte de massa para alto transporte, $k_{w}$.

$k_{w}=k_{w}^{*} \frac{B_{m}}{e^{B_{m}-1}}$

$k_{w}=k_{w}^{*} \frac{B_{m}}{b}$

Substituindo as equações (3.46) e (3.54) na equação (3.53), tem-se a equação (3.56) para fluxo de massa em termos de fração mássica.

$m^{\prime \prime}=k_{w}^{*} \frac{B_{m}}{e^{B m-1}}\left(\frac{x_{s w}-x}{1-x_{s w}}\right)$

A equação para o fluxo de massa em termos da umidade é obtida substituindo as equações (3.47) e (3.54) na equação (3.53): 
$m^{\prime \prime}=k_{w}^{*} \frac{B_{m}}{e^{B m-1}}\left(\frac{w_{s w}-w}{1+w}\right)$

Substituindo a equação (3.47) na equação (3.49) tem-se:

$B_{m}=\ln \left(\frac{1+w_{s w}}{1+w}\right)$

Substituindo as equações (3.58) e (3.55) na equação (3.53) tem-se:

$$
m^{\prime \prime}=k_{w}^{*} \frac{\ln \left(\frac{1+w_{s w}}{1+w}\right)}{w_{s w}-w}\left(w_{s w}-w\right)
$$

A partir da equação (3.59), tem-se o fator de correção para alto transporte de massa, $f_{1}$, que é dado por:

$f_{1}=\frac{\ln \left(\frac{1+w_{s w}}{1+w}\right)}{w_{s w}-w}$

Portanto, a equação (3.59) pode ser reescrita conforme a equação (3.61).

$$
m^{\prime \prime}=k_{w}^{*} f_{1}\left(w_{s w}-w\right)
$$

A relação entre o coeficiente de transporte para alto transporte de massa, $k_{w}$, e o coeficiente de transporte para baixo transporte de massa, $k_{w}{ }^{*}$ pode ser escrita como:

$$
k_{w}=\frac{k_{w}^{*} f_{1}}{1+w}
$$

Assim, no caso do modelo de alto transporte de massa, substitui-se o $k_{w}{ }^{*}$ da equação (3.20) pelo $k_{w}$ expresso pela equação (3.62).

A Figura 3.4 apresenta um exemplo, no qual calculam-se os parâmetros $B_{m}, b, w_{s w}-$ $w, x_{s w}-x$ e $f_{1}$ em função de $x_{s w}$, considerando-se $x=0,02$, que corresponde a uma umidade de saturação, $w_{s w}$, igual a 0,02 e uma temperatura da interface, $T_{w}$ igual a $25^{\circ} \mathrm{C}$. Nota-se que conforme o "blowing factor" para transporte de massa, $B_{m}$, se aproxima de zero, o fator de correção para o alto transporte de massa, $B_{m} / b$, tende a 1 , ou seja, o coeficiente de transporte para alto transporte de massa, $k_{w}$, é aproximadamente igual ao coeficiente de transporte para baixo transporte de massa, $k_{w}{ }^{*}$. 


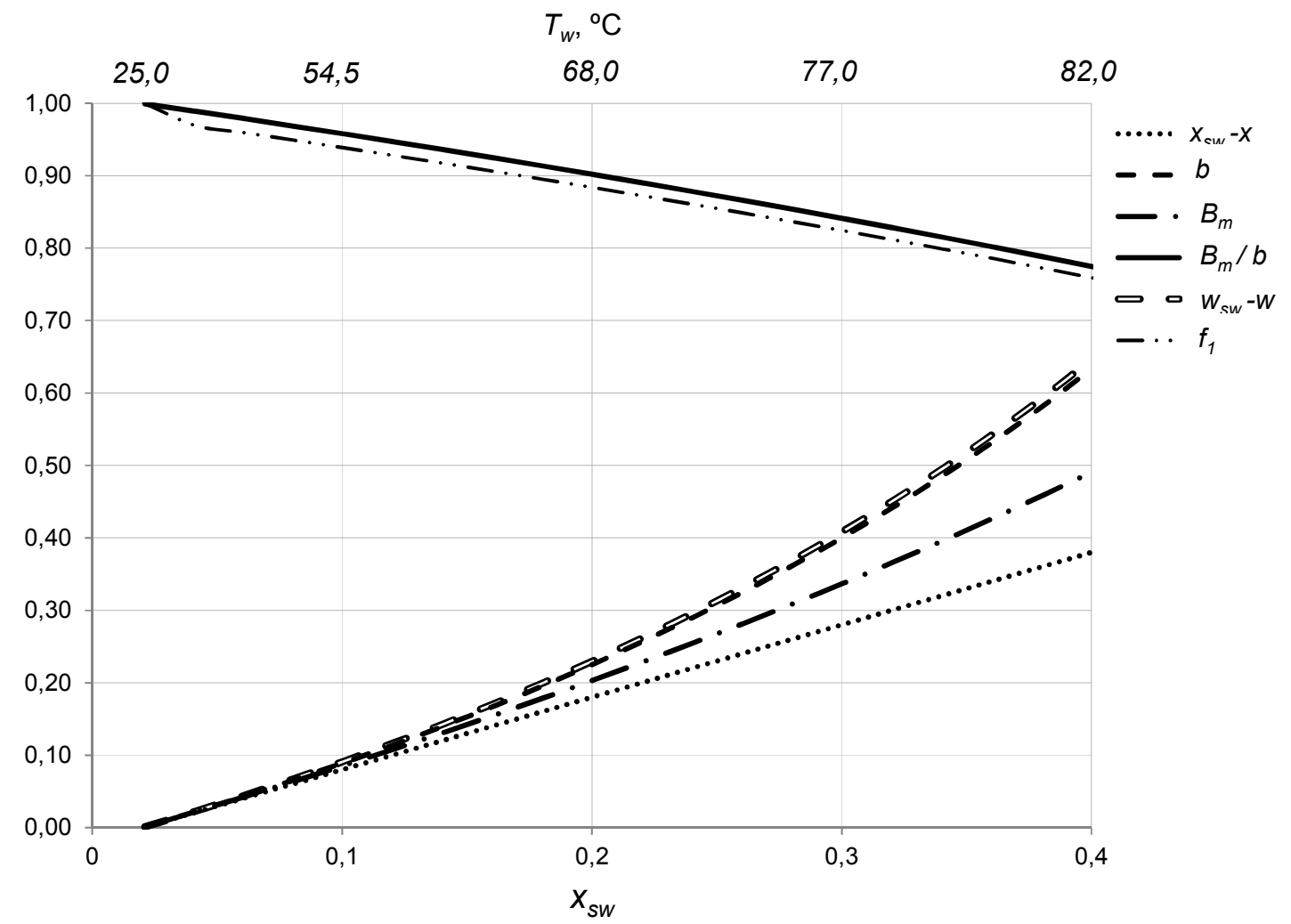

Figura 3.4 - Forças motrizes e fatores de correção de alto transporte de massa para $x=0,02$

\subsection{Modelo para o transporte de calor e fator de Lewis}

O processo de transferência de calor é também afetado pela condição de alto transporte de massa. A relação entre o coeficiente de transferência de calor para alto transporte de massa, $h$, e o coeficiente de transferência de calor para baixo transporte de massa, $h^{*}$ é expresso por:

$h=h^{*} \frac{B_{h}}{e^{B} h-1}$

Segundo Mills (Mills, 2001) o fator $B_{h}$, denominado "blowing factor" para transporte de calor, é expresso por:

$B_{h}=\frac{m^{\prime \prime} C p_{v}}{h^{*}}$ 
Analogamente ao fator de correção para o coeficiente de transporte de massa, $f_{1}$, equação (3.60), tem-se o fator de correção para o coeficiente de transporte de calor, $f_{2}$ expresso pela equação (3.65).

$h=h^{*} f_{2}$

Substituindo-se a equação (3.65) na equação (3.63), tem-se a equação (3.66).

$f_{2}=\frac{B_{h}}{e^{B} h-1}$

O fator de Lewis para baixo transporte de massa é dado pela analogia de ChiltonColburn conforme Kloppers e Kröger (2005c), equação (3.67).

$L e_{f}=L e^{2 / 3}=0,865^{2 / 3}$

Substituindo-se as equações (3.65) e (3.62) na equação (3.14), tem-se a equação (3.68) para o cálculo do fator de Lewis na condição de alto transporte de massa.

$L e_{f}=\frac{h}{C p_{m a} k_{w}}=\frac{h^{*}}{C p_{m a} k_{w}^{*}} \frac{f_{2}}{f_{1}}=L e^{2 / 3} \frac{f_{2}}{f_{1}}$

O fator expresso pela equação (3.68) é o empregado no caso do alto transporte de massa. A correlação (3.68) aqui proposta para o fator de Lewis inclui a correção referente ao transporte de massa e ao transporte de calor, enquanto a equação do fator de Lewis proposta por Bosnjakovic (1965), (2.77), contempla somente a correção referente ao transporte de massa.

\subsection{Modelo para ar supersaturado}

O ar supersaturado é caracterizado pelo excesso de vapor de água, em relação à saturação, na corrente de ar. Considera-se o ar como supersaturado quando a entalpia específica do ar é maior ou igual a entalpia específica de saturação do ar calculada na temperatura do ar.

Na modelagem admitem-se as seguintes hipóteses: 
1. Os coeficientes de transferência de calor e massa são considerados os mesmos para o ar não saturado e supersaturado.

2. O vapor de água presente na corrente de ar, após a supersaturação, condensa na forma de névoa.

A entalpia específica do ar supersaturado é expressa pela equação (3.69).

$i_{s p}=C p_{a}\left(T_{a}-T_{r e f}\right)+w_{s a}\left(i_{w r e f}+C p_{v}\left(T_{a}-T_{r e f}\right)\right)+\left(w-w_{s a}\right) C p_{w}\left(T_{a}-T_{r e f}\right)$

A transferência de massa através da interface é expressa por:

$d m_{w}=k_{w}\left(w_{s w}-w_{s a}\right) d A$

Subtraindo a equação (3.69) da (3.11) e manipulando-se, tem-se:

$T_{w}-T_{a}=\frac{i_{m a w}-i_{s p}-\left(w_{s w}-w_{s a}\right) i_{v}+\left(w-w_{s a}\right) C p_{w}\left(T_{w}-T_{a}\right)}{C p_{s p}}$

O calor específico do ar supersaturado é dado pela seguinte equação:

$C p_{s p}=C p_{a}+w_{s a} C p_{v}+\left(w-w_{s a}\right) C p_{w}$

A umidade de saturação do ar na temperatura do ar é calculada a partir da pressão de vapor saturado, $P_{\text {var, }}$ na temperatura do ar.

Para o cálculo da pressão de vapor saturado, $P_{\text {var, }}$ utilizou-se a equação (3.17), sendo considerada a temperatura do ar, $T_{a}$, e a pressão calculada, $P_{\text {var }}$.

A umidade de saturação é então calculada pela equação (3.73).

$w_{s a}=\frac{P_{\text {var }}}{P_{a}-P_{\text {var }}} \frac{M_{w}}{M_{a}}$

A entalpia específica do ar supondo-se saturado é expresso em função da temperatura do ar e da umidade de saturação, conforme a equação (3.74).

$i_{\text {masp }}=C p_{a}\left(T_{a}-T_{\text {ref }}\right)+w_{s a} i_{\text {var }}$

sendo $w_{s a}$ a umidade de saturação para a temperatura do ar, $T_{a}$.

Na equação acima, $i_{v a r}$ é a entalpia específica do vapor de água calculado na temperatura do ar, conforme a equação (3.75).

$i_{v a r}=i_{w r e f}+C p_{v}\left(T_{a}-T_{r e f}\right)$ 
Assim como foi feito para o ar não saturado, para o ar supersaturado, as manipulações são as mesmas, substituindo-se as equações (3.4) e (3.12) pelas equações (3.70) e (3.71).

A variação da entalpia específica do ar com a altura da torre é então expressa pela seguinte equação:

$\frac{d i_{m a}}{d z}=\frac{k_{w} a_{i} A_{r}}{m_{a}}\left(L e_{f}\left(i_{m a w}-i_{s p}-\left(w_{s w}-w_{s a}\right) i_{v}+\left(w-w_{s a}\right) C p_{w}\left(T_{w}-T_{r e f}\right)\right)+\right.$

$\left.i_{v}\left(w_{s w}-w_{s a}\right)\right)$

A variação da umidade do ar com a variação da temperatura da água é dada pela seguinte equação:

$\frac{d w}{d T_{w}}=\frac{C p_{w} \frac{m_{w}}{m_{a}}\left(w_{s w}-w_{s a}\right)}{i_{m a w}-i_{s p}+\left(L e_{f}-1\right)\left[i_{m a w}-i_{s p}-\left(w_{s w}-w_{s a}\right) i_{v}\right]-\left(w-w_{s a}\right) C p_{w}\left(T_{w}-T_{r e f}\right)}$

A variação da entalpia específica do ar com a variação da temperatura da água é expressa pela equação (3.79).

$$
\begin{aligned}
& \frac{d i_{m a}}{d T_{w}}=\frac{m_{w} C p_{w}}{m_{a}} \times \\
& \times\left(1+\frac{\left(w_{s w}-w_{s a}\right) C p_{w}\left(T_{w}-T_{r e f}\right)}{i_{m a w}-i_{s p}+\left(L e_{f}-1\right)\left[i_{m a w}-i_{s p}-\left(w_{s w}-w_{s a} i_{v}+\left(w-w_{s a}\right) C p_{w}\left(T_{w}-T_{r e f}\right)\right]-\left(w_{s w}-w\right) C p_{w}\left(T_{w}-T_{r e f}\right)\right.}\right)
\end{aligned}
$$

\subsection{Verificação do modelo}

Para a verificação do equacionamento proposto, considerou-se a reprodução de resultados obtidos por Muangnoi (2006). O gráfico representado pela Figura 3.5 corresponde aos resultados de Muangnoi (2006) para as temperaturas do ar, de bulbo úmido e da água, e umidade ao longo da altura obtidos a partir da modelagem matemática baseada em equações de transferência de calor e massa.

Os resultados obtidos a partir da modelagem matemática proposta no presente trabalho seguem apresentados na Figura 3.6. Os perfis de temperatura e umidade representados pelos gráficos destas figuras são muito próximos, validando-se assim 
o modelo proposto neste trabalho. Os perfis da Figura 3.6 foram gerados a partir das seguintes condições iniciais:

Temperatura de entrada da água, $T_{\text {wo }}=28,7^{\circ} \mathrm{C}$

Temperatura de entrada do ar, $T_{a 0}=29^{\circ} \mathrm{C}$

Temperatura de bulbo úmido, $T_{\text {buo }}=21,0^{\circ} \mathrm{C}$

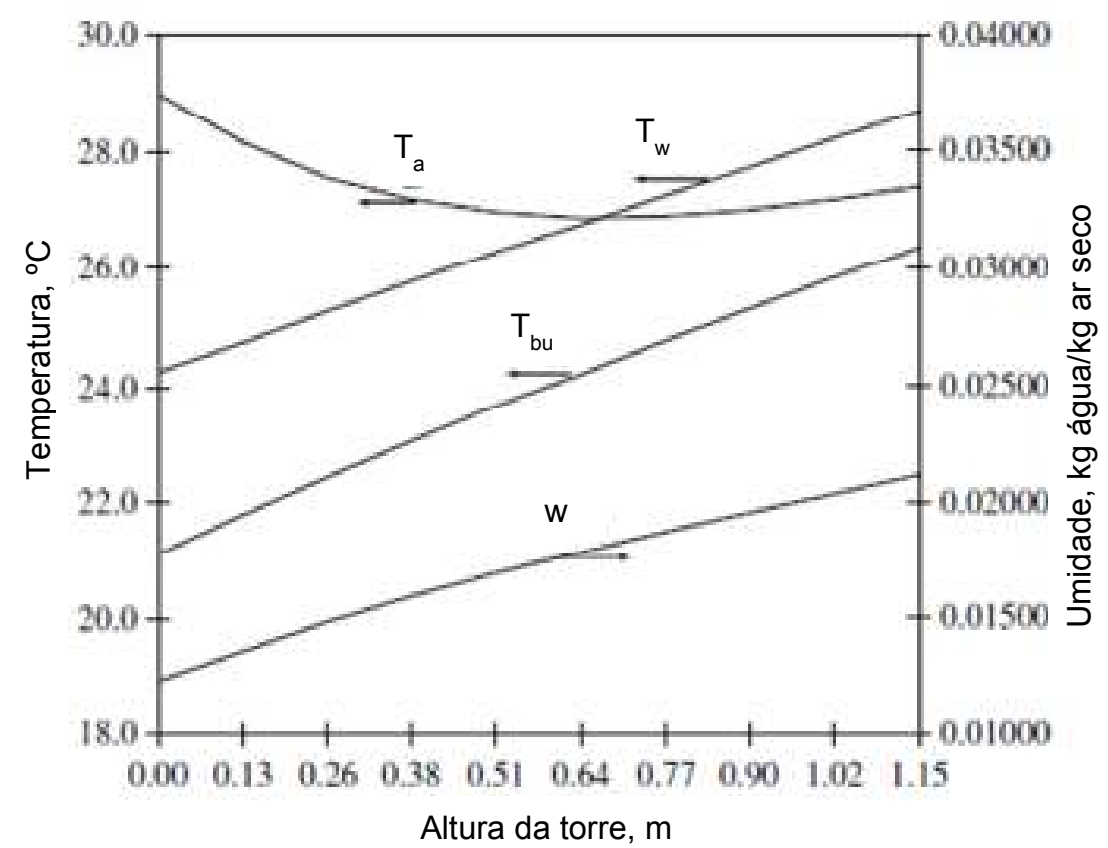

Figura 3.5 - Perfis de temperatura da água e do ar e umidade ao longo da altura da torre de acordo com Muangnoi et al. (2006) 

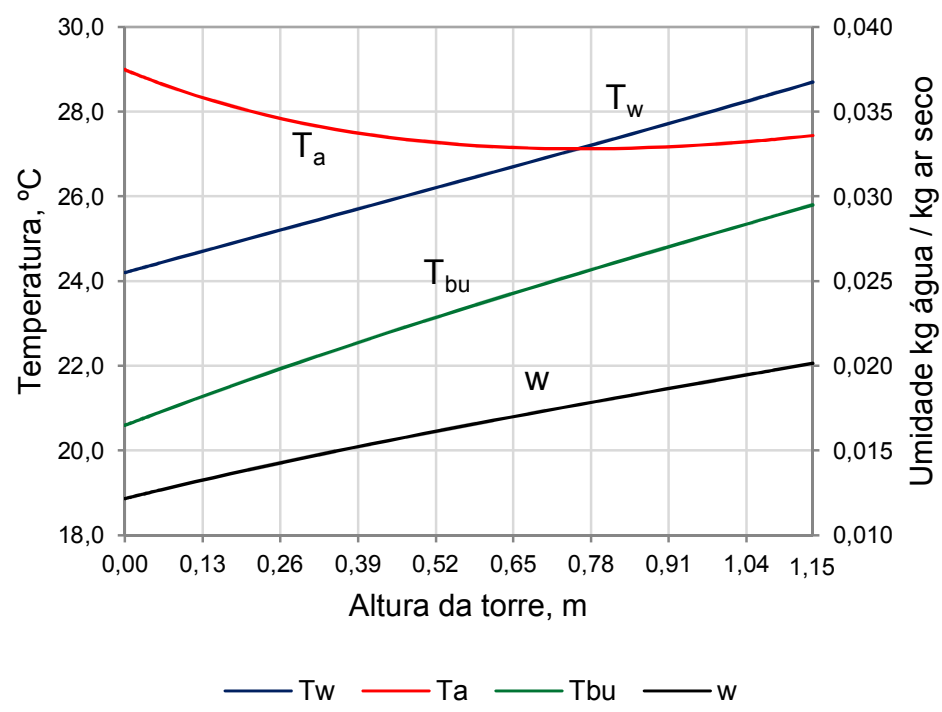

Figura 3.6 - Resultados obtidos pela modelagem proposta para os perfis de $T_{w}, T_{a}, T_{b u}$ e w 


\section{ALGORITMO DO PROGRAMA DE SIMULAÇÃO}

\subsection{Introdução}

Os algoritmos do programa de simulação foram desenvolvidos para a resolução das equações diferenciais referentes aos balanços de energia e massa e equações de transporte simultâneo de calor e massa. O sistema considerado é uma torre de resfriamento com escoamento contracorrente. Os cálculos são efetuados ao longo da altura da torre.

Quatro algoritmos foram considerados:

- Sem supersaturação e sem alto transporte de massa (Poppe);

- Sem supersaturação e com alto transporte de massa;

- Com supersaturação e sem alto transporte de massa;

- Com supersaturação e com alto transporte de massa (modelo proposto).

\subsection{Sem supersaturação e com baixo transporte de massa / sem supersaturação e com alto transporte de massa}

O sistema de Equações Diferenciais Algébricas, sem contemplar o modelo de supersaturação, foi resolvido usando o sistema MATLAB V7.6.0.324. A rotina utilizada para resolver o sistema de Equações Diferenciais Ordinárias (EDO's) foi a ODE45 (Shampine et al., 2003) conforme o algoritmo descrito a seguir e esquematizado na Figura 4.2.

Apresenta-se, na sequência, o roteiro para o cálculo da temperatura da água, umidade e entalpia específica do ar em função da altura. A resolução baseia-se na variação da temperatura de saída da água para que se obtenha uma altura de torre igual à especificada, $z_{q}$. 


\section{a) Variáveis de entrada}

As variáveis de entrada são as seguintes:

$T_{w 0}, T_{w f}(n), z_{q}, T_{a 0}, m_{w 0}, m_{a}, T_{b u 0}, P_{a}, A_{r}$ e $a_{i}$

Para a primeira iteração, $n=1$, a temperatura de saída da água, $T_{w f}$, é estimada.

Para a segunda iteração, $n=2$, a temperatura de saída da água, $T_{w f}$, é calculada a partir da equação (4.1).

$T_{w f}(2)=T_{w f}(1)+\Delta T(=0,5 K)$

onde $\Delta T$ é o passo utilizado para estimar $T_{w f}$.

A partir da terceira iteração $(n \geq 3)$, a temperatura de saída da água, $T_{\text {wf }}$ é calculada pelo método de Newton-Raphson, expressa pela equação (4.2).

$$
T_{w f}(n) \cong T_{w f}(n-1)-\frac{z(n-1)-z_{q}}{\frac{z(n-1)-z(n-2)}{T_{w f}(n-1)-T_{w f}(n-2)}}
$$

b) Cálculo das variáveis a partir das variáveis de entrada

b.1) Baixo transporte de massa

A partir das variáveis de entrada, calculam-se as seguintes variáveis para o caso de baixo transporte de massa:

$P_{\text {vbuo }}$ - calculada através da equação (3.17) calculada na temperatura de bulbo úmido $\left(T_{b u}\right)$

$w_{0}$ - calculada através da equação (3.19)

$C p_{\text {wo }}$ - calculada através da equação (3.25)

$C p_{a 0}$ - calculada através da equação (3.23)

$C p_{v o}$ - calculada através da equação (3.24)

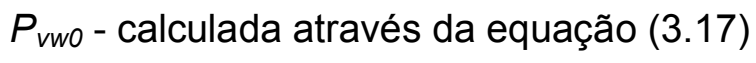

$w_{\text {swo }}$ - calculada através da equação (3.18)

$i_{\text {wo }}$ - calculada através da equação (3.26)

$i_{\text {wref }}$ - calculada através da equação (3.26), fazendo $T_{w}=T_{\text {ref }}$ 
$i_{m a 0}$ - calculada através da equação (3.10)

$i_{v o}$ - calculada através da equação (3.27)

$i_{\text {mawo }}$ - calculada através da equação (3.11)

$L e_{f 0}$ - calculada através da equação (3.16)

$k_{\text {wo }}^{*}$ calculada através da equação (3.28)

\section{b.2) Alto transporte de massa}

Para o caso de alto transporte de massa, a partir das variáveis de entrada, calculam-se as seguintes variáveis:

$P_{\text {vbuo }}$ - calculada através da equação (3.17) calculada na temperatura de bulbo úmido $\left(T_{b u}\right)$

$w_{0}$ - calculada através da equação (3.19)

$C p_{w o}$ - calculada através da equação (3.25)

$C p_{a 0}$ - calculada através da equação (3.23)

$C p_{v o}$ - calculada através da equação (3.24)

$P_{v w o}$ - calculada através da equação (3.17)

$w_{\text {swo }}$ - calculada através da equação (3.18)

$i_{\text {wo }}$ - calculada através da equação (3.26)

$i_{\text {wref }}$ - calculada através da equação (3.26), fazendo $T_{w}=T_{\text {ref }}$

$i_{\text {mao }}$ - calculada através da equação (3.10)

$i_{v o}$ - calculada através da equação (3.27)

$i_{\text {mawo }}$ - calculada através da equação (3.11)

$L e_{f 0}$ - calculada através da equação (3.68)

$k_{w o}$ - calculada através da equação (3.62)

$B_{m 0}$ - calculada através da equação (3.58)

$B_{h o}$ - calculada através da equação (3.64)

$f_{10}$ - calculada através da equação (3.60) 
$f_{20}$ - calculada através da equação (3.66)

c) Resolução do sistema de Equações Diferenciais Ordinárias (EDO’s)

A partir dos valores das variáveis de entrada e das variáveis calculadas acima, resolve-se o sistema de quatro equações diferenciais, equações (4.3), (4.4), (4.7) e (4.9), pelo método de Runge-Kutta de $4^{\mathrm{a}}$ ordem, o que corresponde ao comando ODE45 do Matlab:

$\frac{d w}{d T_{w}}=\frac{C p_{w} \frac{m_{w}}{m_{a}}\left(w_{s w}-w\right)}{i_{m a w}-i_{m a}+\left(L e_{f}-1\right)\left[i_{m a w}-i_{m a}-\left(w_{s w}-w\right) i_{v}\right]-\left(w_{s w}-w\right) C p_{w}\left(T_{w}-T_{r e f}\right)}$

conforme equação (3.21).

$\frac{d i_{m a}}{d T_{w}}=\frac{m_{w} C p_{w}}{m_{a}}\left(1+\frac{\left(w_{s w}-w\right) C p_{w}\left(T_{w}-T_{r e f}\right)}{i_{m a w}-i_{m a}+\left(L e_{f}-1\right)\left[i_{m a w}-i_{m a}-\left(w_{s w}-w\right) i_{v}\right]-\left(w_{s w}-w\right) C p_{w}\left(T_{w}-T_{r e f}\right)}\right)$

conforme equação (3.22).

Para $d m_{w} d d T_{w}$, tem-se o seguinte rearranjo:

$\frac{d m_{w}}{d T_{w}}=\frac{d m_{w}}{d w} \frac{d w}{d T_{w}}$

Mas $d m_{w} / d w$ pode ser expresso conforme equação (4.6).

$\frac{d m_{w}}{d w}=m_{a}$

Substituindo as equações (4.6) e (4.5) na equação (4.3), tem-se:

$\frac{d m_{w}}{d T_{w}}=\frac{C p_{w} m_{w}\left(w_{s w}-w\right)}{i_{m a s w}-i_{m a}+\left(L e_{f}-1\right)\left[i_{m a s w}-i_{m a}-\left(w_{s w}-w\right) i_{v}\right]-\left(w_{s w}-w\right) C p_{w}\left(T_{w}-T_{r e f}\right)}$

Para $d z / d T_{w}$, tem-se:

$\frac{d z}{d T_{w}}=\frac{d z}{d i_{m a}} \frac{d i_{m a}}{d T_{w}}$

Substituindo-se as equações (3.20) e (3.22) na equação (4.8), tem-se a equação (4.7). 


$$
\begin{aligned}
& \frac{d z}{d T_{w}}=\frac{1}{k_{w} a_{i} A_{r}\left[L e_{f}\left(i_{m a w}-i_{m a}\right)+\left(1-L e_{f}\right) i_{v}\left(w_{s w}-w\right)\right]} m_{w} C p_{w}(1+ \\
& \left.\frac{\left(w_{s w}-w\right) C p_{w}\left(T_{w}-T_{r e f}\right)}{i_{m a w}-i_{m a}+\left(L e_{f}-1\right)\left[i_{m a w}-i_{m a}-\left(w_{s w}-w\right) i_{v}\right]-\left(w_{s w}-w\right) C p_{w}\left(T_{w}-T_{r e f}\right)}\right)
\end{aligned}
$$

No caso de baixo transporte de massa $k_{w}=k_{w}{ }^{*}$, e no caso do alto transporte de massa $k_{w}$ é calculado pela equação (3.62).

O fator de Lewis, $L e_{w f}$, para o caso de baixo transporte de massa é expresso pela equação (3.16), e no caso do alto transporte de massa pela equação (3.68).

O sistema de equações diferenciais ordinárias acima, composto pelas equações: (4.3), (4.4), (4.7) e (4.9) é resolvido tendo como especificações para $z=0$ :

$T_{w f}, T_{a 0}, m_{w} d m_{a}$ e $T_{b u}$

O algoritmo descrito acima e esquematizado na Figura 4.2, é simulado várias vezes, variando-se sempre a temperatura de saída da água, $T_{w f}(n)$, conforme descrito no item 4.1.a, até que se encontre uma temperatura de saída da água, $T_{w f}$, na qual a altura da torre seja praticamente igual à altura especificada, ou seja: $z(n)-z_{q}=<$ $10^{-4}$.

Ao final das iterações, obtém-se as seguintes variáveis de saída:

$w(n), i_{m a}(n), z(n)$ e $m_{w}(n)$ 


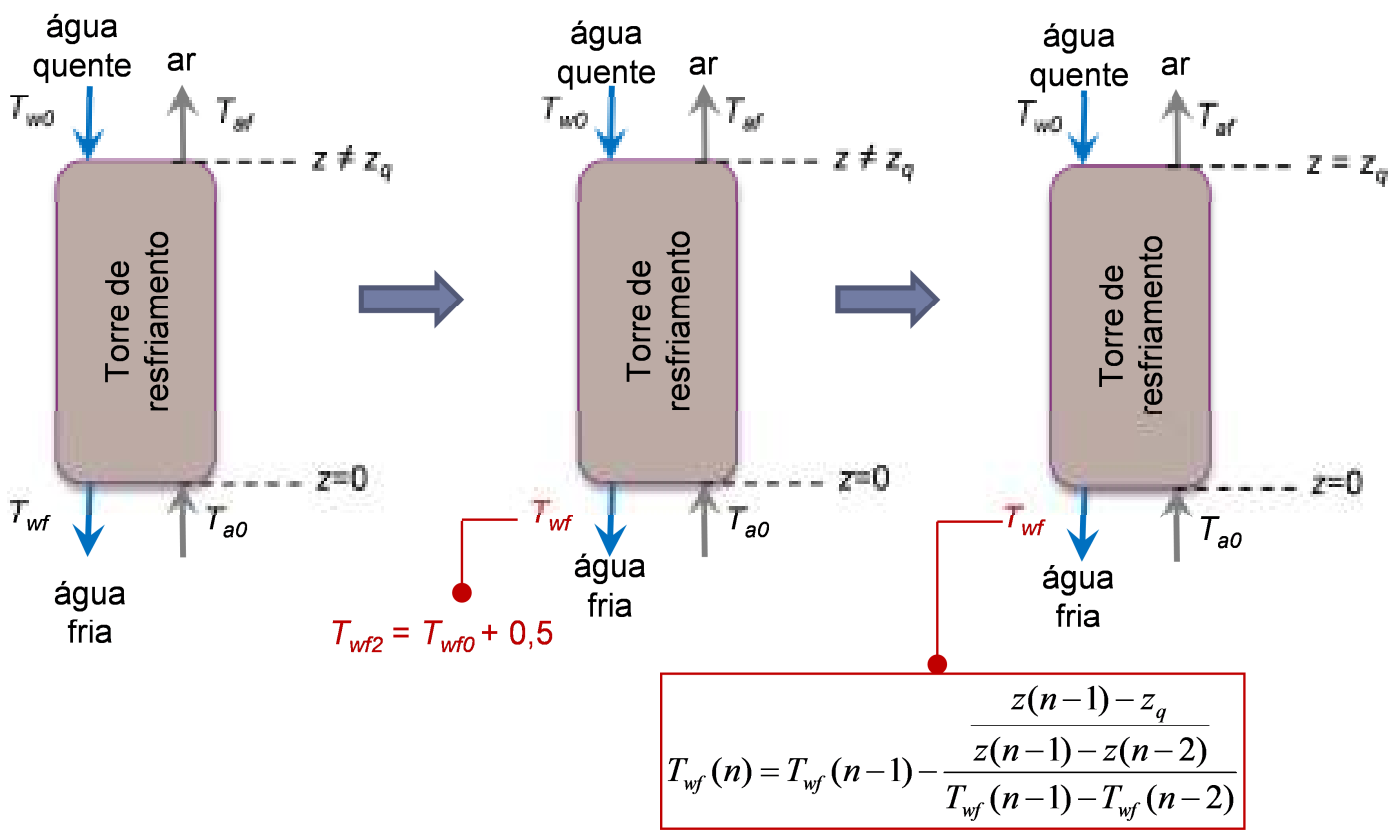

Figura 4.1- Algoritmo para o modelo sem supersaturação, com e sem alto transporte 


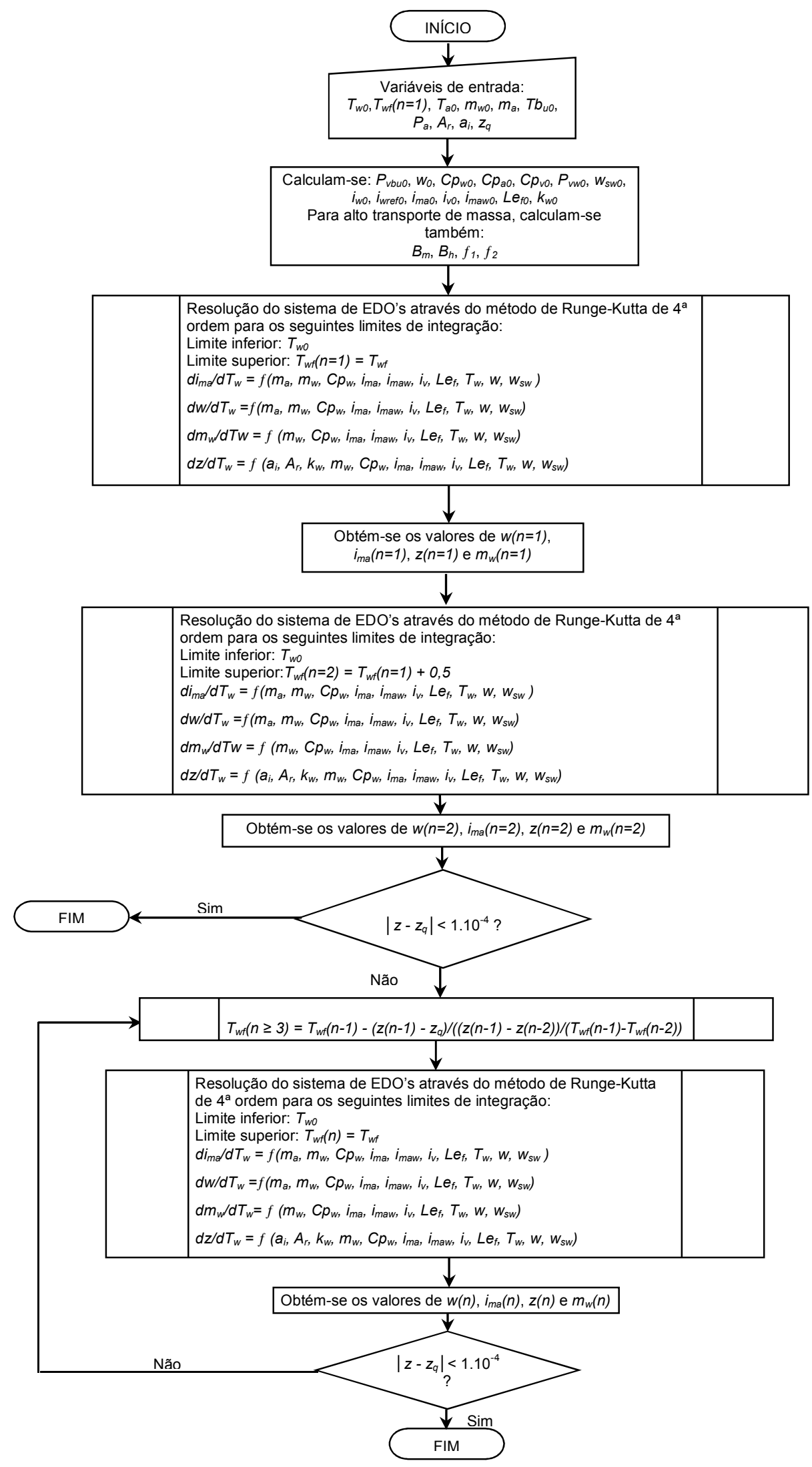

Figura 4.2 - Algoritmo para modelo sem supersaturação, com alto ou baixo transporte de massa 


\subsection{Com supersaturação e com baixo transporte de massa / com supersaturação e com alto transporte de massa}

O sistema de Equações Diferenciais Algébricas, contemplando o modelo de supersaturação, foi resolvido usando o sistema MATLAB V7.6.0.324. A rotina utilizada para resolver o sistema de Equações Diferenciais Ordinárias (EDO's) foi a ODE45 (Shampine et al., 2003) conforme o algoritmo descrito a seguir e representado na Figura 4.4.

Segue abaixo o roteiro para o cálculo da temperatura da água, umidade e entalpia específica do ar em função da altura. Este roteiro é similar ao apresentado no item anterior, 4.1, com exceção da caracterização da condição de supersaturação e do modelo de supersaturação. A resolução baseia-se na variação da temperatura de saída da água para que se obtenha uma altura de torre igual a especificada, $z_{q}$.

\section{a) Variáveis de entrada}

As variáveis de entrada são as seguintes:

$T_{w 0}, T_{w f}(n), z_{q}, T_{a 0}, m_{w 0}, m_{a}, T_{b u 0}, P a, A_{r}$ e $a_{i}$

Para a primeira iteração, $n=1$, a temperatura de saída da água, $T_{w f}$, é estimada.

Para a segunda iteração, $n=2$, a temperatura de saída da água, $T_{w f}$, é calculada a partir da equação (4.1), descrita no item 4.1 e repetida abaixo.

$T_{w f}(2)=T_{w f}(1)+\Delta T(=0,5 K)$

onde $\Delta T$ é o passo utilizado para estimar $T_{w f}$.

A partir da terceira iteração $(n \geq 3)$, a temperatura de saída da água, $T_{w f}$, é aproximada pelo método de Newton-Raphson, expresso pela equação (4.2), descrita no item 4.1 e repetida abaixo.

$$
T_{w f}(n) \cong T_{w f}(n-1)-\frac{z(n-1)-z_{q}}{\frac{z(n-1)-z(n-2)}{T_{w f}(n-1)-T_{w f}(n-2)}}
$$


b) Cálculo das variáveis a partir das variáveis de entrada

b.1) Baixo transporte de massa a partir das variáveis de entrada

A partir das variáveis de entrada, calculam-se as seguintes variáveis, para o caso de baixo transporte de massa:

$P_{\text {vbuo }}$ - calculada através da equação (3.17) calculada na temperatura de bulbo úmido $\left(T_{b u}\right)$

wo $_{0}$ calculada através da equação (3.19)

$C p_{w o}$ - calculada através da equação (3.25)

$C p_{a 0}$ - calculada através da equação (3.23)

$C p_{v o}$ - calculada através da equação (3.24)

$P_{v w 0}$ - calculada através da equação (3.17)

$w_{\text {swo }}$ - calculada através da equação (3.18)

$i_{w 0}$ - calculada através da equação (3.26)

$i_{\text {wref }}$ - calculada através da equação (3.26), fazendo $T_{w}=T_{\text {ref }}$

$i_{\text {mao }}$ - calculada através da equação (3.10)

$i_{\text {vo }}$ - calculada através da equação (3.27)

$i_{\text {mawo }}$ - calculada através da equação (3.11)

$L e_{f 0}$ - calculada através da equação (3.16)

$k_{\text {wo }}^{*}$ - calculada através da equação (3.28)

\section{b.2) Alto transporte de massa}

Para o caso de alto transporte de massa, a partir das variáveis de entrada calculamse as seguintes variáveis:

$P_{\text {vbuo }}$ - calculada através da equação (3.17) calculada na temperatura de bulbo úmido $\left(T_{b u}\right)$

$w_{0}$ - calculada através da equação (3.19)

$C p_{w 0}$ - calculada através da equação (3.25) 
$C p_{a 0}$ - calculada através da equação (3.23)

$C p_{v o}$ - calculada através da equação (3.24)

$P_{v w 0}$ - calculada através da equação (3.17)

$w_{\text {swo }}$ - calculada através da equação (3.18)

$i_{\text {wo }}$ - calculada através da equação (3.26)

$i_{\text {wref }}$ - calculada através da equação (3.26), fazendo $T_{w}=T_{\text {ref }}$

$i_{\text {mao }}$ - calculada através da equação (3.10)

$i_{\text {vo }}$ - calculada através da equação (3.27)

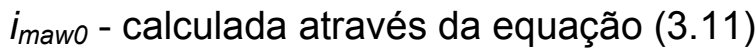

$L e_{f 0}$ - calculada através da equação (3.68)

$k_{w o}$ - calculada através da equação (3.62)

$B_{m 0}$ - calculada através da equação (3.58)

$B_{h o}$ - calculada através da equação (3.64)

$f_{10}$ - calculada através da equação (3.60)

$f_{20}$ - calculada através da equação (3.66)

c) Resolução do sistema de Equações Diferenciais Ordinárias (EDO’s) que não contemplam a supersaturação

A partir dos valores das variáveis de entrada e das variáveis calculadas acima resolve-se o sistema de 4 equações diferenciais descritas no item 4.1, pelo método de Runge-Kutta de $4^{a}$ ordem, o que corresponde ao comando ODE45 do Matlab. Seguem abaixo as equações apresentadas no item 4.1.

$$
\begin{aligned}
& \frac{d w}{d T_{w}}=\frac{C p_{w} \frac{m_{w}}{m_{a}}\left(w_{s w}-w\right)}{i_{m a w}-i_{m a}+\left(L e_{f}-1\right)\left[i_{m a w}-i_{m a}-\left(w_{s w}-w\right) i_{v}\right]-\left(w_{s w}-w\right) C p_{w}\left(T_{w}-T_{r e f}\right)} \\
& \frac{d i_{m a}}{d T_{w}}= \\
& \frac{m_{w} C p_{w}}{m_{a}}\left(1+\frac{\left(w_{s w}-w\right) C p_{w}\left(T_{w}-T_{r e f}\right)}{i_{m a w}-i_{m a}+\left(L e_{f}-1\right)\left[i_{m a w}-i_{m a}-\left(w_{s w}-w\right) i_{v}\right]-\left(w_{s w}-w\right) C p_{w}\left(T_{w}-T_{r e f}\right)}\right)
\end{aligned}
$$




$$
\begin{aligned}
& \frac{d m_{w}}{d T_{w}}=\frac{C p_{w} m_{w}\left(w_{s w}-w\right)}{i_{m a s w}-i_{m a}+\left(L e_{f}-1\right)\left[i_{m a s w}-i_{m a}-\left(w_{s w}-w\right) i_{v}\right]-\left(w_{s w}-w\right) C p_{w}\left(T_{w}-T_{r e f}\right)} \\
& \frac{d z}{d T_{w}}= \\
& \frac{1}{k_{w} a_{i} A_{r}\left[L e_{f}\left(i_{m a w}-i_{m a}\right)+\left(1-L e_{f}\right) i_{v}\left(w_{s w}-w\right)\right]} m_{w} C p_{w}(1+ \\
& \left.\frac{\left(w_{s w}-w\right) C p_{w}\left(T_{w}-T_{r e f}\right)}{i_{m a w}-i_{m a}+\left(L e_{f}-1\right)\left[i_{m a w}-i_{m a}-\left(w_{s w}-w\right) i_{v}\right]-\left(w_{s w}-w\right) C p_{w}\left(T_{w}-T_{r e f}\right)}\right)
\end{aligned}
$$

O sistema de equações diferenciais ordinárias acima, composto pelas equações: (4.3), (4.4), (4.7) e (4.9) é resolvido tendo como especificações para $z=0$ :

$T_{w f}, T_{a 0}, m_{w o} / m_{a}$ e $T_{b u}$

A cada vez que o algoritmo é simulado a temperatura de saída da água, $T_{w f}(n)$, é alterada conforme descrito no início do item a), até que se encontre uma temperatura de saída da água, $T_{w f}$, na qual a altura da torre calculada no item e), $z_{\text {sup }}$, seja igual à altura desejada da torre $z_{q}: z_{\text {sup }}-z_{q}=<10^{-4}$.

Ao final das iterações, obtém-se as seguintes variáveis de saída:

$w(n), i_{m a}(n), z(n)$ e $m_{w}(n)$

\section{d) Verificação ponto de saturação}

Para cada vez que o programa é simulado a partir de uma temperatura de saída da água, $T_{w f}(n)$, a verificação da altura na qual tem-se a condição de saturação do ar é feita comparando-se, em cada incremento de altura da torre, a entalpia específica do ar $\left(i_{m a}\right)$ com a entalpia específica de saturação calculada na temperatura do ar, $T_{a}\left(i_{\text {masp }}\right)$. A partir do ponto em que $i_{\text {ma }}(n) \geq i_{\text {masp }}(n)$, resolve-se o sistema de quatro Equações Ordinárias Diferenciais (EDO's) que contemplam o fenômeno da supersaturação: equações (4.10), (4.11), (4.13) e (4.14).

Para o cálculo da entalpia específica de saturação, $i_{\text {masp }}$, utiliza-se a equação (3.74), que é função das variáveis $w_{s a}$ e $P_{\text {var: }}$ :

$P_{v a r}$ - calculada através da equação (3.17)

$w_{s a}$ - calculada através da equação (3.31) 
e) Resolução do sistema de Equações Diferenciais Ordinárias (EDO's) que contemplam a supersaturação

$\mathrm{Na}$ altura da torre em que se verificou a supersaturação do ar, tem-se os valores das seguintes variáveis:

$i_{m a}, i_{m a s p}, T_{w}, T_{a}, m_{w}, m_{a}, T_{b u}, z$

Os valores destas variáveis serão utilizados como valores entrada para a resolução do sistema de EDO's abaixo.

$\frac{d w}{d T_{w}}=\frac{C p_{w} \frac{m_{w}}{m_{a}}\left(w_{s w}-w_{s a}\right)}{i_{m a w}-i_{s p}+\left(L e_{f}-1\right)\left[i_{m a w}-i_{s p}-\left(w_{s w}-w_{s a}\right) i_{v}\right]-\left(w-w_{s a}\right) C p_{w}\left(T_{w}-T_{r e f}\right)}$

conforme equação (3.77).

$\frac{d i_{m a}}{d T_{w}}=\frac{m_{w} C p_{w}}{m_{a}} \times$

$\times\left(1+\frac{\left(w_{s w}-w_{s a}\right) C p_{w}\left(T_{w}-T_{r e f}\right)}{i_{m a w}-i_{s p}+\left(L e_{f}-1\right)\left[i_{m a w}-i_{s p}-\left(w_{s w}-w_{s a}\right) i_{v}+\left(w-w_{s a}\right) C p_{w}\left(T_{w}-T_{r e f}\right)\right]-\left(w_{s w}-w\right) C p_{w}\left(T_{w}-T_{r e f}\right)}\right)$

conforme equação (3.78).

Substituindo a equação (4.6) na (4.5), tem-se a equação (4.12).

$\frac{d m_{w}}{d T_{w}}=m_{a} \frac{d w}{d T_{w}}$

Substituindo a equação (4.11) na equação (4.10), tem-se a equação (4.13).

$\frac{d w}{d T_{w}}=\frac{C p_{w} m_{w}\left(w_{s w}-w_{s a}\right)}{i_{m a w}-i_{s p}+\left(L e_{f}-1\right)\left[i_{m a w}-i_{s p}-\left(w_{s w}-w_{s a}\right) i_{v}\right]-\left(w-w_{s a}\right) C p_{w}\left(T_{w}-T_{r e f}\right)}$

Para dz/dT $T_{w}$, substitui-se as equações (3.76) e (3.78) na equação (4.8):

$$
\begin{aligned}
& \frac{d z}{d T_{w}}=\frac{1}{\frac{k_{w} a_{i} A_{r}}{m_{a}}\left(L e_{f}\left(i_{\text {maw }}-i_{s p}-\left(w_{s w}-w_{s a}\right) i_{v}+\left(w-w_{s a}\right) C p_{w}\left(T_{w}-T_{r e f}\right)\right)+i_{v}\left(w_{s w}-w_{s a}\right)\right)} \frac{m_{w} C p_{w}}{m_{a}} \times \\
& \left(1+\frac{\left(w_{s w}-w_{s a}\right) C p_{w}\left(T_{w}-T_{r e f}\right)}{i_{m a w}-i_{s p}+\left(L e_{f}-1\right)\left[i_{m a w}-i_{s p}-\left(w_{s w}-w_{s a}\right) i_{v}+\left(w-w_{s a}\right) C p_{w}\left(T_{w}-T_{r e f}\right)\right]-\left(w_{s w}-w\right) C p_{w}\left(T_{w}-T_{r e f}\right)}\right)
\end{aligned}
$$

As equações diferenciais ordinárias (4.10), (4.11), (4.13) e (4.14) serão integradas entre os seguintes limites: 
Limite inferior: $T_{\text {wsupo }}$ (temperatura da água em que houve a saturação)

Limite superior: $T_{w f}(n)$

Então obtém-se uma nova altura da torre diferente $z_{\text {sup }}(n)$.

O algoritmo descrito acima é então repetido, até que $z_{\text {sup }}(n)-z_{q}<10^{-4}$, neste caso, considera-se que $z_{\text {sup }}=z_{q}$ e a simulação é finalizada.

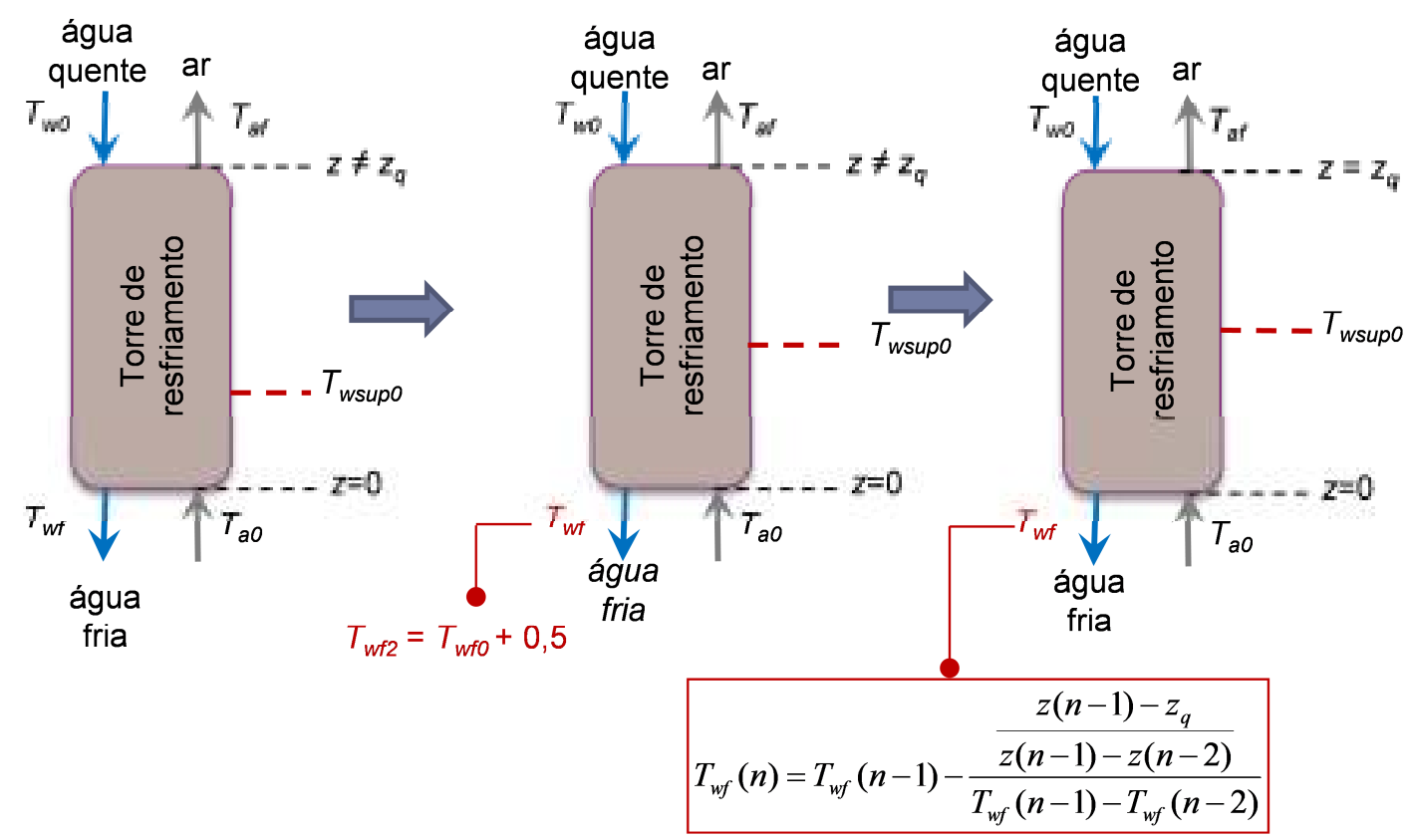

Figura 4.3 - Algoritmo para o modelo com supersaturação, com e sem alto transporte 


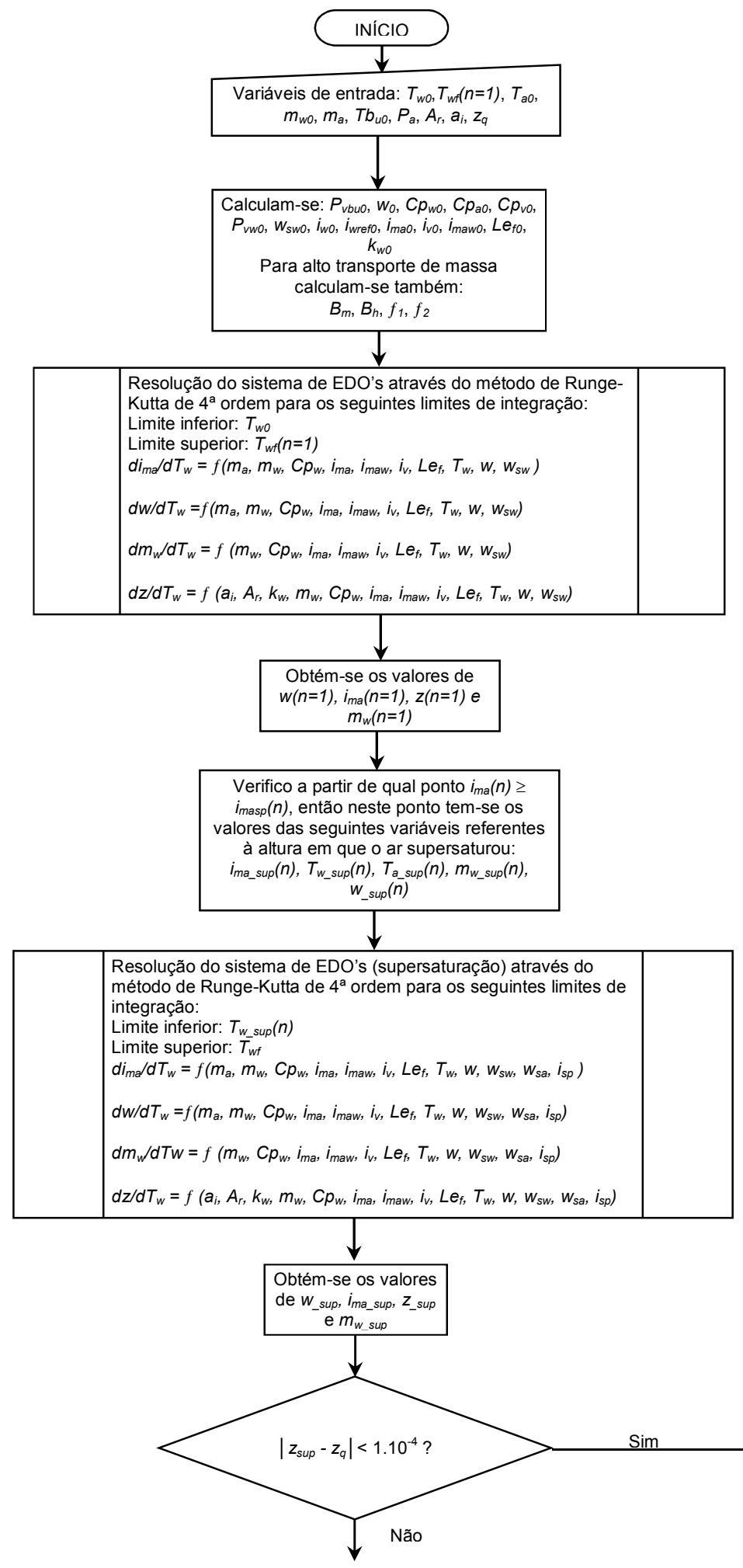




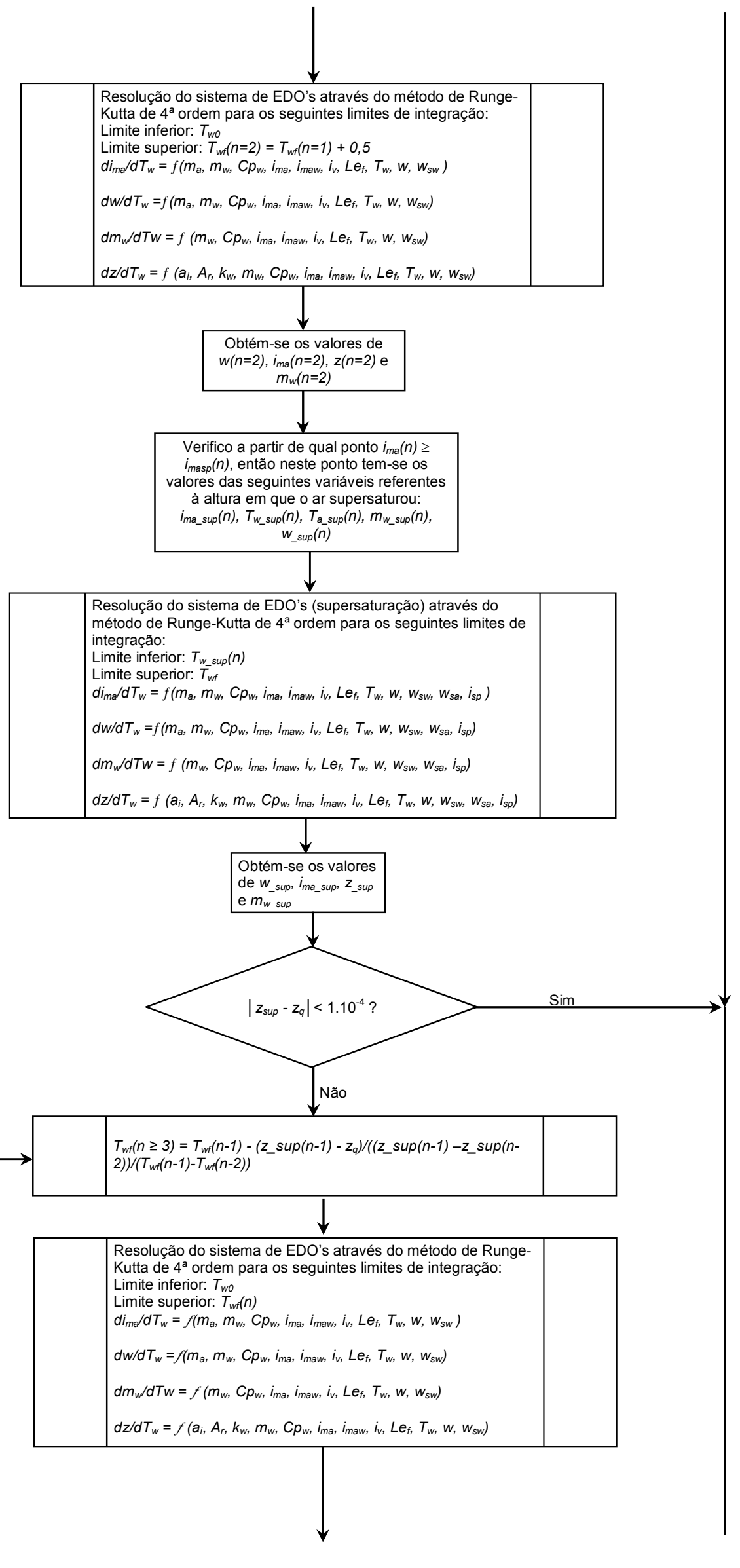




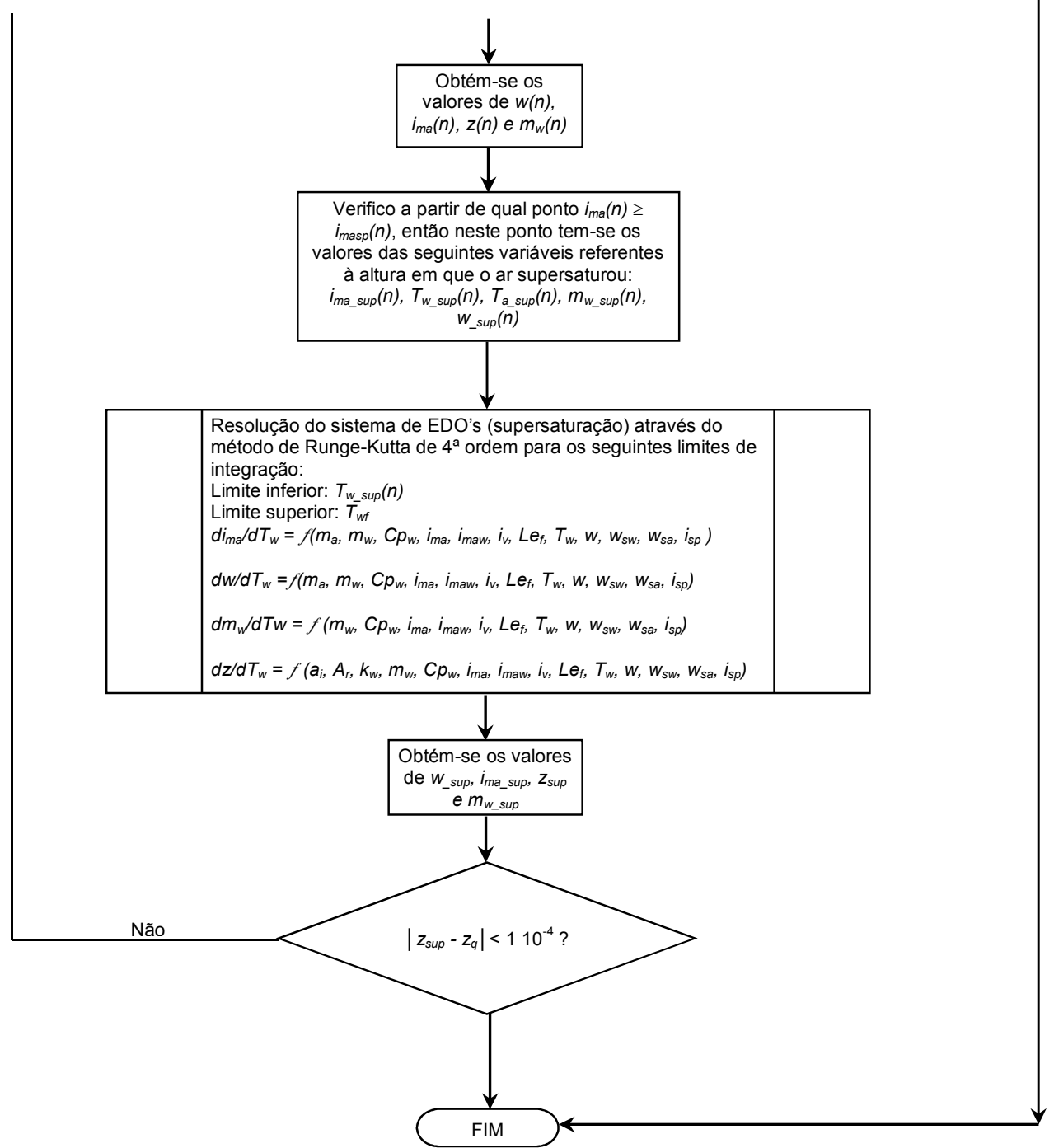

Figura 4.4 - Algoritmo para modelo com supersaturação, alto ou baixo transporte de massa 


\section{RESULTADOS E DISCUSSÕES}

\subsection{Introdução}

Neste capítulo são apresentados os resultados obtidos a partir das simulações dos diferentes modelos de desempenho de torre de resfriamento e as discussões destes resultados.

Através de simulação matemática do modelo desenvolvido, foram estudados diversos casos de aplicação para torres de resfriamento. Estudou-se, também, a influência das principais variáveis de operação no desempenho da torre, por meio da análise dos perfis de temperatura da água, do ar e de umidade ao longo da torre. Investigaram-se as seguintes variáveis de operação: razão entre vazão de água e vazão de $\operatorname{ar}\left(m_{w} / m_{a}\right)$, umidade do ar de entrada $\left(T_{b u 0}\right)$ e temperatura da água de entrada $\left(T_{w 0}\right)$.

Os modelos analisados foram:

- Merkel;

- Poppe;

- Poppe incorporando o fenômeno de alto transporte (denominado Alto Transporte AT);

- Poppe incorporando o fenômeno da supersaturação (denominado Supersaturação);

- Poppe incorporando o alto transporte e a supersaturação (denominado Alto Transporte / Supersaturação), que se refere ao modelo proposto neste trabalho.

Estudaram-se as situações descritas abaixo, fixando-se a altura da torre, considerando-se uma área de seção transversal da torre, $A_{r}$, igual a $3 \mathrm{~m}^{2}$ e a área de recheio específica, $a_{i}$, igual a $100 \mathrm{~m}^{2} / \mathrm{m}^{3}$ :

- Torre existente em uma indústria siderúrgica que opera em alta temperatura de água;

- Influência da relação entre as vazões de água e ar, $m_{w} / m_{a}$; 
- Influência da temperatura de bulbo úmido do ar, $T_{b u}$;

- Influência da temperatura da água quente alimentada à torre, $T_{w 0}$.

O modelo proposto considera a teoria de alto transporte de massa e a condição de supersaturação. A modelagem referente à condição de supersaturação do ar foi incorporada ao modelo proposto a partir do ponto em que há a supersaturação deste. Considerou-se a hipótese de que, a partir do ponto de supersaturação, ocorre a condensação do vapor de água até o limite da saturação, na forma de névoa.

Apesar da condição de supersaturação do ar em torres de resfriamento ser

conhecida, nem sempre é considerada no projeto de torres e na análise do processo. Nos casos de altas temperaturas da água na entrada da torre, estudados neste trabalho, constata-se que a supersaturação ocorre logo no início da torre. Desta forma, o modelo deve contemplar a condição de alto transporte de massa e o fenômeno da supersaturação. No método proposto, calcula-se a quantidade de névoa formada em toda a extensão da torre e a quantidade total de névoa também no ar que deixa a torre.

\subsection{Simulação de uma torre de resfriamento existente}

Os resultados apresentados na Tabela 5.1 referem-se à simulação de uma torre de resfriamento existente em uma indústria siderúrgica.

As condições de entrada da água e do ar consideradas seguem descritas abaixo.

Temperatura de entrada da água: $T_{w 0}=69,3^{\circ} \mathrm{C}$

Temperatura de bulbo úmido do ar: $T_{b u 0}=28^{\circ} \mathrm{C}$

Temperatura de entrada do ar: $T_{a 0}=28^{\circ} \mathrm{C}$

Umidade: $w_{0}=0,0240 \mathrm{~kg}$ água $/ \mathrm{kg}$ ar seco $(U R=100 \%)$

Altura da torre: $z=1,55 \mathrm{~m}$

Vazão de água : $m_{w 0}=134,3 \mathrm{~kg} / \mathrm{s}$

Vazão de ar : $m_{a}=140,7 \mathrm{~kg} / \mathrm{s}$ 
As condições do ar de entrada, e de saída, obtidas através de cada um dos métodos estão representadas na Figura 5.1. Nota-se que o ar entra com umidade relativa, UR, igual a $100 \%$, ou seja, saturado.

\begin{tabular}{|l|l|l|l|l|l|}
\hline \multirow{3}{*}{ Tabela 5.1 - Comparação entre os resultados obtidos para um torre de resfriamento existente. } \\
\cline { 2 - 7 } & Merkel & Poppe & $\begin{array}{c}\text { Alto } \\
\text { Transporte }\end{array}$ & Supersaturação & $\begin{array}{l}\text { Alto Transporte / } \\
\text { Supersaturação }\end{array}$ \\
\hline$T_{\text {wf, }}{ }^{\circ} \mathrm{C}$ & 32,2 & 32,6 & 32,9 & 32,0 & 32,2 \\
\hline$T_{\text {af, }}{ }^{\circ} \mathrm{C}$ & 45,6 & 45,3 & 44,9 & 44,7 & 44,3 \\
\hline "range", ${ }^{\circ} \mathrm{C}$ & 37,1 & 36,7 & 36,4 & 37,3 & 37,1 \\
\hline w, kg água/kg ar seco & 0,0670 & 0,0798 & 0,0795 & $0,0812\left(^{*}\right)$ & $0,0810\left(^{*}\right)$ \\
\hline$\%$ água evaporada & 4,5 & 5,9 & 5,8 & 6,0 & 6,0 \\
\hline
\end{tabular}

(*) Estes valores de umidade incluem a névoa formada devido à supersaturação do ar.

A partir dos resultados encontrados na Tabela 5.1 e das condições do ar de saída representados na Figura 5.1, nota-se que os resultados obtidos, para a temperatura da água de saída, pelos diferentes modelos, são bem próximos.

No caso da temperatura do ar as diferenças são ligeiramente superiores.

Os balanços de energia para a água e para o ar diferem em $0,048 \%$.

A Figura 5.2 apresenta os perfis de $T_{w}$ e $T_{a}$ ao longo da altura da torre para todos os modelos, com exceção de Merkel. Observa-se que apesar do alto valor de "range", em torno de $37^{\circ} \mathrm{C}$, as diferenças entre os perfis não são significantes.

No caso do modelo de Merkel, as condições de saída para o ar são as que mais diferem dos demais modelos. Justifica-se pelo fato de que o modelo de Merkel não calcula diretamente as condições do ar que deixa a torre, simplesmente assume-se que a entalpia do ar de saída corresponde à entalpia de um ar saturado. Como consequência, a porcentagem de água evaporada é subestimada, quando calculada a partir da umidade do ar de saída.

Nota-se a proximidade entre as umidades do ar de saída calculadas através dos modelos Poppe e Alto Transporte, e a mesma observação vale para as umidades do ar de saída calculadas através dos modelos de Supersaturação e Alto Transporte / Supersaturação. 
Pelo modelo Supersaturação obtém-se a menor temperatura de saída para a água, pois este modelo considera que a partir da supersaturação do ar, há a condensação do vapor de água na forma de névoa. Desta forma a "força motriz" para transferência de massa torna-se maior, com consequente maior resfriamento da água.

Comparando-se o método de Poppe com o modelo de Alto Transporte, o "range" deste é inferior ao do Poppe pois o fluxo de transporte de massa é inferior, como pode ser observado pelo fator $f_{1}$ definido no item 3.3 (Figura 3.4). 


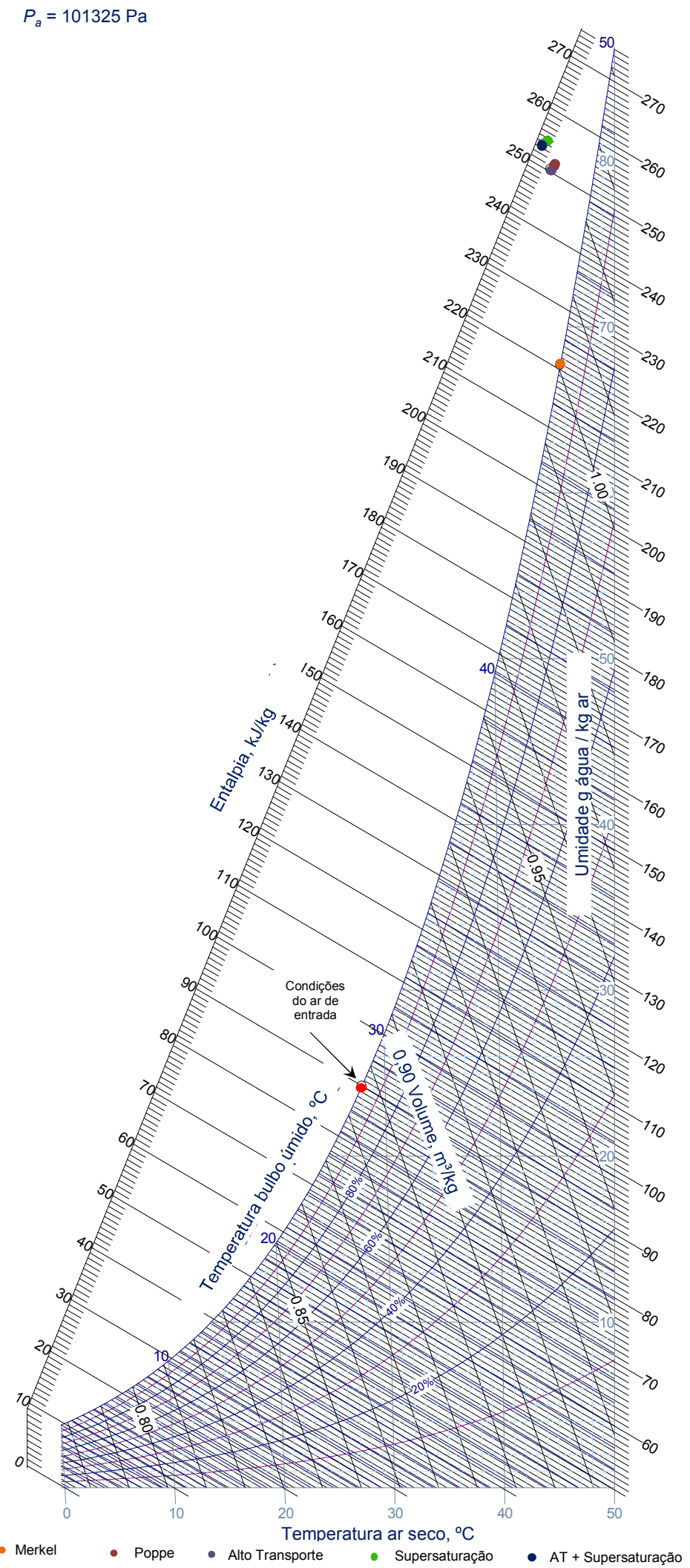

Figura 5.1 - Representação das condições do ar de entrada e saída conforme o modelo utilizado nos cálculos 


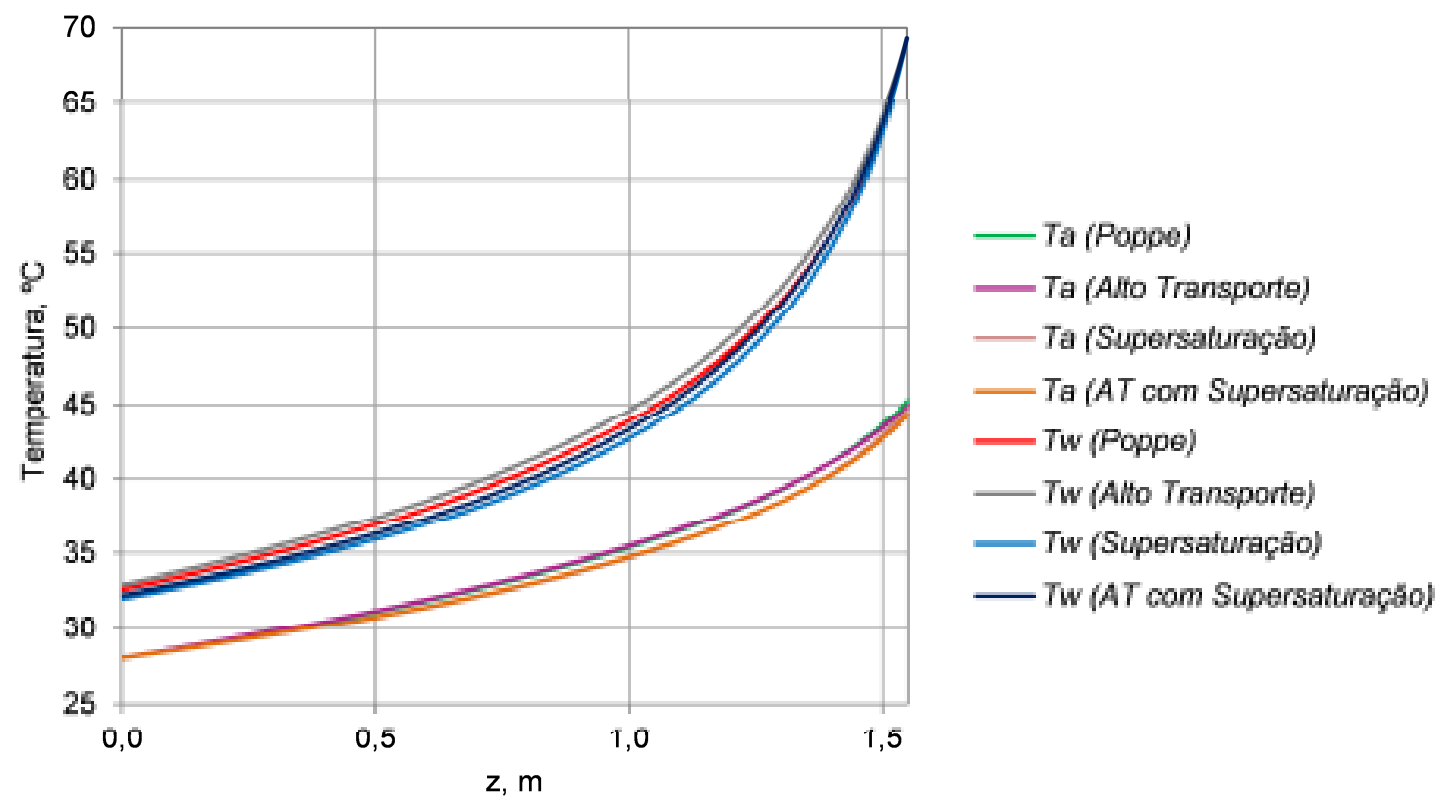

Figura 5.2 - Perfis de $T_{w}$ e $T_{a}$ para todos os modelos.

A

Figura 5.3 apresenta o perfil de umidade, w, para os casos Poppe, Supersaturação e Supersaturação / Alto Transporte e o perfil de névoa formada ao longo da torre para os casos Supersaturação e Supersaturação / Alto Transporte. Observa-se que os perfis de umidade ao longo da torre para os três modelos praticamente coincidem. Para os modelos Supersaturação e Supersaturação / Alto Transporte, os perfis de umidade contemplam a quantidade de vapor de água que condensou na forma de névoa.

A quantidade de névoa formada ao longo da altura da torre é diferente para o modelo que considera ou não o alto transporte de massa.

$\mathrm{Na}$

Figura 5.4, são apresentadas as umidades na interface ar-água $\left(w_{s w}\right)$, no ar $(w)$ e a umidade de saturação no seio do ar $\left(w_{s a}\right)$, definida no item 3.5. Foram analisados somente os modelos Poppe e o proposto (AT com supersaturação).

Verifica-se que, apesar de concordância nos valores calculados para $w$, as "forças motrizes" para o transporte de massa do modelo de Poppe, ( $\left.w_{s w}-w\right)$, e AT com supersaturação, $\left(w_{s w}-w_{s a}\right)$, diferem significativamente. Isto decorre da hipótese de imediata formação de névoa, no caso do modelo de supersaturação. Por outro lado, 
o coeficiente de transporte de massa no caso do modelo de alto transporte é inferior ao predito pelo método de Poppe, conforme analisado no item 3.3. Tem-se, portanto, uma compensação nos resultados. Um outro aspecto é o fator de Lewis que praticamente não varia para alto transporte, pois o fator $f_{2} / f_{1}$ é praticamente igual a 1 (variando de 1,02 a 1,03 ao longo da torre).

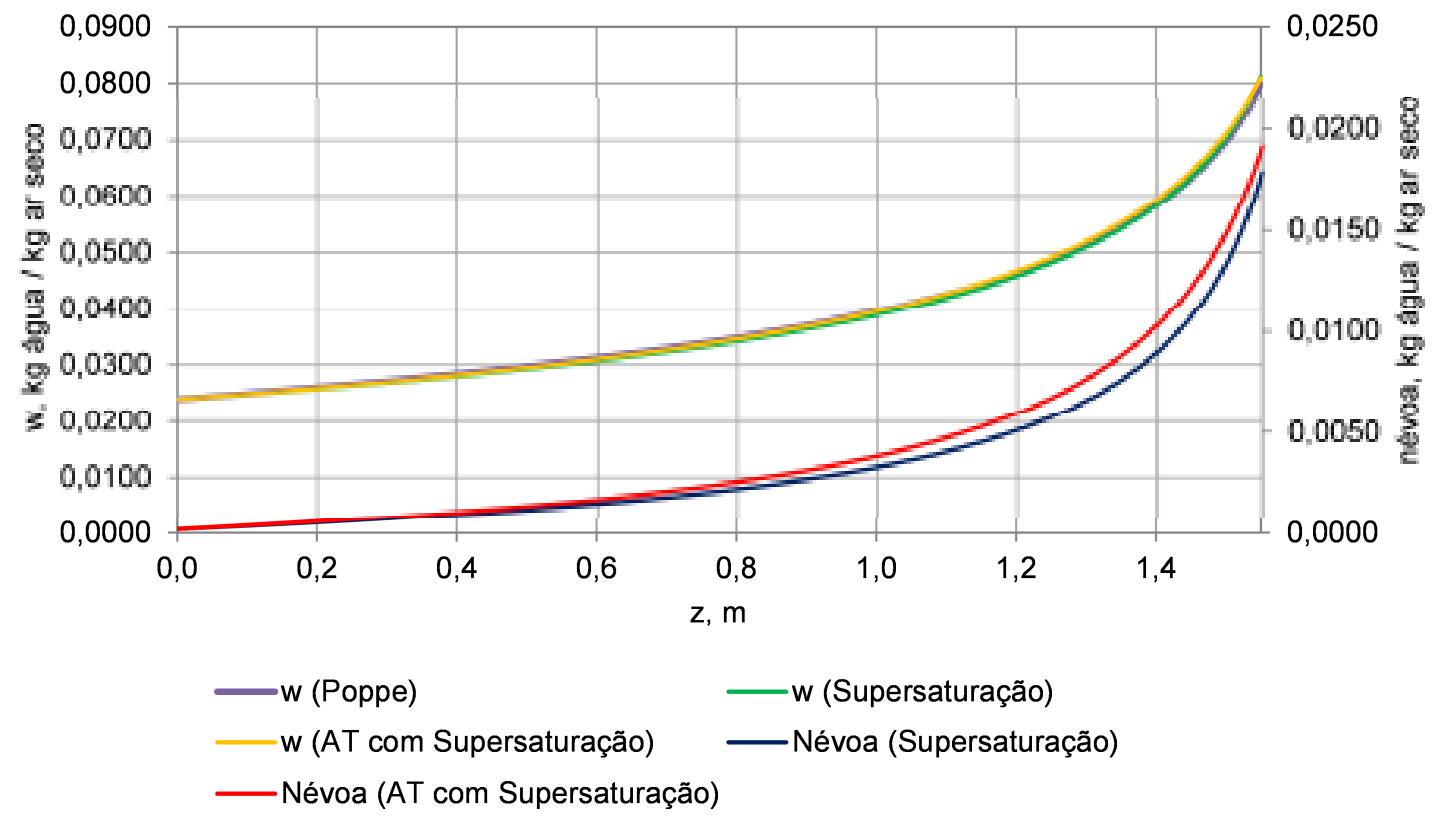

Figura 5.3 - Perfil de umidade e de névoa ao longo da torre.

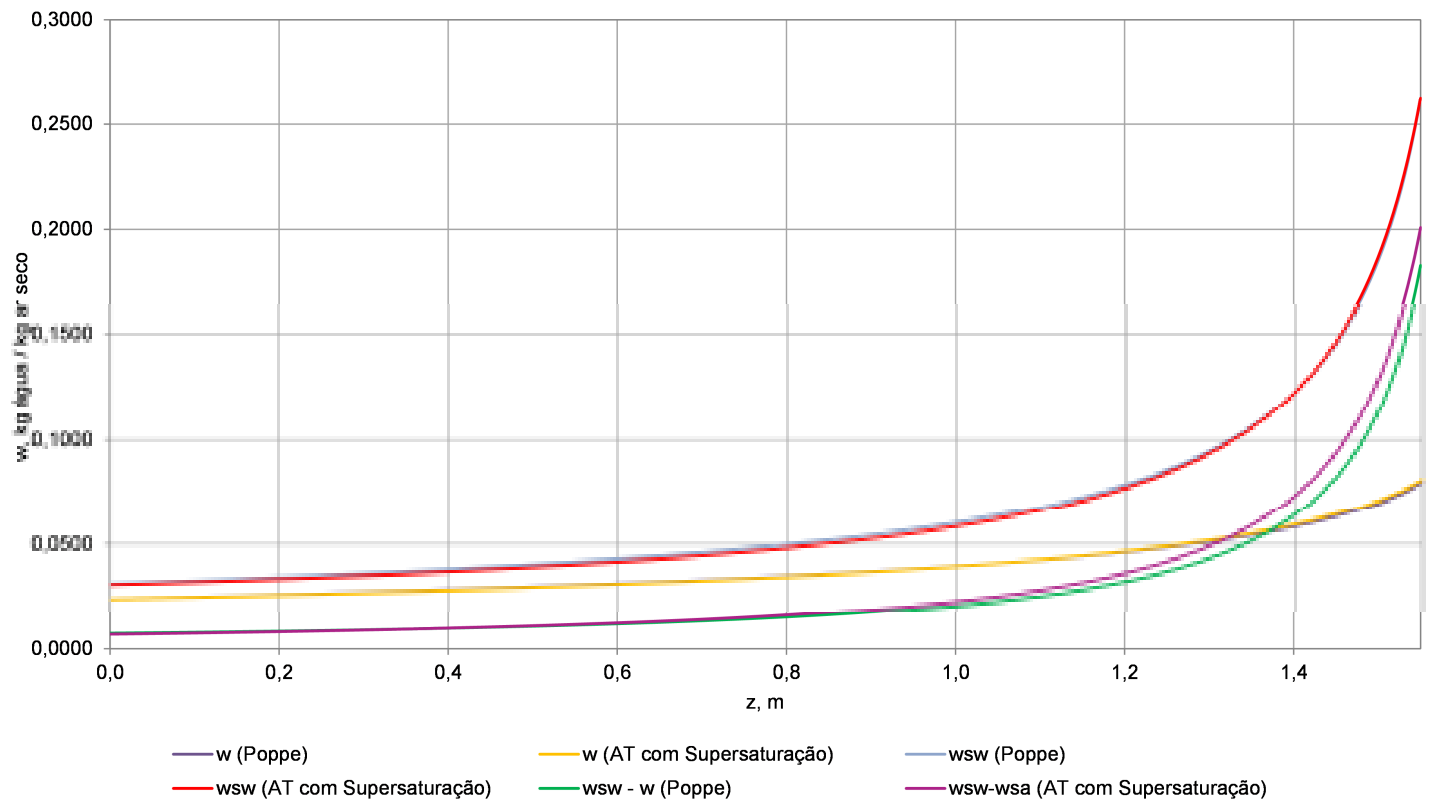


Figura 5.4 - Perfil de $w, w_{s a}$ e $w_{s w}$ ao longo da torre.

\subsection{Influência de $m_{w} / m_{a}$}

Os resultados especificados na Tabela 5.2 referem-se à simulação de uma torre de resfriamento variando-se a relação $m_{w} / m_{a}$ adotando-se os valores 1,2 e 3 .

As condições de entrada da água e do ar consideradas seguem abaixo.

Temperatura de entrada de água: $T_{\text {wo }}=60^{\circ} \mathrm{C}$

Temperatura de bulbo úmido do ar: $T_{b u 0}=20^{\circ} \mathrm{C}$

Temperatura de entrada do ar: $T_{a 0}=30^{\circ} \mathrm{C}$

Umidade: $w_{0}=0,0104 \mathrm{~kg}$ água $/ \mathrm{kg}$ ar seco $(U R=40 \%)$

Altura da torre: $z=2 \mathrm{~m}$

Em todos os casos, o ar entra com $T_{b u 0}$ de $20^{\circ} \mathrm{C}$, que corresponde a uma umidade relativa, UR, de 40\% e uma umidade absoluta de 0,0106 kg água/kg ar seco.

Tabela 5.2 - Comparação entre os resultados obtidos variando-se $m_{w} / m_{a}$.

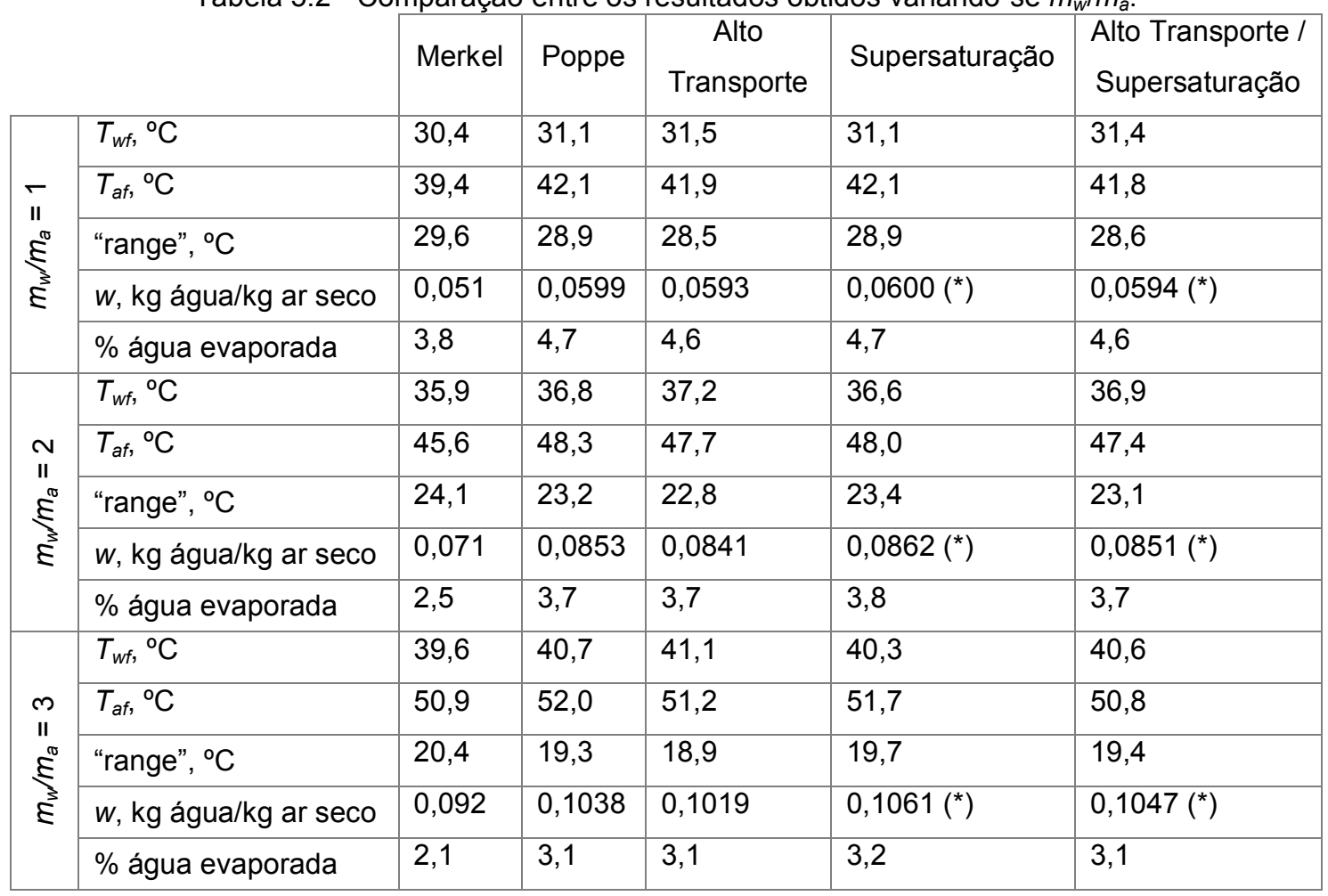

(*) Estes valores de umidade incluem a névoa formada devido à supersaturação do ar. 
Comparando-se todos os modelos, verifica-se que pelo método de Alto Transporte sempre tem-se uma $T_{w f}$ maior que os outros métodos de cálculos simulados.

Comparando-se os modelos Alto Transporte / Supersaturação e Supersaturação, o aumento da razão $m_{w} / m_{a}$ provoca uma diminuição entre as diferenças entre as umidades obtidas. Comparando-se os modelos Alto Tranporte com o modelo de Poppe, este último obtém uma umidade do ar de saída menor e uma temperatura da água de saída maior. Conforme comentado no item 5.2, isto se deve ao fato de o alto transporte levar em conta um fator $f_{1}$ no cálculo de $k_{w}$, que acarreta um transporte de massa inferior em relação ao modelo de Poppe. O modelo de Supersaturação obtém uma temperatura de saída da água inferior aos outros modelos, o que é explicado pelo fato de este modelo fazer a hipótese de formação de névoa, conforme também comentado no item 5.2.

Nota-se uma pequena diferença para as condições do ar de saída calculadas pelos modelos Poppe e Alto Transporte, Supersaturação e Alto Transporte / Supersaturação.

Conforme representado na Tabela 5.3, o aumento da razão $m_{w} / m_{a}$ diminui a altura da torre em que o ar supersatura, devido ao maior fluxo de evaporação.

Tabela 5.3 - Altura em que o ar saturou de acordo com a razão $m_{w} / m_{a}$.
\begin{tabular}{|l|l|}
\hline $\begin{array}{l}\text { Alto Transporte / } \\
\text { Supersaturação }\end{array}$ \\
\hline$m_{w} / m_{a}=1$ & 1,70 \\
\hline$m_{w} / m_{a}=2$ & 1,24 \\
\hline$m_{w} / m_{a}=3$ & 0,93 \\
\hline
\end{tabular}

As Figuras 5.5, 5.6 e 5,7 ilustram os perfis de temperatura da água e do ar ao longo da altura da torre para os modelos de Poppe e Alto Transporte mais Supersaturação. Observa-se que quanto maior a relação $m_{w} / m_{a}$, maior a diferença entre os perfis de temperatura do ar e os perfis de temperatura da água previstos pelos modelos. 


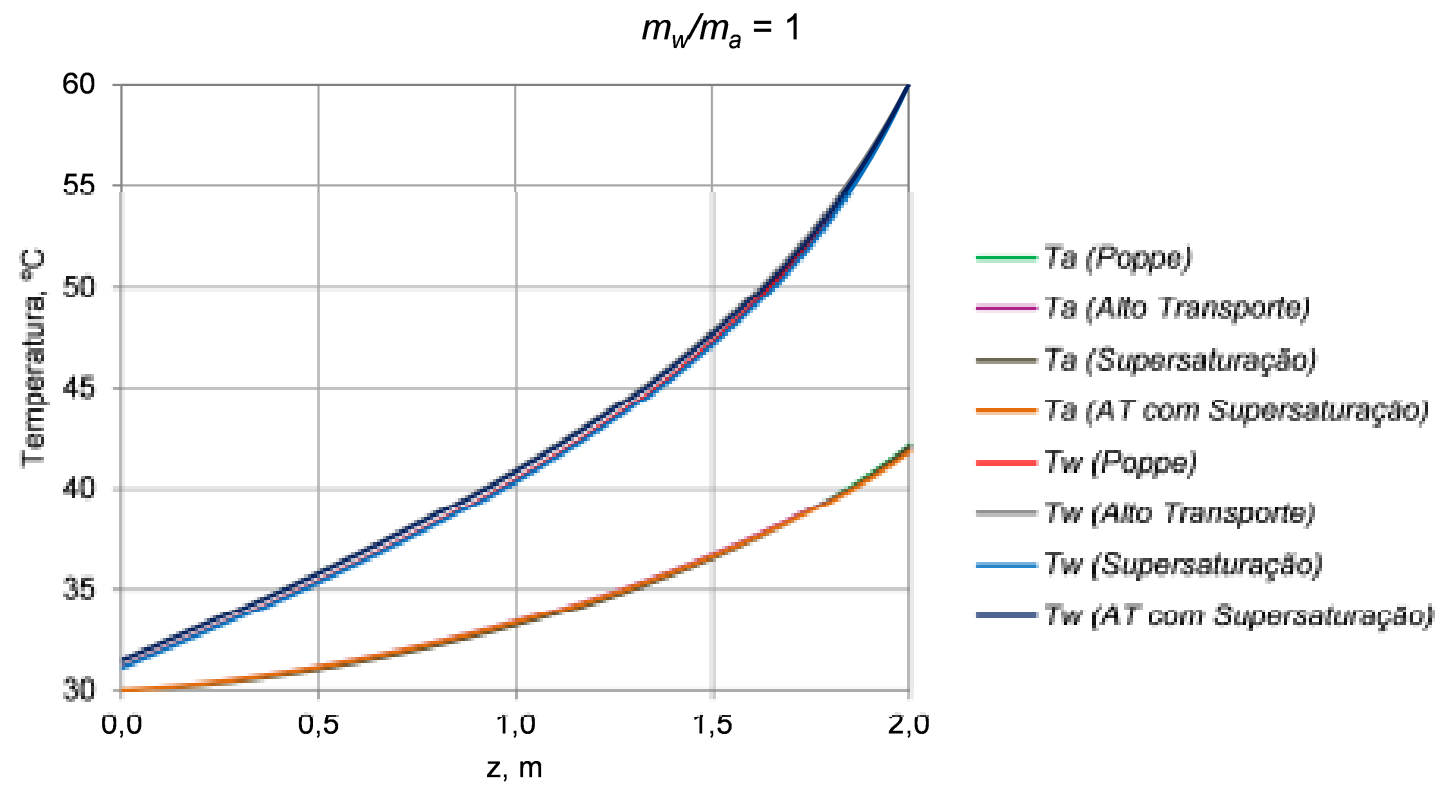

Figura 5.5 - Perfis de $T_{w}$ e $T_{a}$ para todos os modelos $\left(m_{w} / m_{a}=1\right)$.

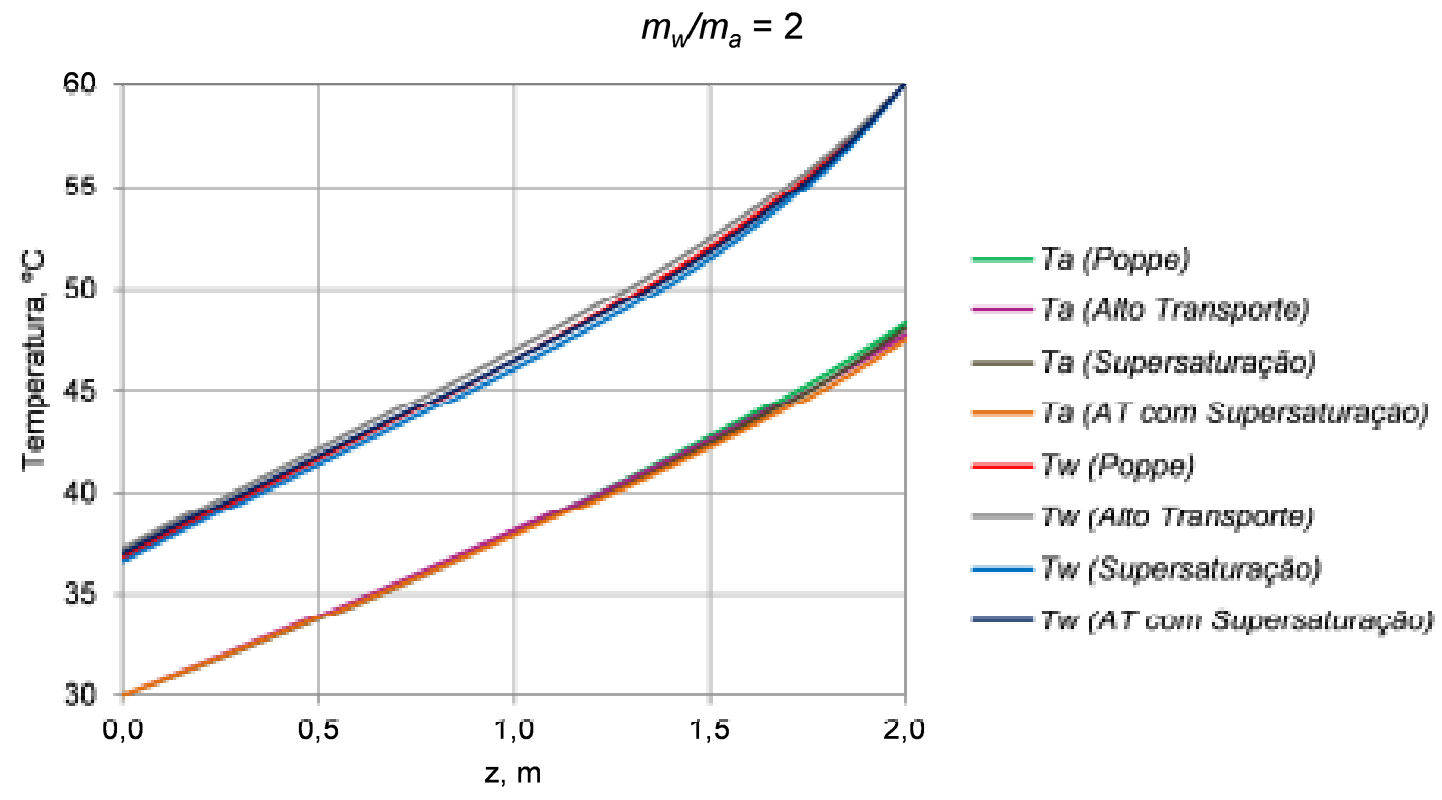

Figura 5.6 - Perfis de $T_{w}$ e $T_{a}$ para todos os modelos $\left(m_{w} / m_{a}=2\right)$. 


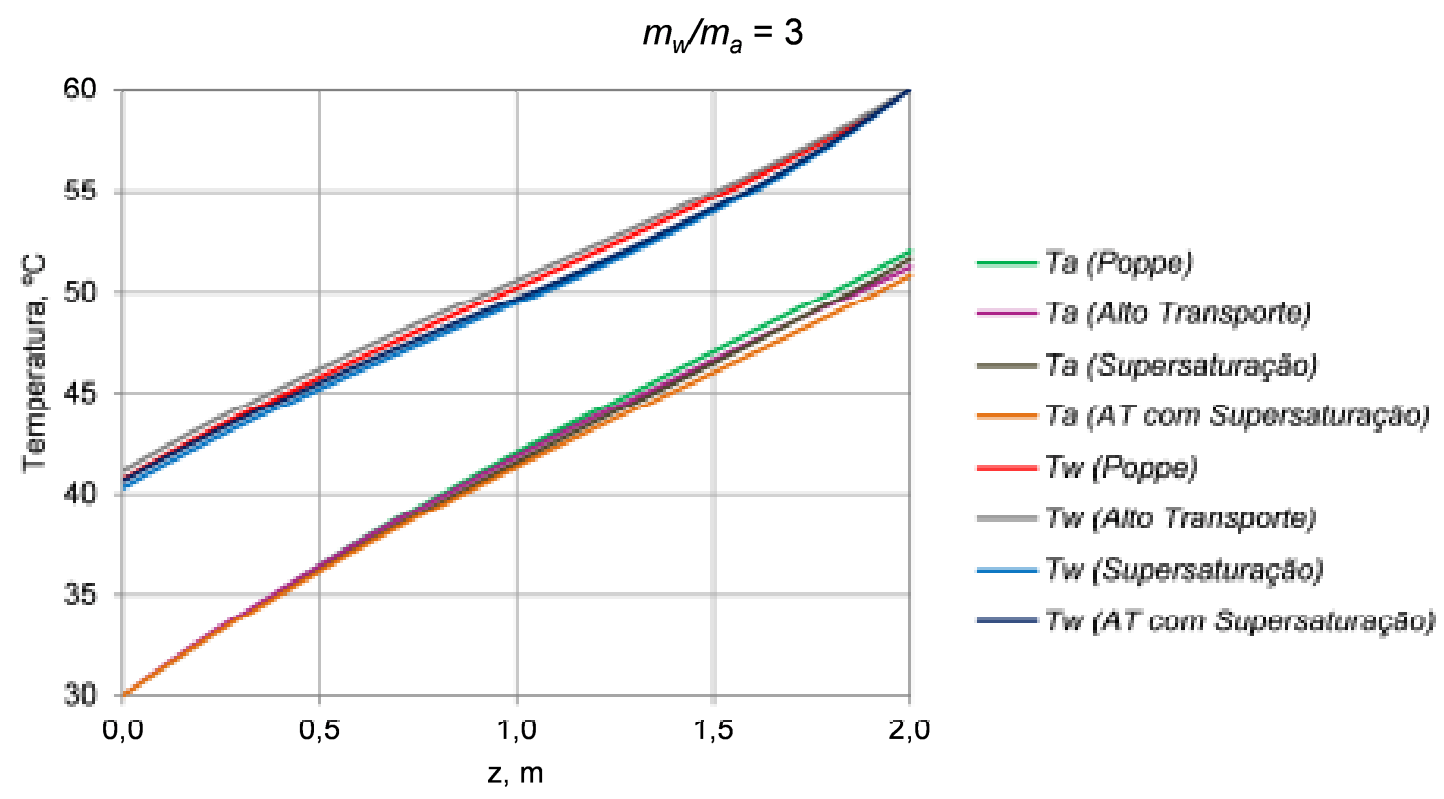

Figura 5.7 - Perfis de $T_{w}$ e $T_{a}$ para todos os modelos $\left(m_{w} / m_{a}=3\right)$.

As Figuras 5.8, 5.9 e 5.10 apresentam os perfis de umidade para os modelos Poppe, Supersaturação e Alto Transporte / Supersaturação e os perfis de névoa formada no decorrer da torre para os modelos Supersaturação e Alto Transporte I Supersaturação. Os perfis de umidade são praticamente coincidentes, apenas para o caso em que $m_{w} / m_{a}$ igual a 3 eles diferem um pouco. Por outro lado, nota-se que a diferença entre a quantidade de névoa formada considerando ou não o alto transporte aumenta quanto maior a razão $m_{w} / m_{a}$. A consideração do alto transporte de massa na modelagem de torres faz com que a saturação do ar ocorra em uma altura de torre menor e conforme as Figuras $5.10,5.11$ e 5.12 nota-se que a quantidade de névoa formada também é maior quando se leva em conta este fenômeno. 


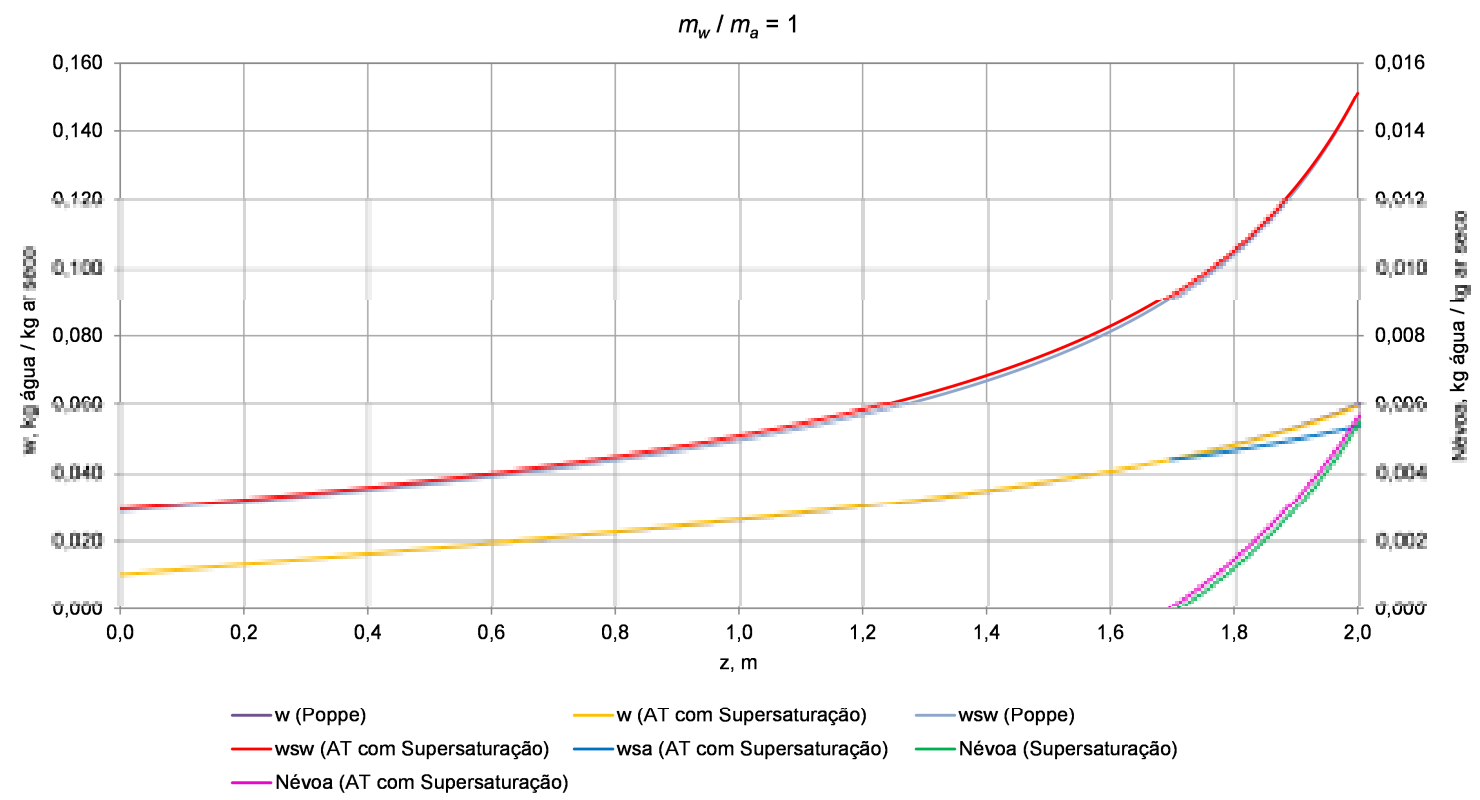

Figura 5.8 - Perfil de névoa, $w, w_{s a}, w_{s w}$ e névoa ao longo da torre para $m_{w} / m_{a}=1$.

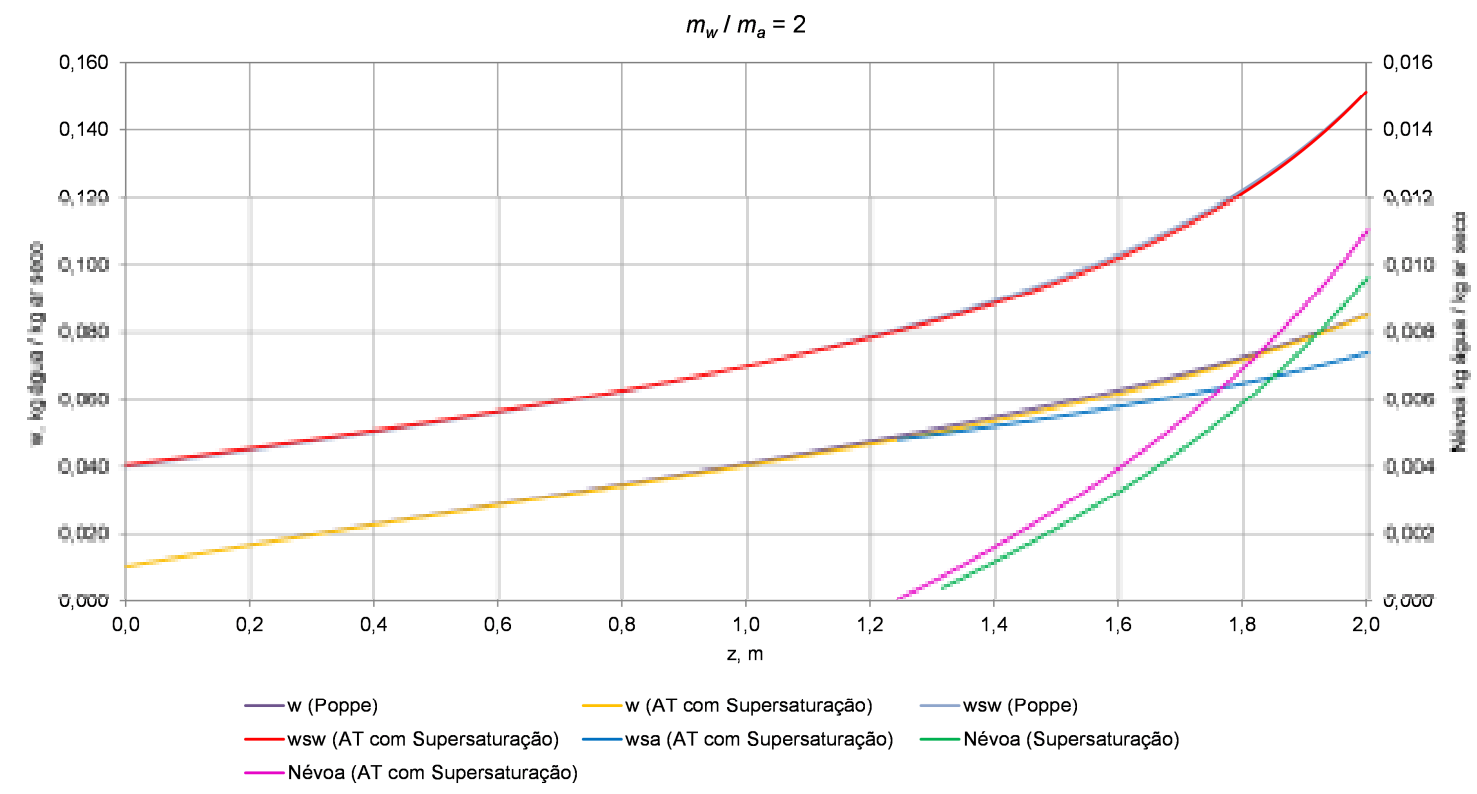

Figura 5.9 - Perfil de névoa, $w, w_{s a}, w_{s w}$ e névoa ao longo da torre para $m_{w} / m_{a}=2$. 


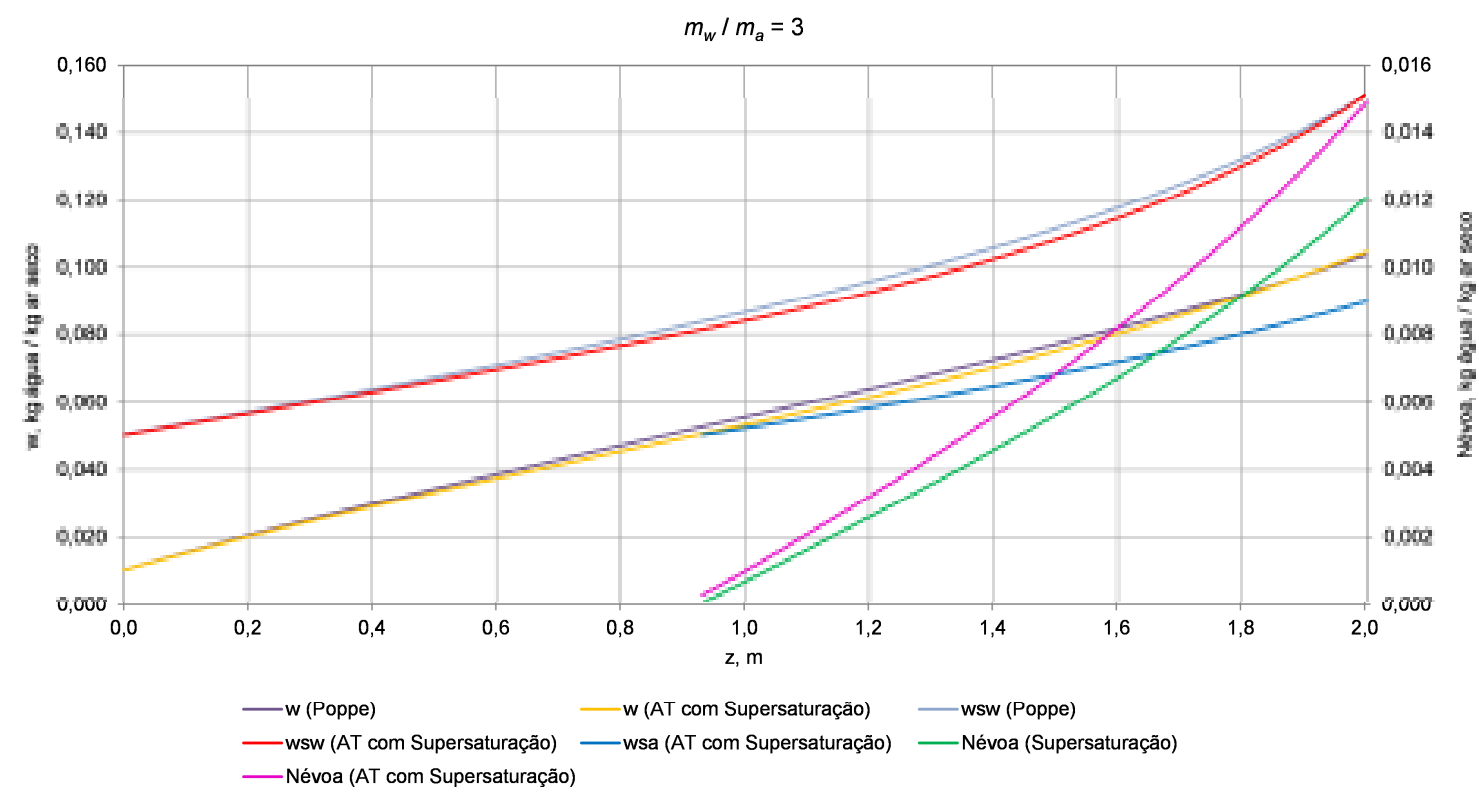

Figura 5.10 - Perfil de névoa, $w, w_{s a}, w_{s w}$ e névoa ao longo da torre para $m_{w} / m_{a}=3$.

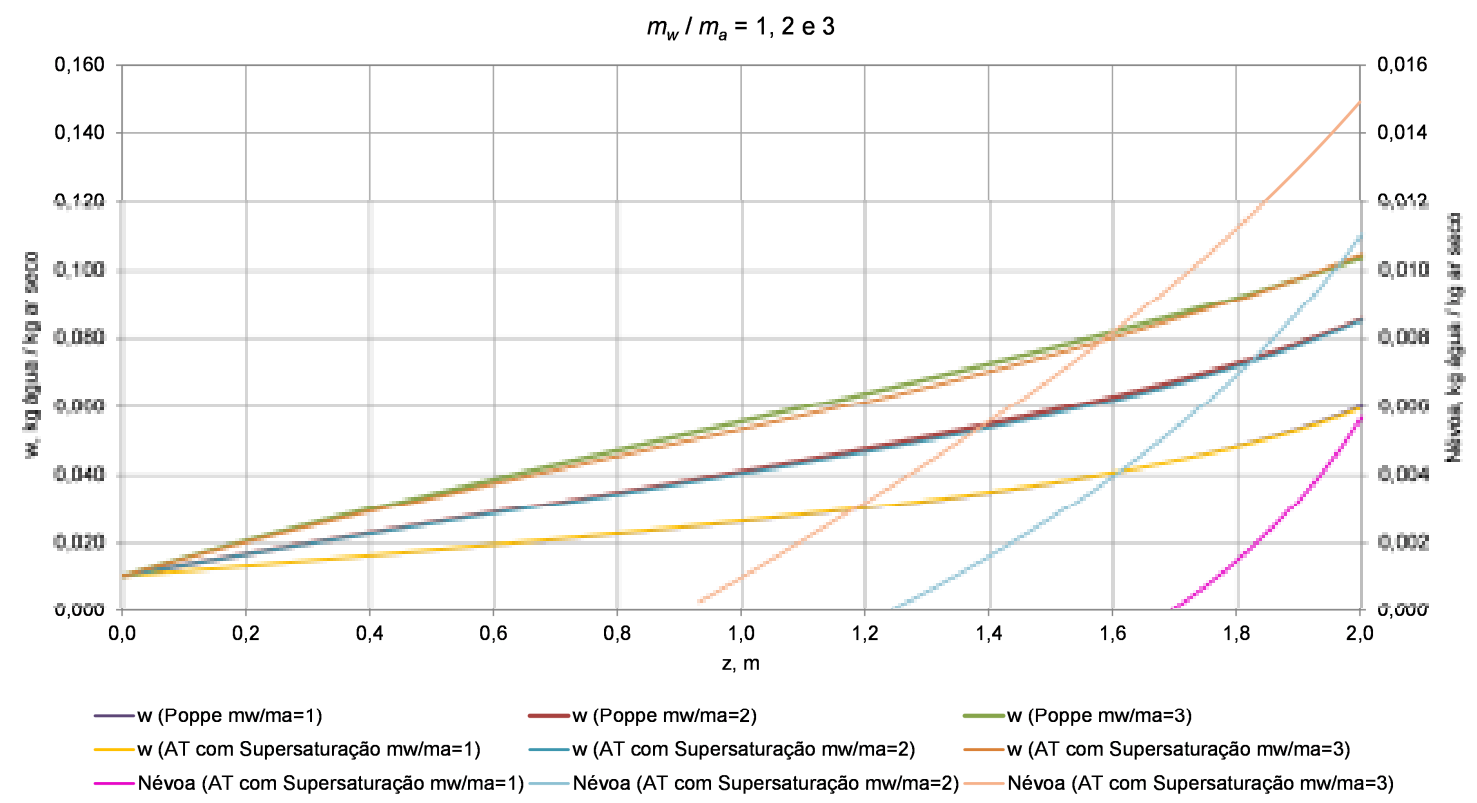

Figura 5.11 - Perfil de névoa, $w$ e névoa ao longo da torre para $m_{w} / m_{a}=1,2$ e 3

\subsection{Influência da $T_{\text {buo }}$}

Os resultados especificados na Tabela 5.4 referem-se à simulação de uma torre de resfriamento variando-se a temperatura de bulbo úmido, $T_{b u}$.

As condições de entrada da água e do ar seguem abaixo. 
Temperatura de entrada da água: $T_{w 0}=60^{\circ} \mathrm{C}$

Temperatura de entrada do ar: $T_{a 0}=30^{\circ} \mathrm{C}$

Vazão de água: $m_{w 0}=3,6 \mathrm{~kg} / \mathrm{s}$

Vazão de ar: $m_{a}=3,4 \mathrm{~kg} / \mathrm{s}$

Altura da torre: $z=2 \mathrm{~m}$

Tabela 5.4 - Comparação entre os resultados obtidos variando-se $T_{b u}$.

\begin{tabular}{|c|c|c|c|c|c|c|}
\hline & \multirow{3}{*}{$\begin{array}{l}\text { Merkel } \\
28,6\end{array}$} & \multirow{3}{*}{\begin{tabular}{|l|} 
Poppe \\
29,4
\end{tabular}} & \multirow{3}{*}{$\begin{array}{c}\text { Alto } \\
\text { Transporte } \\
29,8\end{array}$} & \multirow{3}{*}{$\begin{array}{l}\text { Supersaturação } \\
29,4\end{array}$} & \multirow{3}{*}{$\begin{array}{l}\text { Alto Transporte / } \\
\text { Supersaturação } \\
29,8\end{array}$} \\
\hline & & & & & & \\
\hline \multirow{6}{*}{ 范 } & $T_{w f},{ }^{\circ} \mathrm{C}$ & & & & & \\
\hline & $T_{a f},{ }^{\circ} \mathrm{C}$ & 39,4 & 41,7 & 41,5 & 41,7 & 41,5 \\
\hline & "range", ${ }^{\circ} \mathrm{C}$ & 31,4 & 30,6 & 30,2 & 30,6 & 30,2 \\
\hline & $w_{0}, \mathrm{~kg}$ água $/ \mathrm{kg}$ ar seco & \multicolumn{5}{|c|}{0,0045} \\
\hline & $w_{f}, \mathrm{~kg}$ água/kg ar seco & 0,048 & 0,0573 & 0,0568 & $0,0574\left(^{*}\right)$ & $0,0568\left(^{*}\right)$ \\
\hline & \% água evaporada & 4,1 & 5,0 & 4,9 & 5,0 & 5,0 \\
\hline \multirow{6}{*}{ 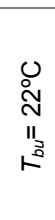 } & $T_{w f},{ }^{\circ} \mathrm{C}$ & 31,2 & 31,9 & 32,2 & 31,8 & 32,2 \\
\hline & $T_{a f},{ }^{\circ} \mathrm{C}$ & 40,6 & 42,3 & 42,1 & 42,2 & 42,0 \\
\hline & "range", ${ }^{\circ} \mathrm{C}$ & 28,8 & 28,1 & 27,8 & 28,2 & 27,8 \\
\hline & $w_{0}, \mathrm{~kg}$ água $/ \mathrm{kg}$ ar seco & \multicolumn{5}{|c|}{0,0134} \\
\hline & $w_{f}, \mathrm{~kg}$ água/kg ar seco & 0,051 & 0,0611 & 0,0605 & $0,0612\left(^{*}\right)$ & $0,0607\left(^{*}\right)$ \\
\hline & \% água evaporada & 3,6 & 4,5 & 4,5 & 4,5 & 4,5 \\
\hline \multirow{6}{*}{ 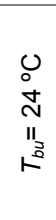 } & $T_{w f},{ }^{\circ} \mathrm{C}$ & 32,0 & 32,6 & 33,0 & 32,6 & 32,9 \\
\hline & $T_{a f},{ }^{\circ} \mathrm{C}$ & 41,4 & 42,5 & 42,2 & 42,4 & 42,1 \\
\hline & "range", ${ }^{\circ} \mathrm{C}$ & 28,0 & 27,4 & 27,0 & 27,4 & 27,1 \\
\hline & $w_{0}, \mathrm{~kg}$ água $/ \mathrm{kg}$ ar seco & \multicolumn{5}{|c|}{0,0161} \\
\hline & $w_{f}, \mathrm{~kg}$ água/ $\mathrm{kg}$ ar seco & 0,053 & 0,0623 & 0,0617 & $0,0624\left(^{*}\right)$ & $0,0619\left(^{*}\right)$ \\
\hline & \% água evaporada & 3,5 & 4,4 & 4,3 & 4,4 & 4,4 \\
\hline \multirow{6}{*}{ 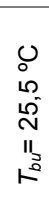 } & $T_{w f},{ }^{\circ} \mathrm{C}$ & 32,8 & 33,4 & 33,7 & 33,3 & 33,6 \\
\hline & $T_{a f},{ }^{\circ} \mathrm{C}$ & 41,7 & 42,7 & 42,4 & 42,5 & 42,2 \\
\hline & "range", ${ }^{\circ} \mathrm{C}$ & 27,2 & 26,6 & 26,3 & 26,7 & 26,4 \\
\hline & $w_{0}, \mathrm{~kg}$ água $/ \mathrm{kg}$ ar seco & \multicolumn{5}{|c|}{0,0189} \\
\hline & $w_{f}$, kg água/kg ar seco & 0,054 & 0,0625 & 0,0630 & $0,0637\left(^{*}\right)$ & $0,0633\left(^{*}\right)$ \\
\hline & \% água evaporada & 3,3 & 4,2 & 4,2 & 4,3 & 4,2 \\
\hline \multirow{6}{*}{$\begin{array}{l}0 \\
\vdots \\
\text { N } \\
11 \\
\text { Na }\end{array}$} & $T_{w f},{ }^{\circ} \mathrm{C}$ & 33,6 & 34,1 & 34,5 & 34,0 & 34,3 \\
\hline & $T_{a f},{ }^{\circ} \mathrm{C}$ & 41,9 & 42,9 & 42,6 & 42,7 & 42,3 \\
\hline & "range", ${ }^{\circ} \mathrm{C}$ & 26,4 & 25,9 & 25,5 & 26,0 & 25,7 \\
\hline & $w_{0}, \mathrm{~kg}$ água $/ \mathrm{kg}$ ar seco & \multicolumn{5}{|c|}{0,0217} \\
\hline & $w_{f}, \mathrm{~kg}$ água/kg ar seco & 0,055 & 0,0647 & 0,0643 & $0,0651\left(^{*}\right)$ & $0,0647\left(^{*}\right)$ \\
\hline & $\%$ água evaporada & 3,1 & 4,1 & 4,0 & 4,1 & 4,1 \\
\hline \multirow{6}{*}{$\begin{array}{l}0 \\
0 \\
0 \\
\infty \\
N \\
2 \\
0 \\
1\end{array}$} & $T_{w f},{ }^{\circ} \mathrm{C}$ & 34,3 & 34,9 & 35,2 & 34,6 & 34,9 \\
\hline & $T_{a f},{ }^{\circ} \mathrm{C}$ & 42,5 & 43,1 & 42,7 & 42,8 & 42,4 \\
\hline & "range", ${ }^{\circ} \mathrm{C}$ & 25,7 & 25,1 & 24,8 & 25,4 & 25,1 \\
\hline & $w_{0}, \mathrm{~kg}$ água $/ \mathrm{kg}$ ar seco & \multicolumn{5}{|c|}{0,0245} \\
\hline & $w_{f}, \mathrm{~kg}$ água/kg ar seco & 0,056 & 0,0660 & 0,0656 & $0,0666\left(^{*}\right)$ & $0,0663\left(^{*}\right)$ \\
\hline & $\%$ água evaporada & 3,0 & 3,9 & 3,9 & 4,0 & 4,0 \\
\hline \multirow{6}{*}{ 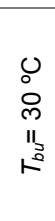 } & $T_{w f},{ }^{\circ} \mathrm{C}$ & 35,1 & 35,6 & 35,9 & 35,0 & 35,3 \\
\hline & $T_{a f},{ }^{\circ} \mathrm{C}$ & 42,8 & 43,3 & 42,9 & 42,9 & 42,4 \\
\hline & "range", ${ }^{\circ} \mathrm{C}$ & 24,9 & 24,4 & 24,1 & 25,0 & 24,7 \\
\hline & $w_{0}, \mathrm{~kg}$ água $/ \mathrm{kg}$ ar seco & \multicolumn{5}{|c|}{0,0273} \\
\hline & $w_{f}, \mathrm{~kg}$ água/kg ar seco & 0,057 & 0,0673 & 0,0669 & $0,0686\left(^{*}\right)$ & $0,0683\left(^{*}\right)$ \\
\hline & $\%$ água evaporada & 2,8 & 3,8 & 3,8 & 3,9 & 3,9 \\
\hline
\end{tabular}

(*) Estes valores de umidade incluem a névoa formada devido à supersaturação do ar. 


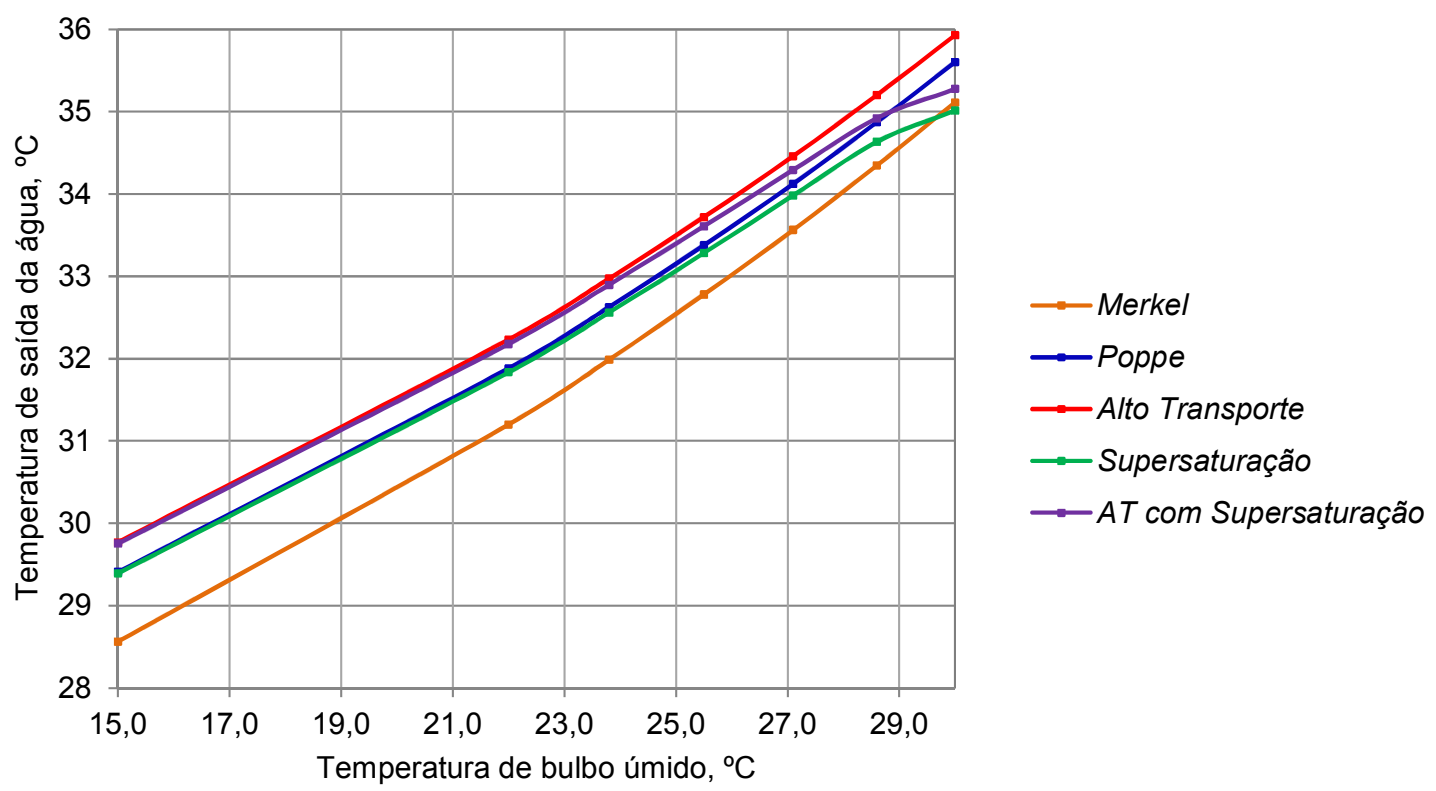

Figura 5.12 - Temperatura de saída da água versus temperatura de temperatura de bulbo úmido na entrada.

Observando a Tabela 5.4, nota-se que os resultados são muito próximos para os modelos Alto Transporte e Alto Transporte com Supersaturação.

A Figura 5.12 ilustra a influência da $T_{b u}$ (umidade do ar) na temperatura de saída da água, para os diferentes modelos. Sistematicamente, o método de Merkel fornece temperaturas de água inferiores às dos demais modelos. Os modelos de Poppe e de Supersaturação fornecem valores muito próximos para ar entrando com umidade mais baixa, no entanto para ar mais úmido, os resultados tendem a ser diferentes devido à rápida saturação do mesmo. Analogamente, comparando-se os modelos AT e AT com supersaturação, também se nota que eles diferem com o aumento da umidade do ar.

Na Tabela 5.5 segue uma comparação entre as umidades do ar na saída da torre obtidas pelo método de Merkel e pelos outros modelos. As umidades obtidas pelos diferentes modelos sempre variam entre 15 e 20\%, tanto para o ar entrando mais seco quanto para o ar entrando mais úmido. 
Tabela 5.5 - Diferença entre as umidades do ar que deixa a torre calculadas para os modelos.

\begin{tabular}{|l|l|l|l|}
\cline { 2 - 4 } & \multicolumn{1}{|c|}{ Merkel } & \multicolumn{1}{|c|}{ Merkel } & \multicolumn{1}{|c|}{ Merkel } \\
\cline { 2 - 4 } & Poppe & $\begin{array}{c}\text { Alto Transporte / } \\
\text { Supersaturação }\end{array}$ & Supersaturação \\
\hline$T_{b u}=15,0^{\circ} \mathrm{C}$ & $16,23 \%$ & $15,49 \%$ & $16,38 \%$ \\
\hline$T_{b u}=22,0^{\circ} \mathrm{C}$ & $19,8 \%$ & $19,0 \%$ & $20,0 \%$ \\
\hline$T_{b u}=24,0^{\circ} \mathrm{C}$ & $17,6 \%$ & $16,8 \%$ & $17,7 \%$ \\
\hline$T_{b u}=25,5^{\circ} \mathrm{C}$ & $15,7 \%$ & $17,2 \%$ & $18,0 \%$ \\
\hline$T_{b u}=27,1^{\circ} \mathrm{C}$ & $17,6 \%$ & $17,6 \%$ & $18,4 \%$ \\
\hline$T_{b u}=28,6^{\circ} \mathrm{C}$ & $17,9 \%$ & $18,4 \%$ & $18,9 \%$ \\
\hline$T_{b u}=30,0^{\circ} \mathrm{C}$ & $18,1 \%$ & $19,8 \%$ & $20,4 \%$ \\
\hline
\end{tabular}

Na Tabela 5.6 são explicitadas as alturas em que houve saturação do ar conforme alterado a temperatura de bulbo úmido do ar de entrada da torre. Quanto maior a umidade do ar de entrada, menor a altura na qual ocorre a supersaturação.

Tabela 5.6 - Altura em que o ar saturou de acordo com $T_{b u}$.

\begin{tabular}{|l|l|}
\cline { 2 - 2 } \multicolumn{1}{c|}{} & $\begin{array}{c}\text { Alto Transporte } / \\
\text { Supersaturação }\end{array}$ \\
\hline$T_{b u}=15,0^{\circ} \mathrm{C}$ & 1,84 \\
\hline$T_{b u}=22,0^{\circ} \mathrm{C}$ & 1,63 \\
\hline$T_{b u}=24,0^{\circ} \mathrm{C}$ & 1,53 \\
\hline$T_{b u}=25,5^{\circ} \mathrm{C}$ & 1,41 \\
\hline$T_{b u}=27,1^{\circ} \mathrm{C}$ & 1,17 \\
\hline$T_{b u}=28,6^{\circ} \mathrm{C}$ & 0,87 \\
\hline$T_{b u}=30^{\circ} \mathrm{C}$ & 0,00 \\
\hline
\end{tabular}

Os perfis de temperatura da água e do ar para todos os modelos, exceto Merkel, seguem representados nas Figuras 5.13, 5.14 e 5.15. Observa-se que quanto maior 
a umidade relativa do ar que entra na torre ou maior a $T_{b u}$, mais distantes são os perfis de $T_{w}$. Os perfis de $T_{a}$ são bastante próximos.

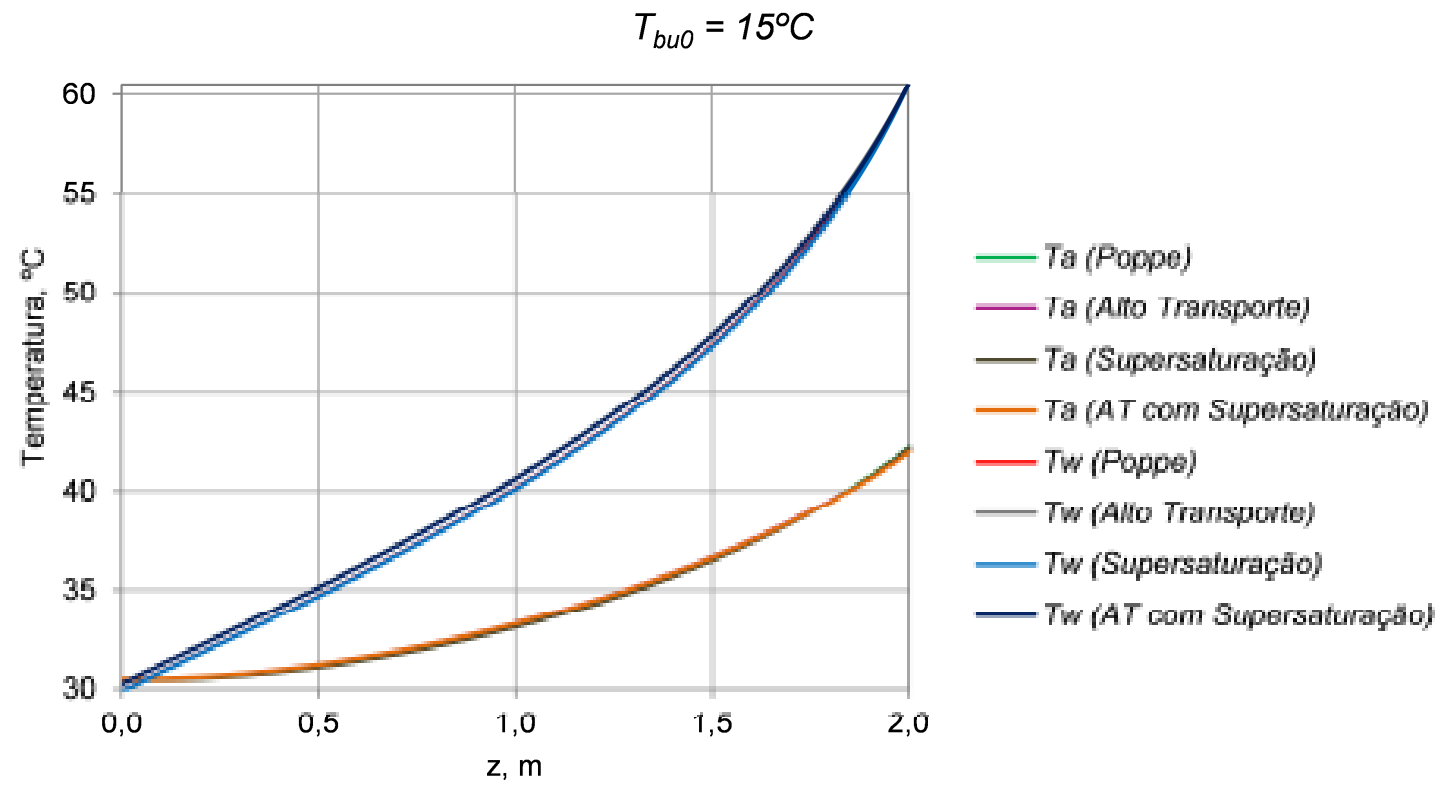

Figura 5.13 - Perfis de $T_{w}$ e $T_{a}$ para todos os modelos $\left(T_{\text {buo }}=15^{\circ} \mathrm{C}\right)$.

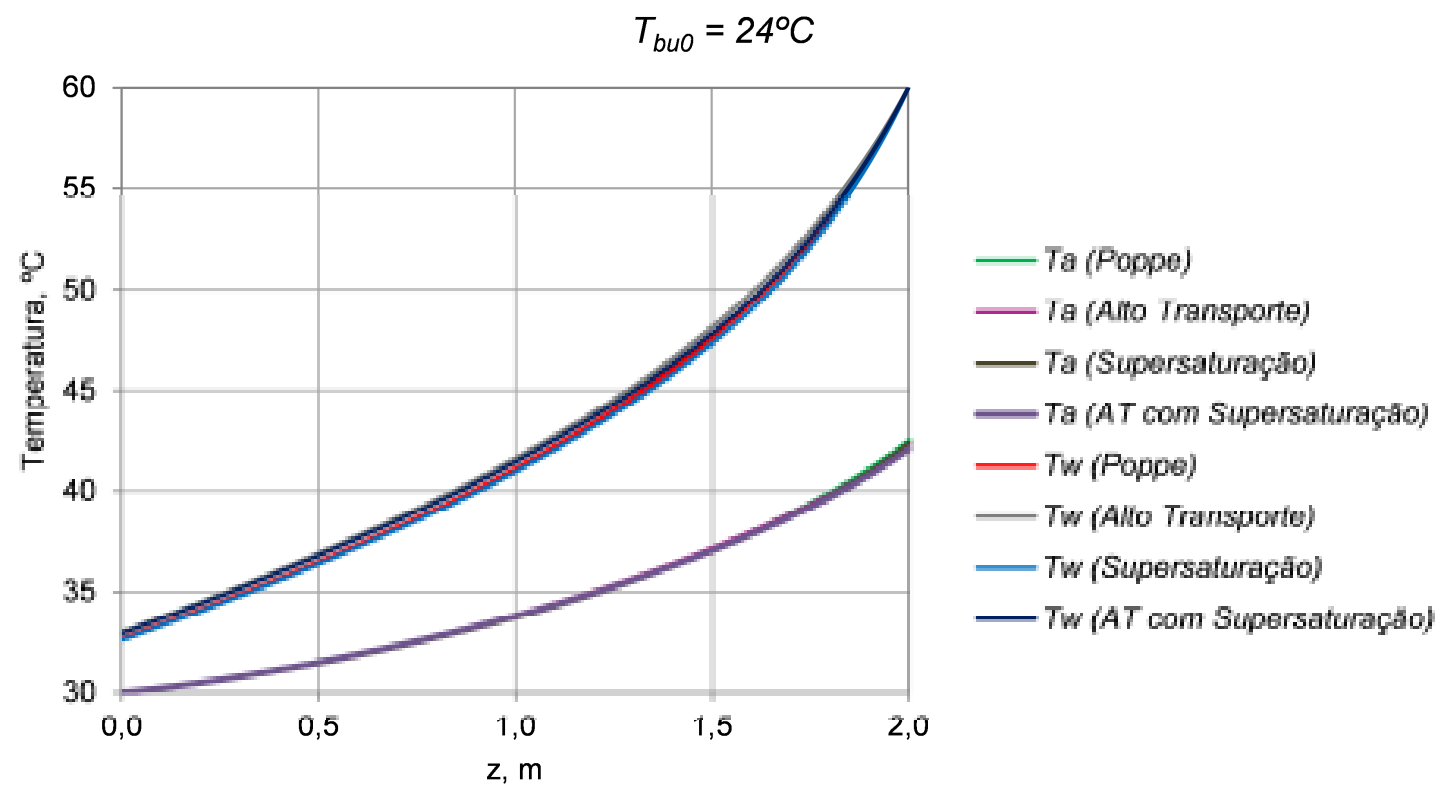

Figura 5.14 - Perfis de $T_{w}$ e $T_{a}$ para todos os modelos $\left(T_{\text {buo }}=24^{\circ} \mathrm{C}\right)$. 


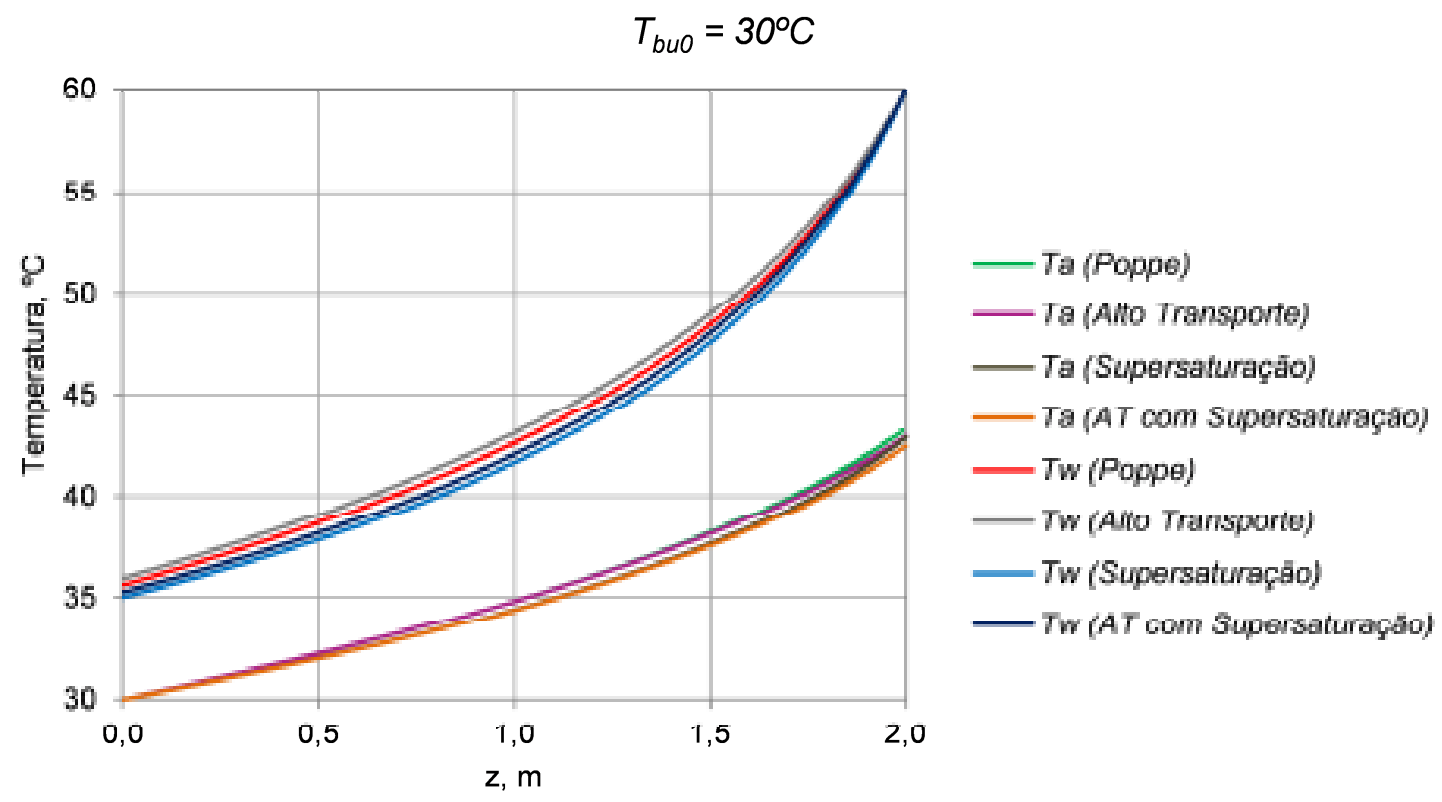

Figura 5.15 - Perfis de $T_{w}$ e $T_{a}$ para todos os modelos $\left(T_{b u 0}=30^{\circ} \mathrm{C}\right)$.

A partir dos gráficos das Figuras 5.16, 5.17 e 5.18, nota-se que quanto mais úmido o ar de entrada na torre, antes ele satura e maior é a diferença entre os perfis de névoa obtidos pelos modelo supersaturação e alto transporte com supersaturação. Os perfis de umidade são praticamente coincidentes. 


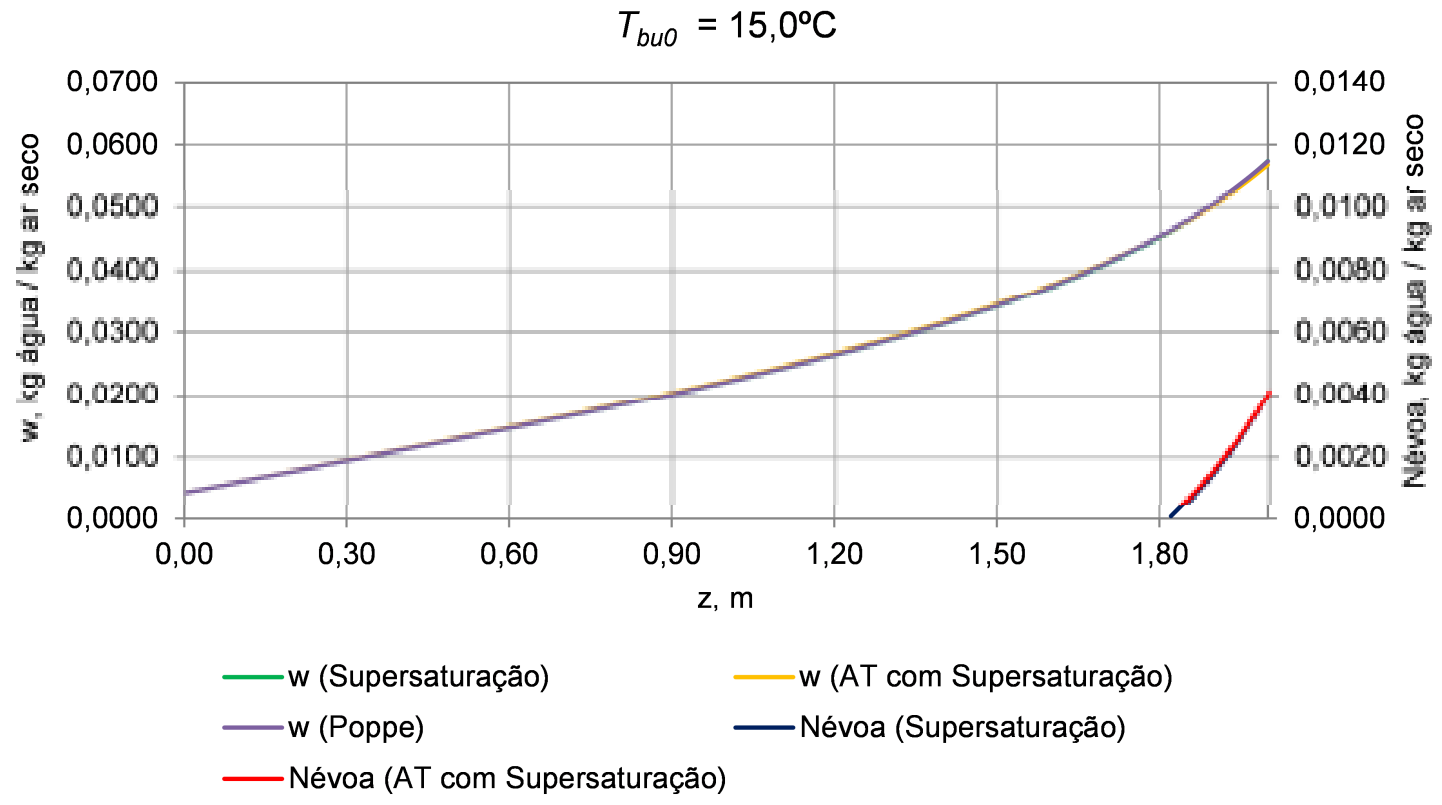

Figura 5.16 - Perfil de névoa formada e umidade ao longo da torre, para $T_{b u}=15^{\circ} \mathrm{C}$.

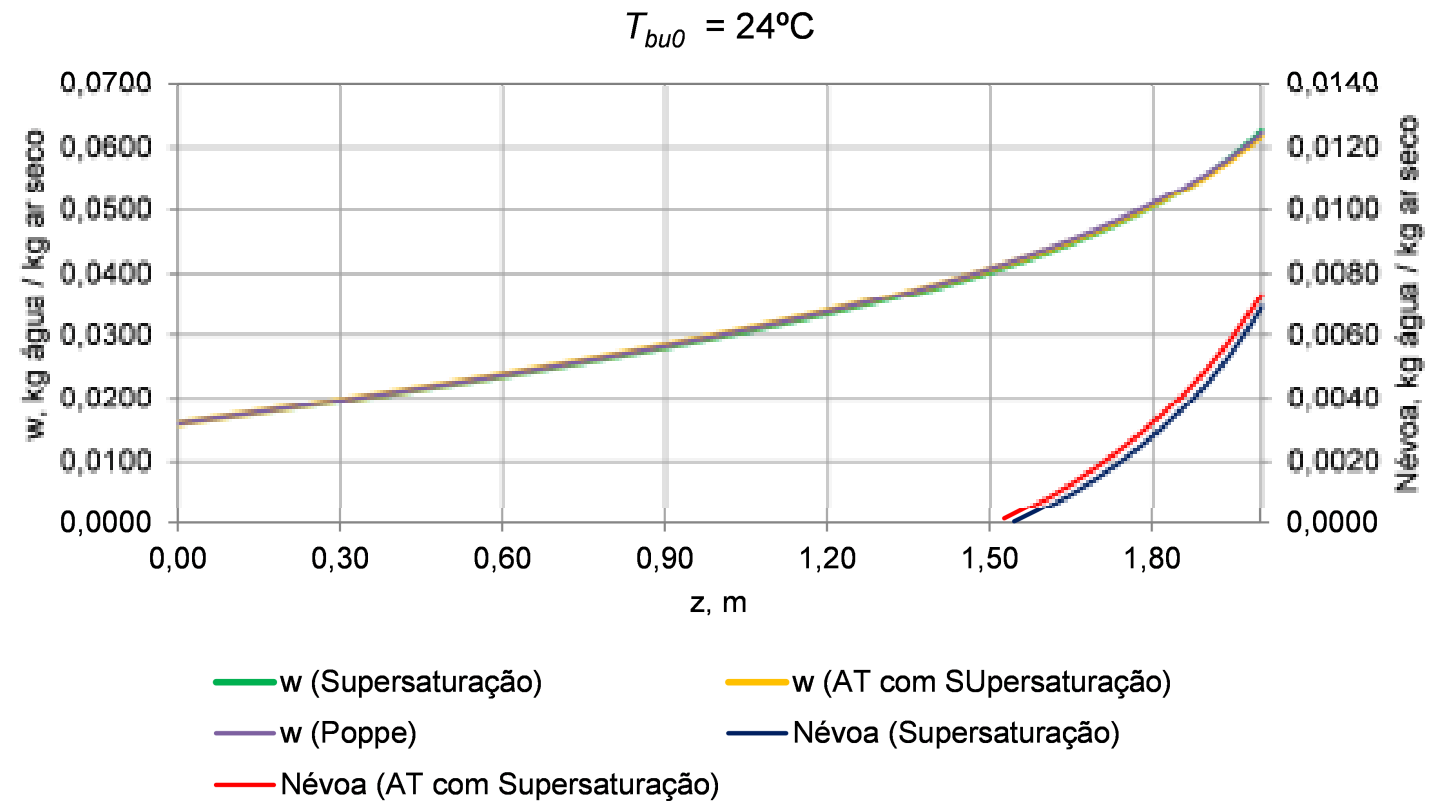

Figura 5.17 - Perfil de névoa formada e umidade ao longo da torre, para $T_{b u}=24^{\circ} \mathrm{C}$. 


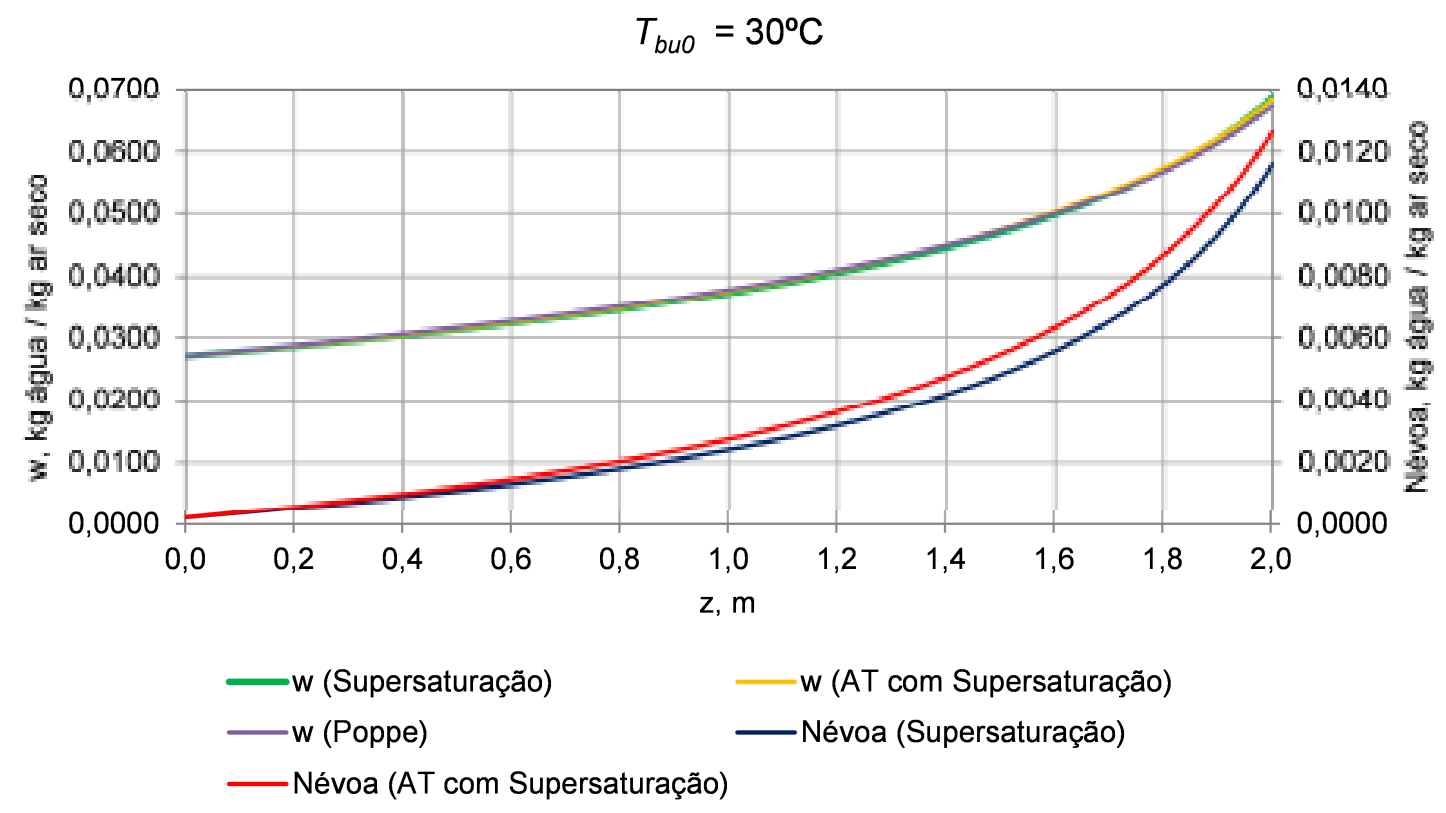

Figura 5.18 - Perfil de névoa formada e umidade ao longo da torre, para $T_{b u}=30^{\circ} \mathrm{C}$.

\subsection{Influência da $T_{\text {wo }}$}

Os resultados especificados na Tabela 5.7 referem-se à simulação de uma torre de resfriamento variando-se a temperatura de entrada da água, $T_{\text {wo }}$.

As condições de operação consideradas são apresentadas a seguir.

Temperatura de bulbo úmido do ar: $T_{\text {bu }}=20^{\circ} \mathrm{C}$

Temperatura de entrada do ar: $T_{a 0}=30^{\circ} \mathrm{C}$

Umidade: $w_{0}=0,0104 \mathrm{~kg}$ água $/ \mathrm{kg}$ ar seco $(U R=40 \%)$

Vazão de água: $m_{w 0}=3,6 \mathrm{~kg} / \mathrm{s}$

Vazão de ar: $m_{a}=3,4 \mathrm{~kg} / \mathrm{s}$

Altura da torre: $z=2 \mathrm{~m}$ 
Tabela 5.7 - Comparação entre os resultados obtidos variando-se $T_{\text {wo }}$.

\begin{tabular}{|c|c|c|c|c|c|c|}
\hline & & & & & \\
\hline & & Merkel & Poppe & $\begin{array}{c}\text { Alto } \\
\text { Transporte }\end{array}$ & Supersaturação & $\begin{array}{l}\text { Alto Transporte / } \\
\text { Supersaturação }\end{array}$ \\
\hline \multirow{5}{*}{ 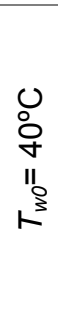 } & $T_{w f},{ }^{\circ} \mathrm{C}$ & 27,2 & 27,7 & 27,8 & $-\left({ }^{* *}\right)$ & $-\left({ }^{* *}\right)$ \\
\hline & $T_{a f},{ }^{\circ} \mathrm{C}$ & 29,4 & 33,8 & 33,7 & $-\left({ }^{* *}\right)$ & $-\left({ }^{* *}\right)$ \\
\hline & "range", ${ }^{\circ} \mathrm{C}$ & 12,8 & 12,3 & 12,2 & $-\left({ }^{* *}\right)$ & $-\left({ }^{* *}\right)$ \\
\hline & $\begin{array}{l}\text { w, kg água/kg ar } \\
\text { seco }\end{array}$ & 0,027 & 0,0314 & 0,0312 & $-\left({ }^{* *}\right)$ & $-\left({ }^{* *}\right)$ \\
\hline & \% água evaporada & 1,6 & 2,0 & 2,0 & $-\left({ }^{* *}\right)$ & $-\left({ }^{* *}\right)$ \\
\hline \multirow{5}{*}{ 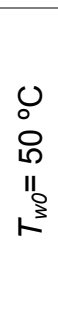 } & $T_{w f},{ }^{\circ} \mathrm{C}$ & 29,2 & 29,8 & 30,1 & 29,8 & 30,1 \\
\hline & $T_{a f},{ }^{\circ} \mathrm{C}$ & 48,3 & 38,3 & 38,2 & 38,3 & 38,2 \\
\hline & "range", ${ }^{\circ} \mathrm{C}$ & 20,8 & 20,2 & 19,9 & 20,2 & 19,9 \\
\hline & $\begin{array}{l}\text { w, kg água/kg ar } \\
\text { seco }\end{array}$ & 0,064 & 0,0445 & 0,0441 & $0,0445\left(^{*}\right)$ & $0,0441\left(^{*}\right)$ \\
\hline & \% água evaporada & 2,5 & 3,2 & 3,2 & 3,2 & 3,2 \\
\hline \multirow{5}{*}{ 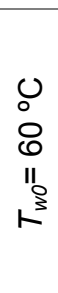 } & $T_{w f},{ }^{\circ} \mathrm{C}$ & 30,4 & 31,1 & 31,5 & 31,1 & 31,4 \\
\hline & $T_{a f},{ }^{\circ} \mathrm{C}$ & 35,0 & 42,1 & 41,9 & 42,1 & 41,8 \\
\hline & "range", ${ }^{\circ} \mathrm{C}$ & 29,6 & 28,9 & 28,5 & 28,9 & 28,6 \\
\hline & $w, \mathrm{~kg}$ água/kg ar & 0,035 & 0,0599 & 0,0593 & $0,060\left(^{*}\right)$ & $0,0594\left(^{*}\right)$ \\
\hline & \% água evaporada & 3,8 & 4,7 & 4,6 & 4,7 & 4,6 \\
\hline \multirow{5}{*}{$\begin{array}{l}0 \\
\circ \\
\circ \\
11 \\
N^{3} \\
\end{array}$} & $T_{w f},{ }^{\circ} \mathrm{C}$ & 31,1 & 31,8 & 32,3 & 31,8 & 32,2 \\
\hline & $T_{a f},{ }^{\circ} \mathrm{C}$ & 45,0 & 45,2 & 44,9 & 45,1 & 44,8 \\
\hline & "range", ${ }^{\circ} \mathrm{C}$ & 38,9 & 38,9 & 37,7 & 38,2 & 37,8 \\
\hline & $w, \mathrm{~kg}$ água/kg ar & 0,065 & 0,0772 & 0,0765 & $0,0774\left(^{*}\right)$ & $0,0767\left(^{*}\right)$ \\
\hline & \% água evaporada & 5,1 & 6,3 & 6,2 & 6,3 & 6,3 \\
\hline \multirow{5}{*}{$\begin{array}{l}0 \\
\circ \\
\infty \\
\infty \\
11 \\
\wp \\
1\end{array}$} & $T_{w f},{ }^{\circ} \mathrm{C}$ & 31,6 & 32,2 & 32,8 & 32,1 & 32,7 \\
\hline & $T_{a f},{ }^{\circ} \mathrm{C}$ & 48,6 & 47,7 & 47,4 & 47,6 & 47,3 \\
\hline & "range", ${ }^{\circ} \mathrm{C}$ & 48,4 & 47,8 & 47,2 & 47,9 & 47,3 \\
\hline & $w, \mathrm{~kg}$ água/kg ar & 0,08 & 0,0961 & 0,0952 & $0,0964\left(^{*}\right)$ & $0,0954\left(^{*}\right)$ \\
\hline & \% água evaporada & 6,6 & 8,1 & 8,0 & 8,1 & 8,0 \\
\hline
\end{tabular}

$\left({ }^{*}\right)$ Estes valores de umidade incluem a névoa formada devido à supersaturação do ar.

$\left.{ }^{(* *}\right) \mathrm{O}$ ar não supersatura para $T_{\text {wo }}=40^{\circ} \mathrm{C}$.

A Figura 5.19 ilustra a influência da temperatura de entrada da água na temperatura de saída da água. Conforme observado no item 5.4, o método de Merkel fornece temperaturas de água inferiores às dos demais modelos. Observa-se também que para temperaturas maiores de entrada da água, maior a diferença entre as 
temperaturas de saída da água para os modelos Poppe e Supersaturação. Os modelos AT e AT com supersaturação também diferem mais com o aumento da temperatura de entrada da água.

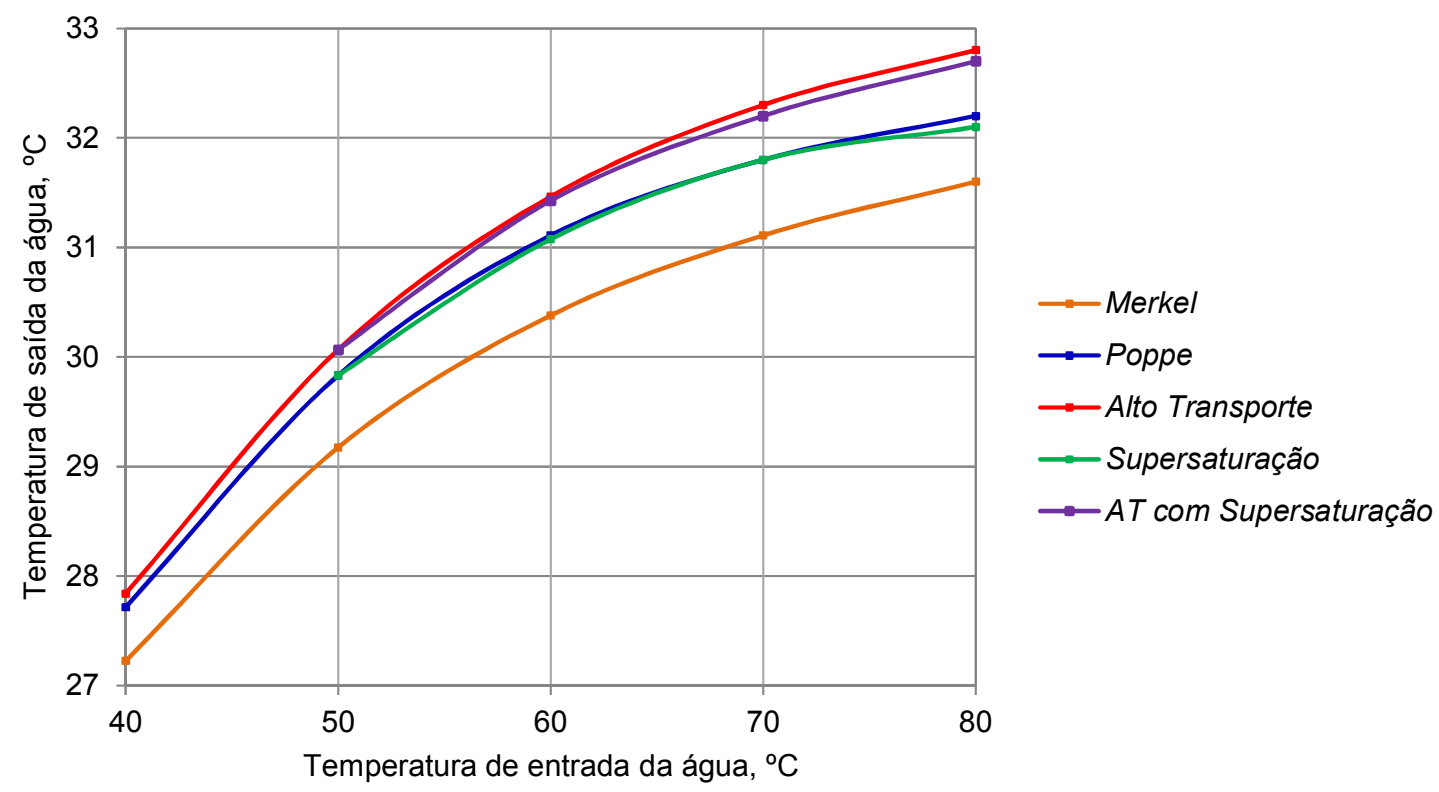

Figura 5.19 - Temperatura de saída da água versus temperatura de entrada da água.

As umidades do ar de saída obtidas pelos modelos são praticamente coincidentes. No entanto, para o modelo de Merkel, a umidade obtida é sempre menor, quando comparada aos demais modelos. O que era esperado, dado que o Merkel assume a umidade do ar de saída como igual a de um ar saturado, quando na verdade, este ar já está supersaturado. 


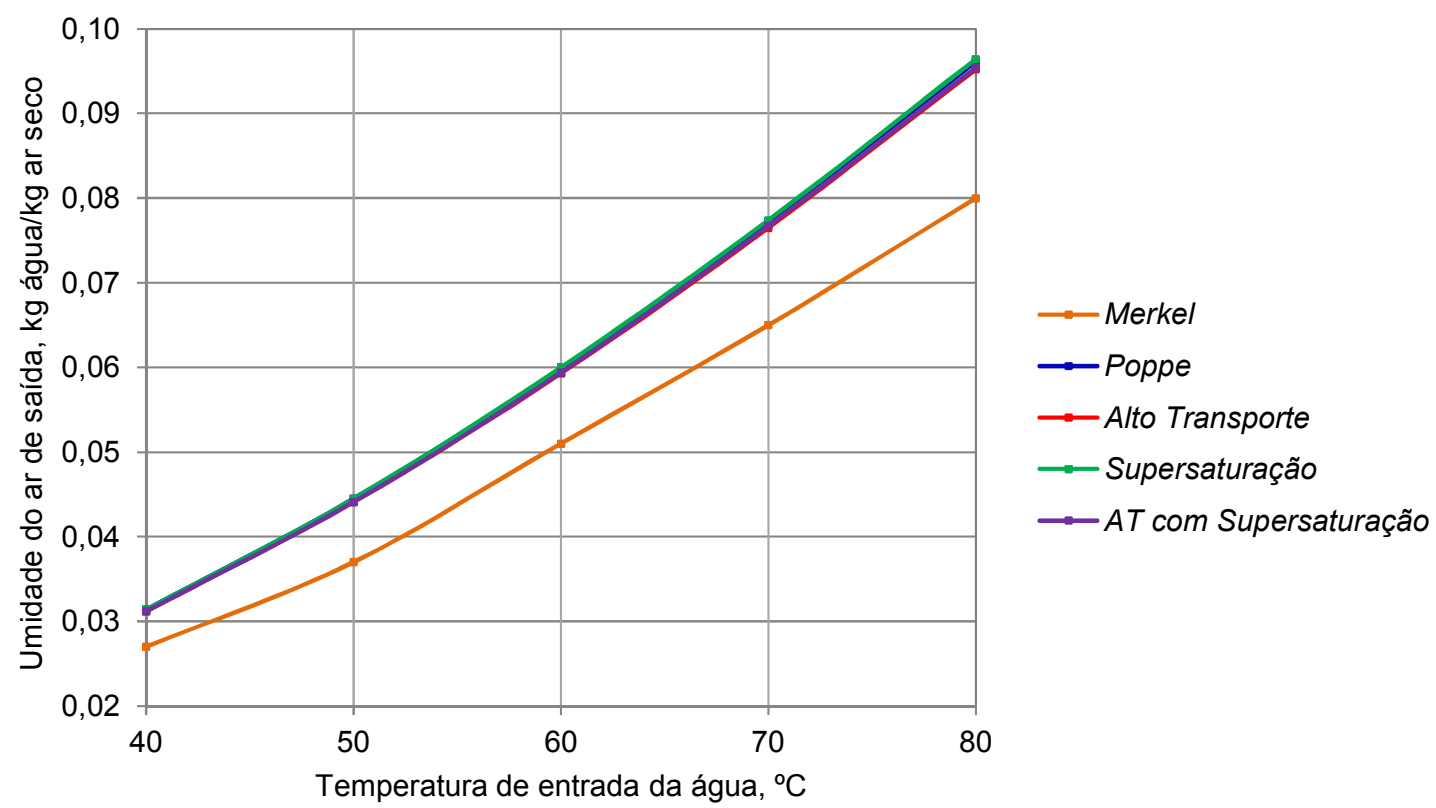

Figura 5.20 - Umidade do ar de saída versus temperatura de entrada da água.

Em relação à altura da torre em que o ar satura, analisando-se a Tabela 5.8 concluise que quanto maior a temperatura de entrada da água, menor é a altura em que ocorre a supersaturação do ar.

Tabela 5.8 - Altura em que o ar saturou de acordo com a $T_{\text {wo }}$.

\begin{tabular}{|l|l|}
\cline { 2 - 2 } \multicolumn{1}{c|}{} & \multicolumn{1}{|c|}{$\begin{array}{c}\text { Alto Transporte } / \\
\text { Supersaturação }\end{array}$} \\
\hline$T_{w 0}=40^{\circ} \mathrm{C}$ & $-\left(^{* *}\right)$ \\
\hline$T_{w 0}=50^{\circ} \mathrm{C}$ & 1,99 \\
\hline$T_{w 0}=60^{\circ} \mathrm{C}$ & 1,70 \\
\hline$T_{w 0}=70^{\circ} \mathrm{C}$ & 1,57 \\
\hline$T_{w 0}=80^{\circ} \mathrm{C}$ & 1,50 \\
\hline
\end{tabular}

$\left.{ }^{(* *}\right) \mathrm{O}$ ar não supersatura para $T_{w 0}=40^{\circ} \mathrm{C}$.

As Figuras 5.21, 5.22 e 5.23 representam os perfis de $T_{a}$ e $T_{w}$ para os modelos Poppe e o alto transporte com supersaturação. Os perfis obtidos em ambos os modelos são muito próximos entre os modelos, exceto para a temperatura de entrada da água igual a $80^{\circ} \mathrm{C}$, Figura 5.23 , para a qual os perfis de $T_{w}$ diferem consideravelmente. 


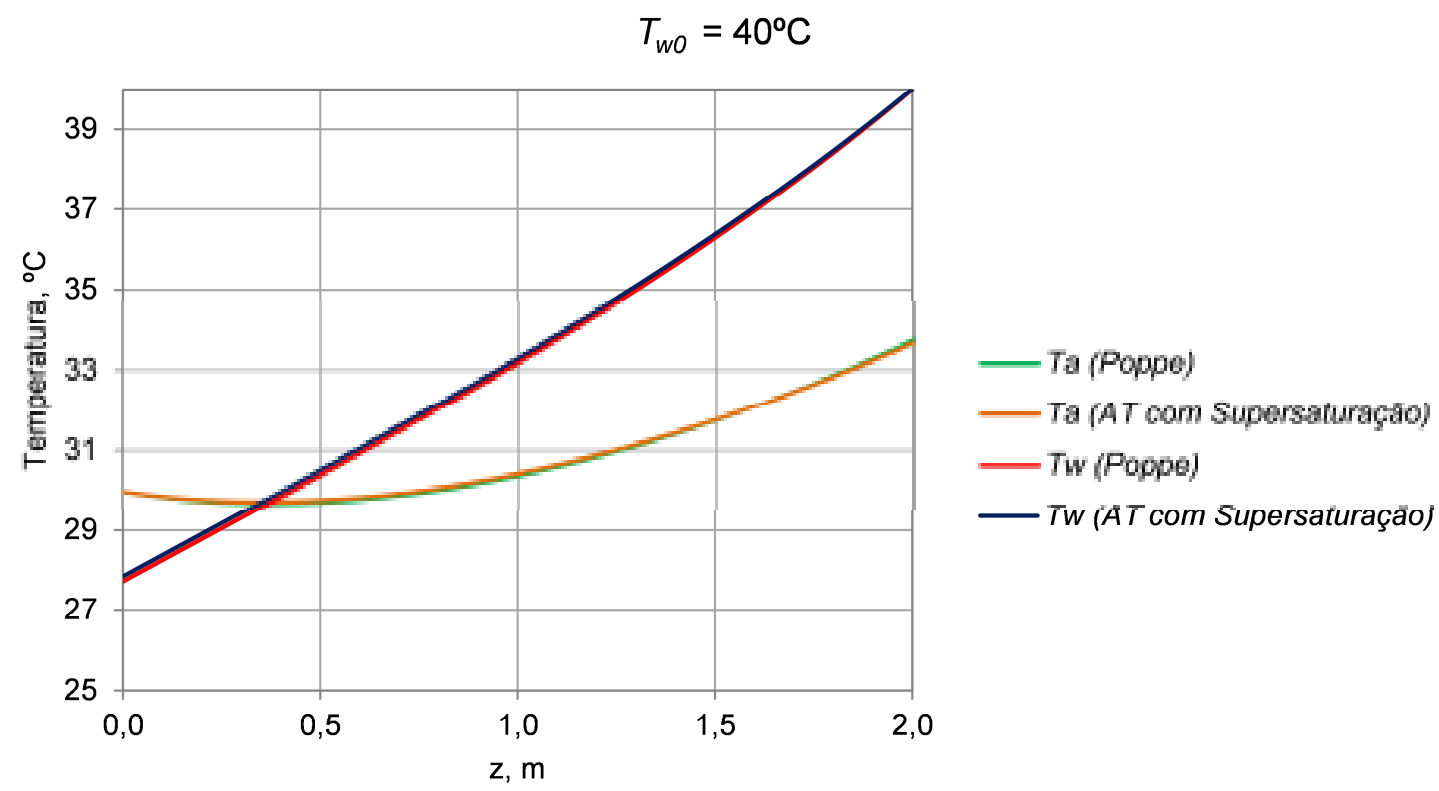

Figura 5.21 - Perfis de $T_{w}$ e $T_{a}$ para Poppe e AT com Supersaturação $\left(T_{w 0}=40^{\circ} \mathrm{C}\right)$.

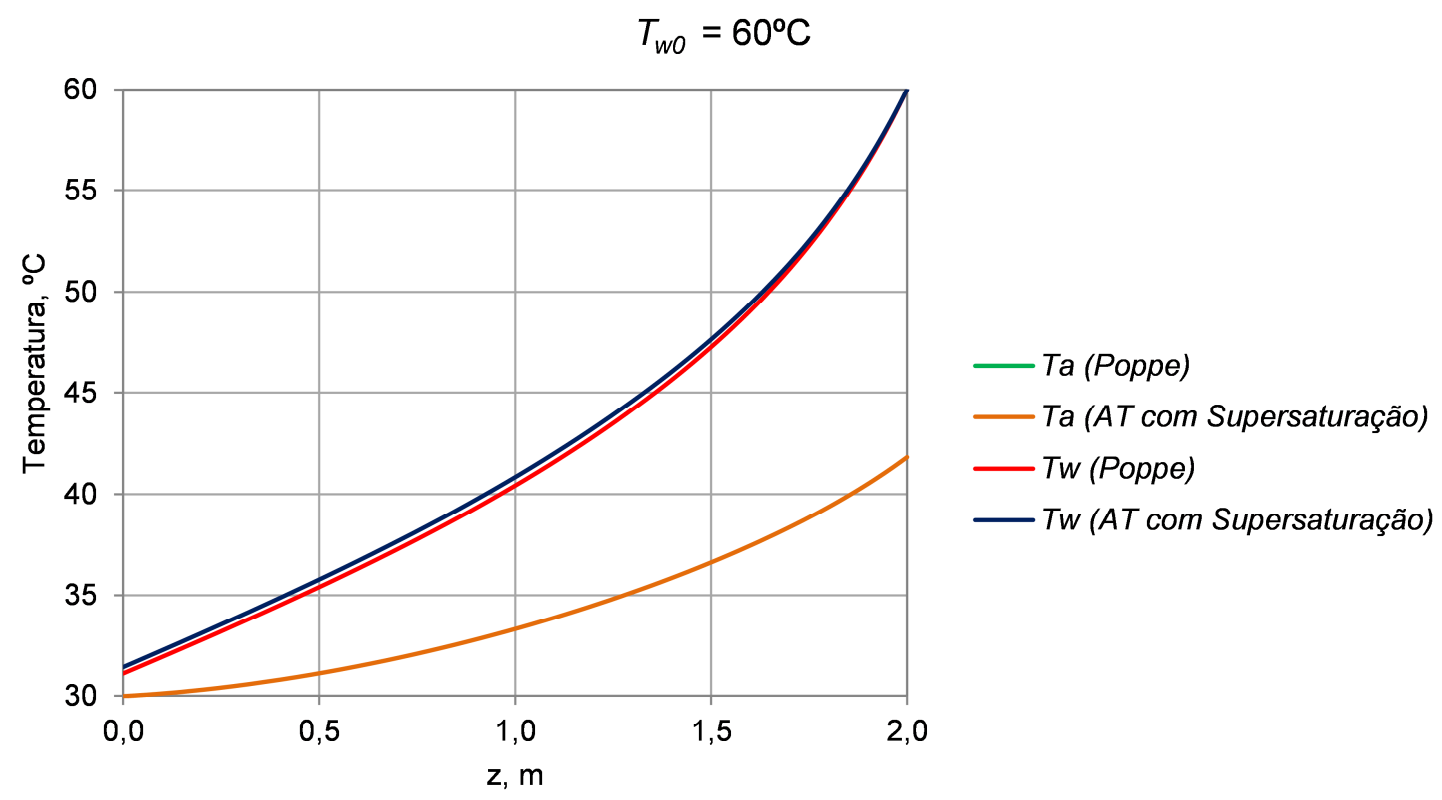

Figura 5.22 - Perfis de $T_{w}$ e $T_{a}$ para Poppe e AT com Supersaturação $\left(T_{w 0}=60^{\circ} \mathrm{C}\right)$. 


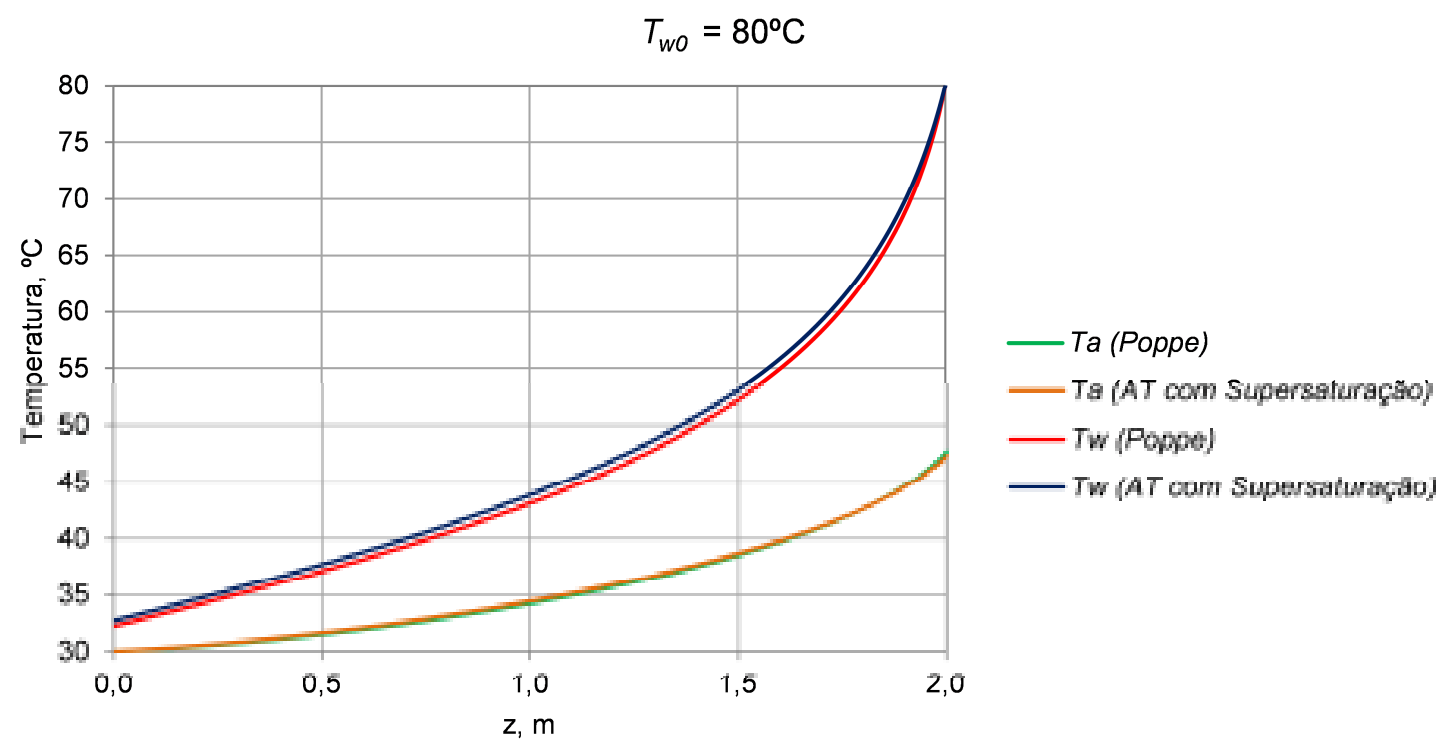

Figura 5.23 - Perfis de $T_{w}$ e $T_{a}$ para Poppe e AT com Supersaturação $\left(T_{w 0}=80^{\circ} \mathrm{C}\right)$.

As Figuras 5.24, e 5.25 ilustram os perfis de umidade para todos os modelos, exceto para Merkel, e os perfis de névoa considerando ou não o alto transporte. Os perfis de umidade ao longo da torre são muito próximos, e por outro lado os perfis de névoa diferem mais para a temperatura de entrada da água igual a $80^{\circ} \mathrm{C}$, isso porque neste caso a supersaturação ocorre em uma altura menor. Os perfis de névoa não foram traçados para a temperatura de entrada da água igual a $40^{\circ} \mathrm{C}$ pois neste caso não ocorre a supersaturação do ar. 


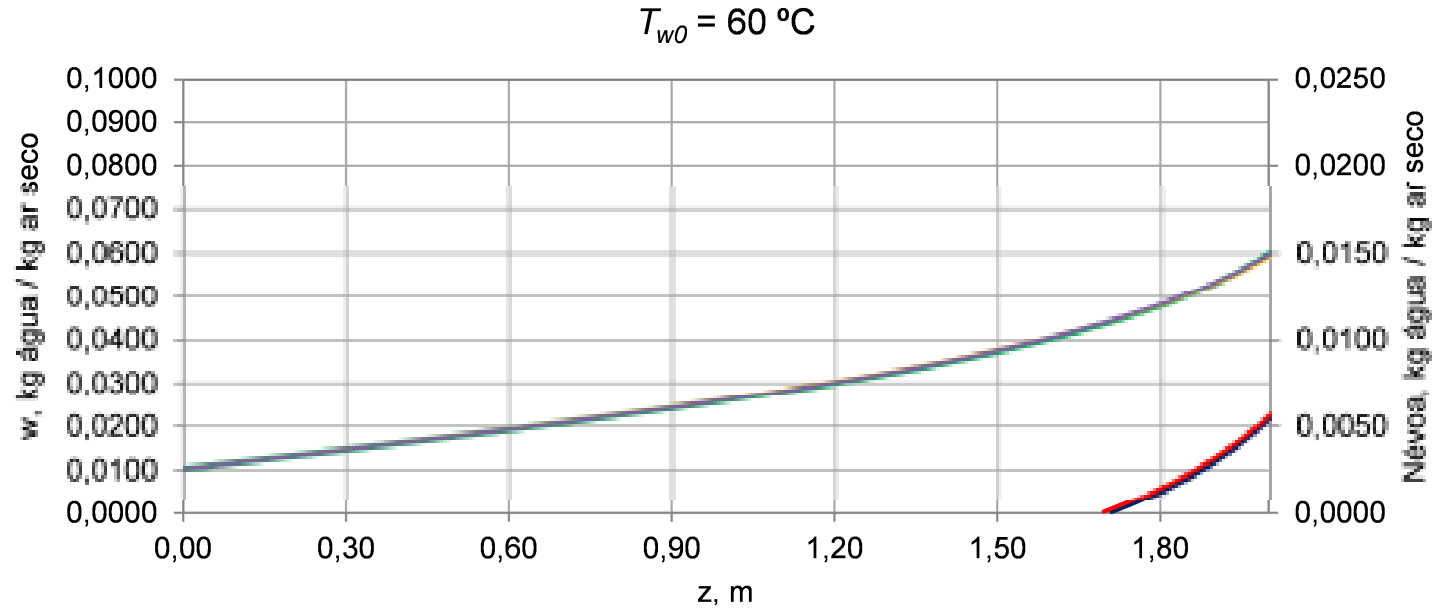

$\begin{array}{ll}\text { w (Supersaturação) } & \text { w (AT com Supersaturação) } \\ \text { w (Poppe) } & \text { Névoa (Supersaturação) }\end{array}$

Figura 5.24 - Perfil de névoa formada e umidade ao longo da torre, para $T_{w 0}=60^{\circ} \mathrm{C}$.

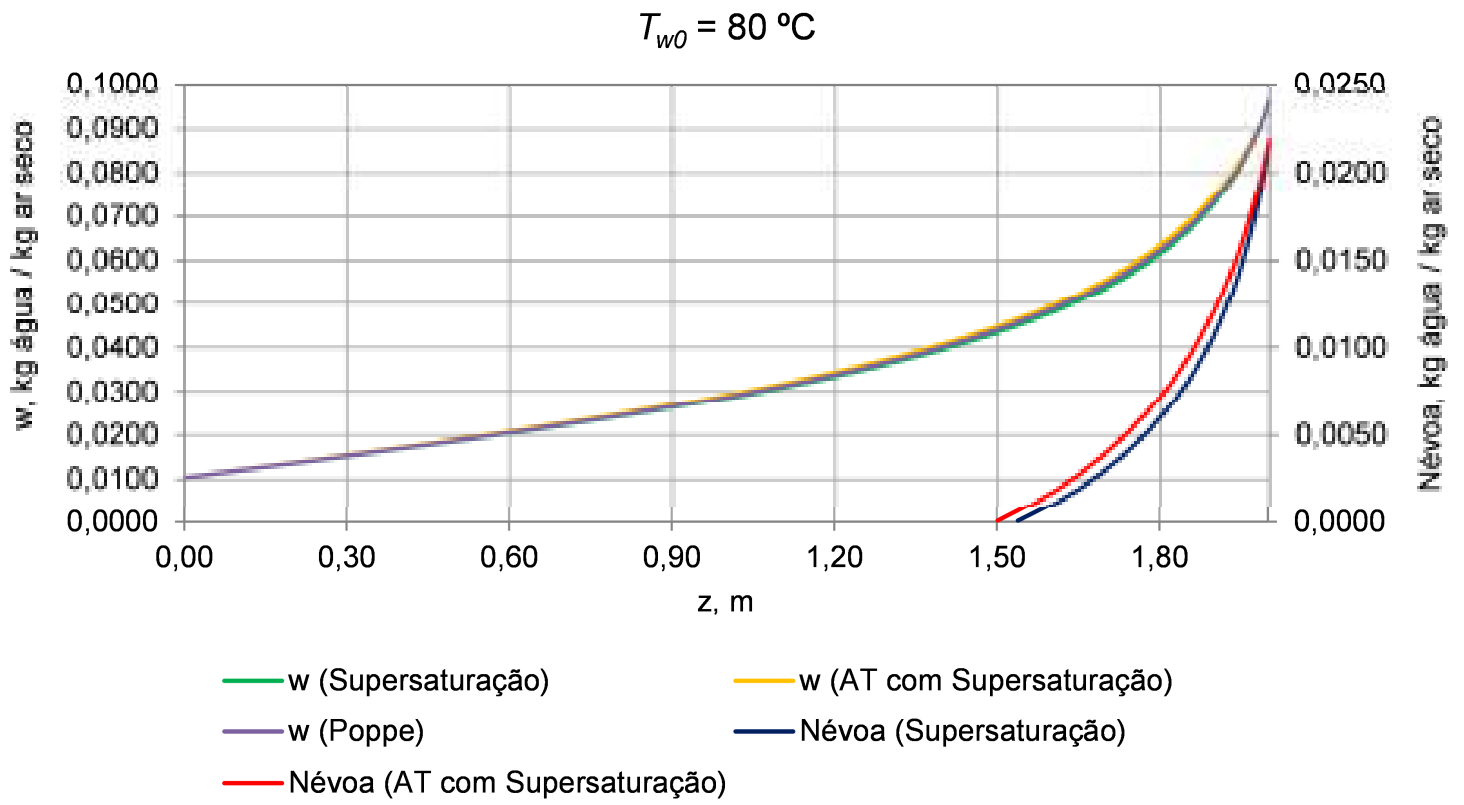

Figura 5.25 - Perfil de névoa formada e umidade ao longo da torre, para Tw0 $=80^{\circ} \mathrm{C}$. 


\section{CONCLUSÕES}

Este trabalho apresenta um modelo para torres de resfriamento de água operando em contracorrente, válido inclusive para temperatura de água, na entrada da torre, superior a $50^{\circ} \mathrm{C}$. Apresenta-se uma comparação entre os resultados obtidos por este modelo e dois dos modelos mais recomendados pela literatura aberta, Merkel e Poppe.

O método de Merkel subestima a quantidade de água evaporada, em relação ao modelo proposto, em até $33 \%$, conforme casos estudados. A quantidade de água evaporada é um dado importante em projetos de torres de resfriamento, pois a partir desta variável determina-se a quantidade de água de "make-up" ou reposição e o custo inerente ao tratamento desta água é alto.

Os perfis de umidade obtidos pelo modelo proposto e pelo modelo de Poppe são coincidentes. As umidades do ar de saída obtidas entre o método de Merkel e o modelo proposto diferem mais para temperaturas de entrada da água maiores, conforme Tabela 5.7, em que estas umidades diferem em $40 \%$.

Os perfis de temperatura da água e do ar ao longo da torre, diferem mais ou apresentam curvas mais distantes para temperaturas maiores da água de entrada na torre. As temperaturas da água de saída diferem entre os modelos em até $1,2^{\circ} \mathrm{C}$.

A quantidade de névoa formada no decorrer da torre é maior quanto maior a relação $m_{w} / m_{a}$

De fato, a condição de alto transporte afeta a taxa de transferência de massa, no entanto, os resultados obtidos para as temperaturas e umidades são muito próximos dos obtidos pelos modelos de Merkel e Poppe, que não consideram tal condição no modelo. Isto decorre do fato de, apesar da redução no coeficiente de transporte de massa, no caso do alto transporte de massa, a força motriz expressa em termos de fração mássica ser superior à expressa em termos de relação mássica.

A equação para o fator de Lewis apresentada em Bosnjakovic (1965), conforme demonstrado no item 2.8, considera, em parte, a influência do alto transporte de massa, pois não contempla a correção devida ao transporte de calor, conforme proposto neste trabalho pelo fator de correção $f_{2} / f_{1}$. 
Recomenda-se o modelo proposto para projetos de torres de resfriamentos industriais em que se necessita determinar precisamente a temperatura da água de saída, condições do ar de saída e a quantidade de água evaporada. No entanto, para uma estimativa destas variáveis, o método de Merkel pode ser utilizado exceto para cálculo da quantidade de água evaporada. O modelo de Poppe por outro lado, determina a quantidade de água evaporada muito próxima da calculada pelo modelo proposto, diferindo em até $2 \%$, e pode ser utilizado mesmo para temperaturas de entrada da água em torno de $80^{\circ} \mathrm{C}$.

Entre as variáveis estudadas, a temperatura de bulbo úmido é a variável que mais diferencia as condições de saída da água e do ar entre os modelos. Para condições do ar de entrada mais úmido, os resultados são mais discrepantes entre os modelos devido à rápida saturação do ar.

Apesar das hipóteses simplificadoras inerentes ao modelo de Merkel, que pressupõe temperatura de água quente limitada ao valor máximo de $40^{\circ} \mathrm{C}$, constata-se que os resultados obtidos para a temperatura da água fria são próximos dos previstos pelo modelo aqui proposto, inclusive para temperaturas de entrada da água até $80^{\circ} \mathrm{C}$. 


\section{REFERÊNCIAS}

BOSNJAKOVIC (1965), F.TechnischeThermodinamik.Theodor Steinkopf, Dresden, 1965.

CASTRO, M. M.; SONG, T.W.; PINTO, J.M. Minimization of operational cost in cooling water systems. Trans IChemE., v.78, part A, p.192-201, 2000.

CHUCHOTTAWORN, P.; FUJINAMI, A.; KOICHI, A. Experimental study of evaporation of a volatile pendant drop under high mass flux conditions. Journal of Chemical Engineering of Japan, v. 17, $n^{\circ} 1$, p. 7-137, 1984a.

CHUCHOTTAWORN, P.; FUJINAMI, A.; KOICHI, A. Numerical analysis of the effect of mass injection or suction on drag coefficients of a sphere. Journal of Chemical Engineering of Japan, v. 16, $n^{\circ} 1$, p. 18-24, 1983.

CHUCHOTTAWORN, P.; FUJINAMI, A.; KOICHI, A. Numerical analysis of heat and mass transfer from a sphere with surface mass injection or suction. Journal of Chemical Engineering of Japan, v. 17, $n^{\circ} 1$, p. 1-7, 1984b.

COOLING TOWER INSTITUTE, Revised February 2000.

CORTINOVIS, G. F.; RIBEIRO, M. T.; PAIVA, SONG, T. W. J. L.; PINTO, J. M. Integrated analysis of cooling water systems: Modeling and experimental validation. Applied Thermal Engineering, v. 29, p. 3124-3131, 2009.

KIM, J.; SMITH, R. Cooling water system design. Chemical Engineering Science, v. 56 p. 3641-3658, 2001. 
KLIMANEK, A.; BIALECKI, R. A. Solution of heat and mass transfer in counterflow wet-cooling tower fills. International Communications in Heat and Mass Transfer, v. 36, p. 547-553, 2009.

KLOPPERS, J. C.; KRÖGER, D.G. A critical investigation into the heat and mass trasnfer analysis of counterflow wet-cooling towers. International Journal of Heat and Mass Transfer,v.48, p.765-777, 2005a.

KLOPPERS, J. C.; KRÖGER, D.G. Cooling Tower Performance Evaluation: Merkel, Poppe, and e -NTU Methods of Analysis. Journal of Engineering for Gas Turbines and Powerv.127, p.1-7, 2005b.

KLOPPERS, J. C.; KRÖGER, D.G.The Lewis factor and its influence on the performance prediction of wet-cooling towers.International Journal of ThermalScience,v. 44 p. 878-884, 2005c.

$\mathrm{KOICHI}$ A. Mass Transfer from Fundamentals to Modern Industrial Applications, Tokyo Institute of Technology, 2006.

MELLO, L. C.; SONG, TahWun; PAIVA, J. L. Metodología para caracterización del desempeño operacional de una torre de enfriamiento. In: $\mathbf{X}$ Congreso Iberoamericano de Aire Acondicionado y Refrigeración, Guayaquil, 2009.

MELLO, L. C. Influência de variáveis de processo no desempenho de torres de resfriamento. 2008. 138 f.Dissertação (Mestrado em Engenharia Química) Escola Politécnica, Universidade de São Paulo, São Paulo-SP, Brasil, 2008.

MILLS, A. F. Mass Transfer. Prentice Hall NJ, 2001.

MUANGNOI, T.; ASVAPOOSITKUL, W.; WONGWISES, S. An exergy analysis on the performance of a counterflow wet cooling tower. Applied Thermal Engineering, v.27 p.910-917, 2006. 
PERRY E GREEN, R. H.; GREEN, D. Perry e Green's chemical engineers' handbook. $7^{\text {th }}$ ed. New York: McGraw Hill, 1997.

QI, X.; LIU, Z.Further. Investigation on the performance of a shower cooling tower. Energy Conversion and Management, v.49 p. 570-577, 2007.

REID, R. C.; PRAUSNITZ, J. M.; SHERWOOD T. K. The properties of gases and liquids, 3rd ed. Mc Graw Hill, New York, 1997, Appendix A.

SHAMPINE, L. F.; GLADWELL, I.; THOMPSON, S. Solving ODEs with MATLAB. Cambridge University Press, New York, USA, 2003

ZEMP, R. J.; WAKI, R.; SILVA, F. V. A direct formula to compute wet-bulb temperature from dry-bulb temperature and relative humidity. XVIII Congresso Brasileiro de Engenharia Química, p. 3158-3163, 2010. 